\title{
Planejamento Apoiado em Inteligência Artificial: \\ Sistemas e Abordagens
}

\author{
Ricardo Luís de Freitas
}

Orientador Profa. Dra. Maria Carolina Monard

Dissertaçào apresentada ao Instituto de Ciências Matemáticas de São Carlos da liniversidade de Sáo Paulo, como parte dos requisitos para a obtenção de título de Mestre -émi Ciências de Computação e Matemática Computacional.

São Carlos

Maŗo 1991 
À Amélia, pela saudade.

Aos meus pais, Altino e Zaíra, pela dedicação.

À Malu, pelo apoio, carinho, e compreensão. 


\section{Agradecimentos}

À Maria Carolina, pela dedicação e amizade demonstrada ao longo do desenvolvimento deste trabalho;

Às funcionárias Beth e Laura, da secretaria de Pós-Graduação deste Instituto;

Aos amigos Bráulio Coelho Ávila, João do Espirito Santo Batista Neto, e José Pacheco de Almeida Prado pela amizade e constante participação na realização deste trabalho;

Ao CNPq pelo apoio financeiro;

Àqueles que de um modo ou de outro contribuiram para a realização deste trabalho. 


\section{Resumo}

Planejamento é uma área muito difundida em Inteligência Artificial. Seu grande escopo de aplicação tem despertado interesse em pesquisadores do mundo todo. A idéia central de planejamento é gerar uma sequência de ações para um agente - por exemplo um robô-, que poderá alterar a descrição de um determinado ambiente. A esta sequência de ações dá-se o nome de plano.

Os planos são construídos pela escolha das ações que são capazes de resolver os objetivos que compõem uma determinada meta. Para esta escolha, devem ser levadas em conta as ações disponíveis - para o domínio de aplicação-, as situações nas quais elas serão aplicadas, bem como as mudanças que elas irão provocar na descrição do ambiente.

Ao longo dos mais de 30 anos de pesquisa na área de planejamento, várias técnicas - que ainda constituem parte importante para muitos planejadores - têm sido desenvolvidas.

Neste trabalho, são definidos alguns dos termos, conceitos e aspectos básicos comumente encontrados em planejamento. São, também, discutidos alguns dos problemas que surgem no projeto de planejadores, bem como as principais soluções propostas ao longo dos diversos anos de pesquisa nesta área.

O principal aspecto, que deve ser considerado em planejamento, é o problema de busca. De fato, planejamento é essencialmente um problema de busca. São discutidas algumas - das técnicas usādas para reduzir o número de estados intermediários, tais como: análise dos meios e fins, menor comprometimento e fixação de restrições.

Em adição ao problema de controlar a busca, a ordem na qual são resolvidos os objetivos é um fator marcante para a eficiência do processo de busca. A solução de tal problema é discutida para algumas técnicas, tais como: ordenação de objetivos, regressão de objetivos e ordenação por níveis de importância.

São, também, apresentadas implementações simplificadas que ilustram os princípios de planejamento usando algumas destas técnicas. 


\begin{abstract}
Planning is a large, popular and growing area of Artificial Intelligence. The central idea of planning is the generation of an action sequence for an agent, such as a robot, that can change its environment.

Plans are constructed by reasoning about how available actions can be applied to achieve various goals. For this reasoning process to occur, the planner must be aware of its available actions, the situations in which those actions are applicable as well as the changes in the environment due to their execution.

For more than 30 years, planning systems have been an active research topic and a number of techniques - that still form an essential part of many of today's AI planning systemshave been developed during this period.

In this work some terms commonly used in the planning literature are defined and some of the problems that have arisen in the design of planning systems as well as solutions that have been developed over several years of research in this area are described.

The major issue for any planning system is reducing search. In fact, planning is essentially a search problem. Several techniques to reduce the number of intermediate states such as: means-ends-analysis, least commitment and others are discussed.

In addition to the problem of controlling the search, the order in which several simultaneous goals are tackled can have a marked effect on the efficiency of the search process. The solving of such problem is discussed by some techniques, such as: ordering goals; regressed goals and ordering the various goals by level of importance.

It is also developed several simple planners, that illustrate the principles of planning using those techniques.
\end{abstract}




\section{Conteúdo}

1 Introdução 1

2 Conceitos Básicos 4

2.1 Considerações Iniciais . . . . . . . . . . . . . . . . 4

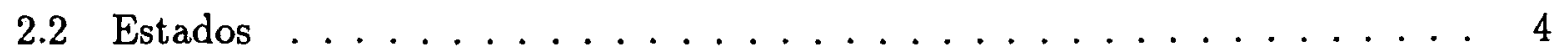

2.3 Ações . . . . . . . . . . . . . . . . . . . . . 9

2.4 O Problema do Frame . . . . . . . . . . . . . . . . . 12

2.5 Considerações Finais . . . . . . . . . . . . . . 15

3 Planejamento $\quad 16$

3.1 Considerações Iniciais . . . . . . . . . . . . . . . . . 16

3.2 Planejamento e Resolução de Problemas . . . . . . . . . . . . . . 16

3.2.1 Decomposição do Problema . . . . . . . . . . . . 17

3.2 .2 Simulação do Mundo Real . . . . . . . . . . . . . . 18

3.2 .3 Geração de Planos . . . . . . . . . . . . . . . . 18

3.3 Etapas do Planejamento ...................... . 19

3.4 Um Exemplo Prático . . . . . . . . . . . . . . . . 20

3.5 Considerações Finais . . . . . . . . . . . . . . . . . 24

4 Abordagens para Planejamento $\quad 26$

4.1 Considerações Iniciais . . . . . . . . . . . . . . . . . . 26 
4.2 Planejamento Não Hierárquico . . . . . . . . . . . . . . . 26

4.2 .1 O Sistema Strips. . . . . . . . . . . . . . 27

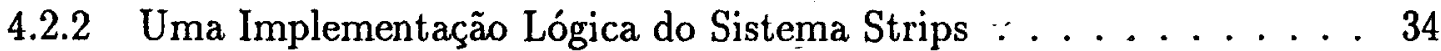

4.3 Planejamento Hierárquico . . . . . . . . . . . . . . . 39

4.4 Planejamento Baseado em Scripts . . . . . . . . . . . . . . . . 42

4.5 Planejamento Oportunístico . . . . . . . . . . . . . . 43

4.6 Considerações Finais . . . . . . . . . . . . . . . . . 44

5 Principais Aspectos e Sistemas de Planejamento 45

5.1 Considerações Iniciais . . . . . . . . . . . . . . . . 45

5.2 Técnicas de Redução de Busca . . . . . . . . . . . . . . . . 45

5.2.1 Análise dos Meios e Fins . . . . . . . . . . . . . . . . 46

5.2.2 Menor Comprometimento ............... 46

5.2.3 Fixação de Restrições . . . . . . . . . . . . . . . . . . . 47

5.2 .4 Backtracking ...................... 48

5.2 .5 Outras Técnicas . . . . . . . . . . . . . 49

5.3 Tratamento de Objetivos Conjuntivos ............... 50

5.3.1 Ordenação de Objetivos por Níveis de Importância . . . . . . . 50

5.3 .2 Interação entre Diferentes Objetivos . . . . . . . . . . 50

5.3.3 Reordenação e Regressão de Objetivos . . . . . . . . . . . . . 51

5.4 Representação de Operadores . . . . . . . . . . . . . . 54

5.5 Tratamento de Mudanças no Ambiente . . . . . . . . . . . . 54

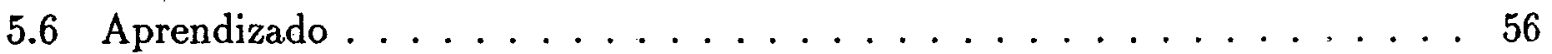

5.7 Condições e Interações . . . . . . . . . . . . . . . 56

5.8 Incerteza . . . . . . . . . . . . . . . . 57

5.9 Alguns Sistemas de Planejamento Existentes . . . . . . . . . . . . 57

5.10 Considerações Finais . . . . . . . . . . . . . . . 59 
6 Algumas Implementações de Técnicas Básicas de Planejamento

6.1 Considerações Iniciais . . . . . . . . . . . . . . . . 60

6.2 Domínio de Aplicação . . . . . . . . . . . . . . . . 60

6.3 Análise dos Meios e Fins . . . . . . . . . . . . . 62

6.4 Análise dos Meios e Fins com Reordenação de Objetivos . . . . . . . . 65

6.5 Análise dos Meios e Fins com Regressão de Objetivos . . . . . . . . . . 70

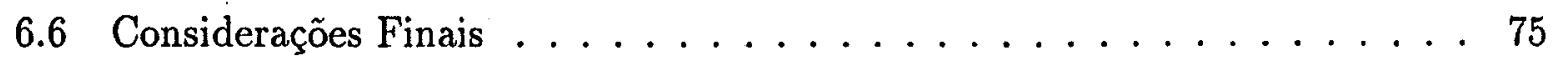

7 Implementação de um Sistema Hierárquico e de um Não Hierárquico 76

7.1 Considerações Iniciais . . . . . . . . . . . . . . . . 76

7.2 Sistema Não Hierárquico $\ldots \ldots \ldots \ldots \ldots \ldots \ldots$

7.3 Sistema Hierárquico . . . . . . . . . . . . . . . . . 82

7.4 Considerações Finais . . . . . . . . . . . . . . . . 95

8 Conclusões $\quad \cdot \quad 97$

8.1 Problemas Encontrados . . . . . . . . . . . . . . . . 98

8.2 Trabalhos Futuros . . . . . . . . . . . . . . . . 99

Bibliografia . . . . . . . . . . . . . . . 101 


\section{Lista de Figuras}

2.1 Estados Possíveis para o Mundo dos Blocos . . . . . . . . . . . . 5

2.2 Representação de Estados Iguais . . . . . . . . . . . . . . . . . 6

2.3 Representação de Estados $-1 \ldots \ldots \ldots$. . . . . . . . . . . 7

2.4 Representação de Estados $-2 \ldots \ldots$. . . . . . . . . . . . 10

2.5 Ações e Estados Possiveis para o Mundo dos Blocos . . . . . . . . . . . . 11

3.1 Diagrama Básico para o Problema de Viajar entre São Carlos e Itabuna . . 22

3.2 Generalização para o Problema de Viagem . . . . . . . . . . . . . 23

4.1 Representação de Estados $-3 \ldots \ldots$. . . . . . . . . . . . 28

4.2 Estado Atual . . . . . . . . . . . . . . . . . . 30

4.3 Estado Resultante da Execução das Ações . . . . . . . . . . . . . 30

4.4 Representação de Estados $-4 \ldots \ldots$. . . . . . . . . . . . 31

4.5 Diagrama de Execução do $\operatorname{Strips}($ Parte 1) . . . . . . . . . . . . 32

4.5 Diagrama de Execução do Strips(Parte 2) . . . . . . . . . . . . 33

4.6 Representação de Estados -5 . . . . . . . . . . . . . . . 37

5.1a Falha devido a Ordem Inadequada de Solução dos Objetivos . . . . . . . 47

5.1b Reordenação para os Objetivos devido ao Menor Comprometimento . . . . 47

5.2 Representação de Estados $-6 \ldots \ldots \ldots$. . . . . . . . . . 51

5.3 Representação de Falha devido a Objetivos Conjuntivos . . . . . . . . . . 52

5.4 Representação do Conceito de Regressão de Objetivos . . . . . . . . . . . . 53

6.1 Estado Inicial . . . . . . . . . . . . . . . . . . 61

6.2 Representação de Estados $-7 \ldots \ldots \ldots$

6.3 Representação de Estados $-8 \ldots \ldots$. . . . . . . . . . . . . . . .

6.4 Relações entre Objetivos ... . . . . . . . . . . . . . 70

7.1 Representação de Estados $-9 \ldots \ldots \ldots$. . . . . . . . . 82 
7.2 Estado Inicial - Problema do Robo $\ldots \ldots \ldots \ldots \ldots \ldots$

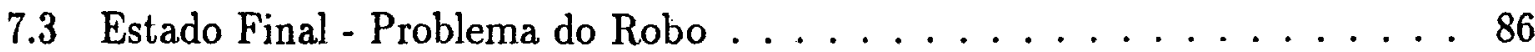




\section{Capítulo 1}

\section{Introdução}

Um problema que persiste no campo de raciocínio automatizado é projetar sistemas capazes de descrever um conjunto de ações -ou um plano- que possibilite ao sistema atingir um dado objetivo. Normalmente, este conjunto de ações é passado para um agente - por exemplo um robô- que, seguindo o plano montado, produz o resultado desejado.

Considera-se também que a habilidade para raciocinar sobre ações é a parte central do comportamento inteligente [Kautz 88], e que, conhecendo as consequências das ações que venham a ser executadas, é possivel atingir os objetivos desejados com menos riscos usando um mínimo de recursos necessários [Nilsson 82].

Planejamento consiste, basicamente, em decidir um caminho de ação antes de agir. Para tanto, as entradas - inputs - do sistema de planejamento são, geralmente, as seguintes:

- Um conjunto de objetivos -meta.

- Um conjunto de ações primitivas.

- Uma descrição de um estado inicial.

O resultado produzido pelo sistema será uma sequência de ações que, aplicada ao estado inicial, leve à meta desejada.

Muitos problemas do mundo real podem ser considerados como problemas de planejamento. Exemplos extraídos do cotidiano como pintar uma casa, fazer uma viagem, preparar um bolo ou, até mesmo, a própria rotina diária de uma pessoa, podem ser realizados seguindo um plano completo de ações. Existem também outras áreas de aplicação que tem recebido grande atenção por parte de pesquisadores, entra elas destacam-se:

- Planejamento de robô, onde o objetivo é encontrar uma sequência de movimentos necessários para que o robô realize uma determinada tarefa. 
- Programação automática, onde o objetivo é encontrar uma sequência de instruções - linhas de programa - que realize uma tarefa computacional determinada.

- Projeto experimental em genética molecular, onde o objetivo é propor uma sequência de passos laboratoriais que levem uma bacteria à produzir uma proteína desejada.

- Interpretação geológica, onde o objetivo é supor uma sequência de eventos geológicos - por exemplo sedimentação- que poderiam ocorrer em uma formação geológica estudada.

- Linguagem Natural, onde o objetivo é construir uma sequência de expressões que satisfaça determinados objetivos dentro de um processo de comunicação.

Devido ao seu grande escopo de aplicação, os estudos em planejamento têm despertado grande interesse em pesquisadores do mundo todo, e muitos sistemas foram e estão sendo desenvolvidos ao longo dos 30 anos de pesquisas realizadas nesta área.

Este trabalho procura enfocar os conceitos básicos e terminologias mais frequentemente usadas para definir planejamento, bem como onde ele pode ser usado no mundo real. São, também, apresentadas as principais abordagens e os principais aspectos a serem considerados em planejamento. A fim de mostrar a adequação da linguagem de programação lógica Prolog para implementar sistemas de planejamento, são apresentadas implementações simplificadas de algumas técnicas para tratamento de objetịvos conjuntivos. São apresentadas, também, implementaçôes simplificadas que contém as características básicas encontradas em sistemas hierárquicos e não hierárquicos, .

O trabalho está organizado da seguinte forma, segundo sua distribuição em capítulos:

No capítulo 2, são introduzidos os conceitos básicos existentes em planejamento. Uma vez que um plano é composto de ações e que essas ações provocam alterações na descrição do estado, é importante que estes conceitos sejam bem entendidos antes de se iniciar o estudo em planejamento propriamente dito. Outro aspecto é quanto as partes do estado que não sofrem alterações quando se executa uma ação; este tipo de ocorrência é denominado problema do frame.

No capítulo 3, é apresentada uma visão geral para planejamento e também onde ele pode ser aplicado em situações do mundo real. Suas etapas básicas de procedimento são comentadas e, para reforçar as definições e conceitos vistos, é usado um exemplo prático muito simples para aplicação de planejameñto. Uma implementação em Prolog é fornecida para este exemplo.

No capítulo 4, são apresentadas as principais abordagens para planejamedìo, que são: planejamento não hierárquico, planejamento hierárquico, planejamento baseado em scripts e planejamento oportunistico. São apresentadas as principais vantagens e desvantagens dessas abordagens, bem como procura-se mostrar, através de exemplos práticos, onde melhor se adequa cada uma delas. É dado um enfoque maior em planejamento não hierárquico - por ser de mais rápida assimilação- e em planejamento hierárquico - por trazer maiores ganhos em termos de busca. 
No capítulo 5, os principais aspectos que devem ser considerados em planejamento são apresentados. Estes aspectos, basicamente, são: busca, objetivos conjuntivos, representação de operadores, tratamento das mudanças no mundo, aprendizado, condições e incerteza. Para mostrar como estes aspectos estão sendo estudados, procurou-se dar uma breve idéia de quais os planejadores que tratam cada um dos aspectos, e como é esse tratamento. Ao final, é apresentada uma tabela contendo os principais sistemas de planejamento desenvolvidos ao longo dos vários anos de pesquisa nesta área.

No capítulo 6, são apresentadas implementações simplificadas para as técnicas de reordenação e regressão de objetivos - usadas no tratamento de objetivos conjuntivos. Para guiar a busca, é usada a técnica de análise dos meios e fins.

No capítulo 7, são apresentadas implementações que contém as principais características de um sistema não hierárquico e de um sistema hierárquico. É, portanto, possível visualizar, através das implementações, que um sistema hierárquico elabora vários esqueletos de plano, sendo um para cada nível de abstração, enquanto que um sistema não hierárquico elabora o plano em um único nível de representação.

No capítulo 8, são apresentadas as conclusões do trabalho, os possíveis trabalhos futuros e os problemas encontrados. 


\section{Capítulo 2}

\section{Conceitos Básicos}

\subsection{Considerações Iniciais}

É possível visualizar o processo de solução de problemas como uma busca através de um espaço de estados, onde cada estado corresponde a uma situação possivel de surgir. A busca começa em uma situação inicial —estado inicial-e realiza uma sequência de ações possíveis até que seja atingida a meta desejada - estado final. Cada ação provoca alterações na descrição do estado. Porém, nem sempre toda a descrição é alterada, a. parcela que não sofre alteração é tratada como problema do frame.

Os conceitos de estado e ações são importantes para a conceitualização do mundo físico. A seguir é apresentada uma conceitualização segundo Genesereth e Nilsson [Genesereth 87].

\section{$2.2 \quad$ Estados}

Um estado - ou situação- é uma instância do mundo ${ }^{1} \mathrm{em}$ um dado ponto no tempo, sendo que, em diferentes pontos no tempo, o mundo pode estar em diferentes estados. Esta idéia é facilmente ilustrada usando o Mundo dos Blocos. Neste mundo tem-se:

- Cada bloco pode estar sobre a mesa ou sobre um outro bloco;

- Cada bloco pode ter, no máximo, um único bloco imediatamente acima dele.

Diferentes estados deste mundo correspondem a diferentes configurações dos blocos. Considerando que o número de blocos é três, o número de possíveis estados é 13, como mostra a Figura 2.1 .

\footnotetext{
${ }^{1} \mathrm{O}$ termo mundo refere-se ao mundo físico onde se tem o dominio de aplicação.
} 

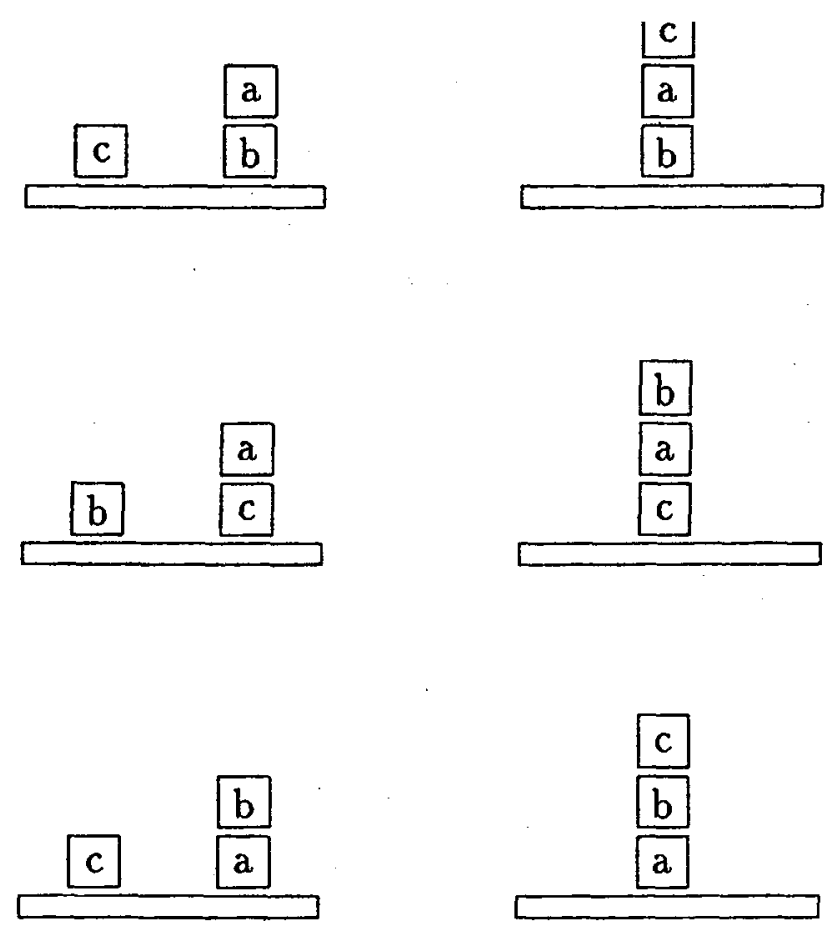

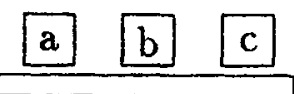
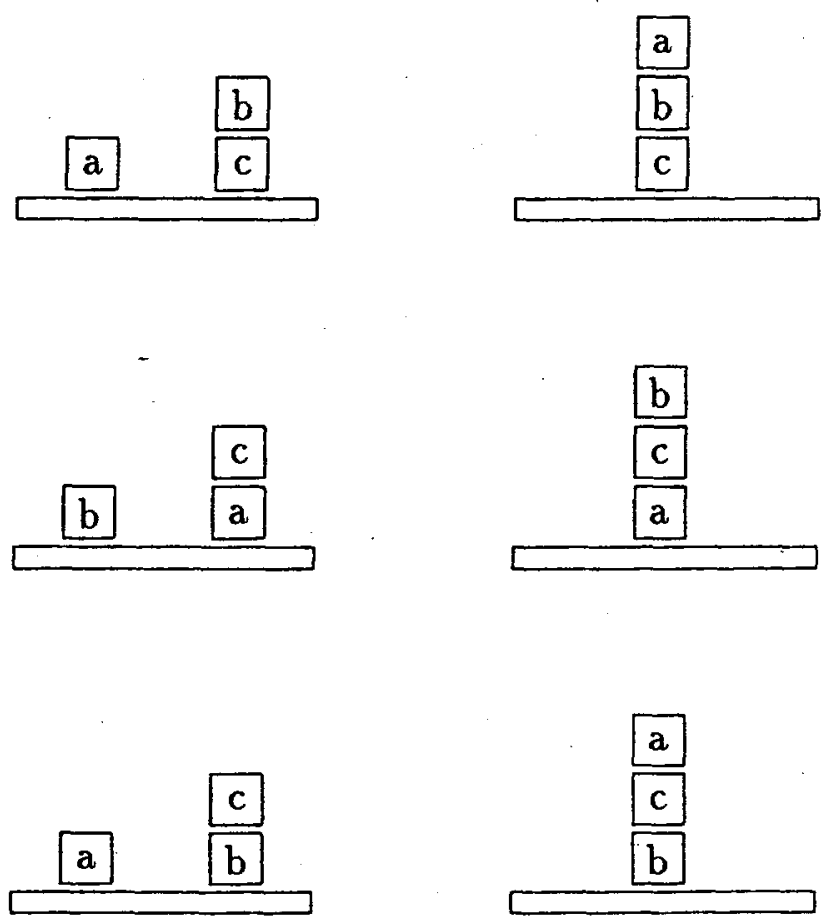

Figura 2.1: Estados Possíveis para o Mundo dos Blocos 
É importante observar que a conceitualização de estados não é, necessariamente, única. Por exemplo, os estados representados na Figura 2.1 levam em conta apenas os relacionamentos verticais dos blocos, ignorando suas posições laterais. Para melhor visualizar isso, observe que na Figura 2.2 tem-se o mesmo estado representado, embora suas posições laterais sejam diferentes.
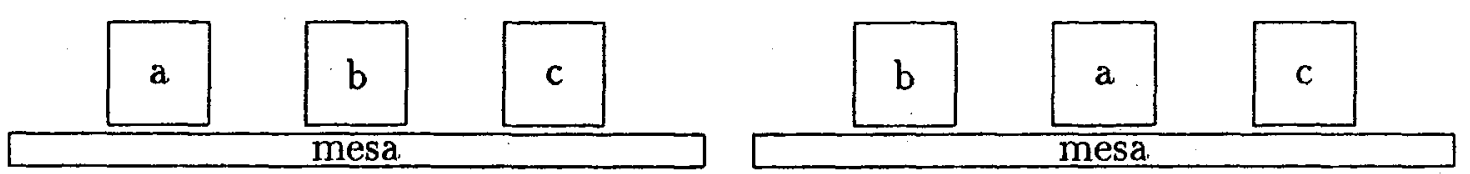

Figura 2.2: Representação de Estados Iguais

A importância da noção de estados está no fato de que o estado permite descrever as mudanças que ocorrem no mundo. Na conceitualização de mudança no mundo, os estados são considerados como objetos no universo de discurso, e são criadas funçôes e relaçóes que dependem deles. Após dada essa conceitualização, são escritas sentenças que determinam quais os objetos que satisfazem quais relações e em quais estados. Como os estadōs são objetos no universo de discurso, é fácil nomeá-los, inventando simplesmente objetos constantes apropriados, tais como S1 e S2, bem como usando termos mais complexos. Um termo que denota um estado específico pode ser chamado de designador de estado.

Uma maneira simples de descrever um estado é usando uma função ou relação para cada parcela de informação referente ao estado. No exemplo do mundo dos blocos, pode ser usada uma relação ternária sobre para indicar que, em um dado estado, um bloco está diretamente sobre outro bloco. Pode também ser usada uma relação binária livre para indicar que, num dado estado, não existe nenhum outro bloco sobre o bloco especificado. $\mathrm{E}$, finalmente, pode ser usada uma relação binária mesa para indicar que, num dado estado, o bloco especificado está sobre a mesa. Por exemplo, considerando os dois estados mostrados na Figura 2.3, a representação seria a seguinte:

\begin{tabular}{|c|c|}
\hline $\begin{array}{l}\text { sobre }(a, b, S 1) \\
\text { sobre }(b, c, S 1) \\
\text { mesa }(c, S 1) \\
\operatorname{livre}(a, S 1)\end{array}$ & $\begin{array}{l}\operatorname{sobre}(b, a, s 2) \\
\text { mesa }(a, s 2) \\
\text { mesa }(c, S 2) \\
\operatorname{livre}(c, s 2) \\
\operatorname{livre}(b, S 2)\end{array}$ \\
\hline
\end{tabular}




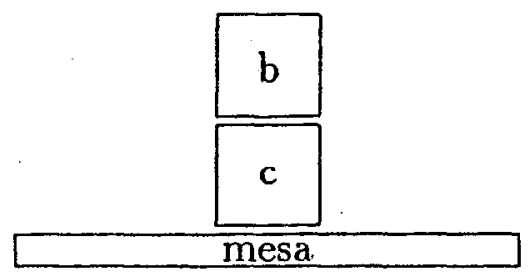

S1

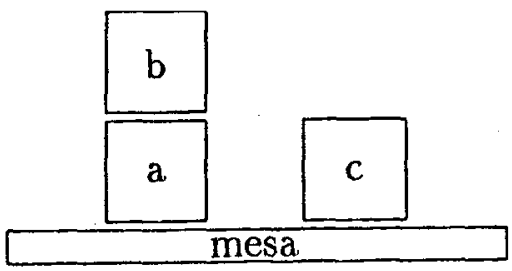

S2

Figura 2.3: Representação de Estados - 1

As propriedades dependentes do estado podem ser conceitualizadas como funções independentes do estado, as quais mapeiam objetos no conjunto de estados nos quais estes objetos tem associadas as propriedades dependentes do estado. Por exemplo, é possivel usar a função unária livre(a) para especificar o conjunto de estados nos quais não existe outro bloco sobre o bloco a. Um termo desta forma pode ser chamado de descritor de estado e o conjunto de estados que ele especifica é chamado de corrente (fluent).

Para escrever sentenças dependentes do estado pode ser usada uma relação binária verdade, a qual especifica que uma propriedade é válida em um determinado estado. Por exemplo:

verdade(Iivre(a), S1)

significa que não existe outro bloco sobre o bloco a no estado S1. Em outras palavras, tem-se que, ao invés de usar relações dependentes do estado, tais como:

$$
\operatorname{livre}(a, S 1)
$$

usa-se funções independentes do estado, por exemplo:

$$
\text { Iivre(a) }
$$

e relações binárias, que associam as funções aos estados, por exemplo:

$$
\operatorname{verdade}(\operatorname{livre}(a), \text { S1) }
$$

Nesse caso, a descrição dos estados da Figura 2.3 seria: 


\subsection{Ações}

Um mundo persiste em um estado até que uma ação é executada e o leva para um novo estado. No caso de ações, é também possível conceitualizá-las comó objetos do universo de discurso. No exemplo considerado do Mundo dos Blocos, a ação de mover o bloco c que está sobre o bloco a para que ele fique sobre o bloco $b$ pode ser considerada como um objeto, ainda que um objeto muito especial. A ação de desempilhar $c$ de a e colocálo sobre a mesa é um outro objeto. A ação de pegar b e empilhá-lo sobre c é outra possibilidade, bem como a ação de não fazer nada.

Nesta conceituação, para poder determinar o que existe em comum entre algumas ações, é conveniente que sejam incluídos operadores, bem como ações simples. Um operador é uma função de objetos para açôes, as quais mapeiam um grupo de objetos em uma forma comum de manipulá-los.

No Mundo dos Blocos, a ação genérica de mover um bloco do topo de um bloco para o topo de um outro bloco pode ser considerada como um operador. Ele mapeia os três blocos envolvidos na ação mover correspondente. Similarmente, uma ação genérica de desempilhar um bloco do topo de outro bloco para colocá-lo sobre a mesa pode ser considerada como uma função binária dos dois blocos envolvidos na ação desempilhar correspondente. A ação genérica de pegar um bloco que está sobre a mesa e empilhá-lo sobre outro bloco pode ser considerada como uma função binária dos dois blocos envolvidos na ação empilhar correspondente. As ações ao alcance de um operador são, frequentemente, chamadas de instâncias do operador.

No Mundo dos Blocos, se for assumido que todas as ações são instâncias dos operadores mover, empilhar e desempilhar ou é uma ação nula, então é necessário adicionar 19 novos objetos ao universo de discurso. Existem seis caminhos possiveis para mover um bloco de um segundo bloco para um terceiro. Existem três escolhas para o bloco a ser movido. Feita esta escolha, existem duas escolhas para o bloco do qual ele será movido e, após ter sido escolhido um deles, o outro bloco restante deverá ser aquele para qual será movido o bloco. Do mesmo modo, existem seis caminhos para desempilhar um bloco de cima de outro e também seis caminhos para empilhar um bloco em cima de outro. E, finalmente, existe uma única ação nula.

Para descrever operadores e ações, primeiro nomeia-se cada um deles. No exemplo usase o símbolo move para o operador mover (função ternária), o símbolo empilha para o operador empilhar (função binária) e o símbolo desempil ha para o operador desempilhar (função binária). Através deste vocabulário podem ser nomeadas ações individuais. Por exemplo, o termo

desempilha $(a, b)$

especifica a ação de mover o bloco a de cima de b, colocando-o na mesa. Isto é mostrado na Figura 2.4: 


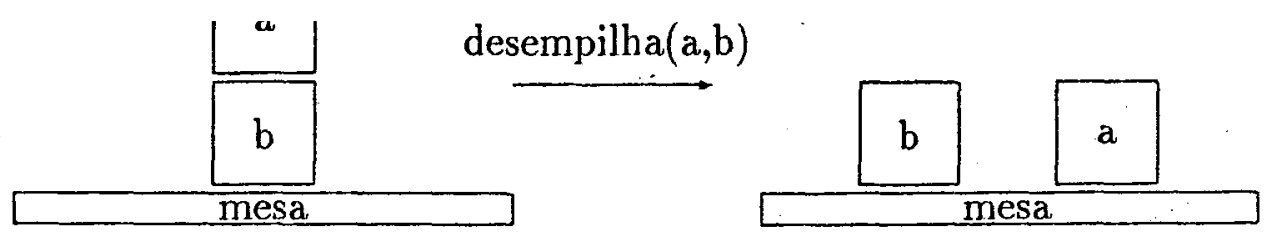

Figura 2.4: Representação de Estados - 2

A Figura 2.5 ilustra as ações possiveis de serem executadas entre os estados representados, sendo que, as setas indicam o sentido (estado anterior levando ao próximo estado). Por motivo de simplificação é usado o símbolo $\mathrm{E}$ para o operador empilha, o símbolo D para o operador desempilha e o simbolo $\mathrm{M}$ para o operador move.

Os efeitos das ações podem ser conceitualizados na forma de uma função - fazer - que mapeia uma ação, do conjunto $A$ de todas as açôes, e um estado, do conjunto $S$ de todos os estados possíveis, em um estado que resulta da execução da ação específica no estado específico.

$$
\text { fazer: } A x S \rightarrow S
$$

Será usado o símbolo faz para especificar a função fazer (função binária). Portanto, o termo

$$
\text { faz(move }(a, b, c), \bar{S} 1)
$$

representa o estado que resulta da execução de move $(a, b, c)$ a partir do estado $\mathrm{S} 1$.

A seguir são descritos os efeitos dos operadores através de sentenças lógicas. $\mathrm{O}$ axioma é verdadeiro para todos os blocos $\mathrm{X}, \mathrm{Y}$ e $\mathrm{Z}$, e para todos os estados $\mathrm{S}$ (os quantificadores universais serão suprimidos por motivo de simplificação).

O efeito do operador move é descrito pela seguinte sentença:

Se num dado estado $\mathrm{S}$ um bloco $\mathrm{X}$ está sobre um bloco $\mathrm{Y}, \mathrm{X}$ e $\mathrm{Z}$ estão com os seus respectivos topos livres e $X$ é diferente de $Z$, então a ação move $(X, Y, Z)$ provocará os efeitos indicados pelo consequente da implicação, que é o estado onde o bloco $\mathrm{X}$ está sobre o bloco $\mathrm{Z}$ e o bloco $\mathrm{Y}$ tem seu topo livre. 

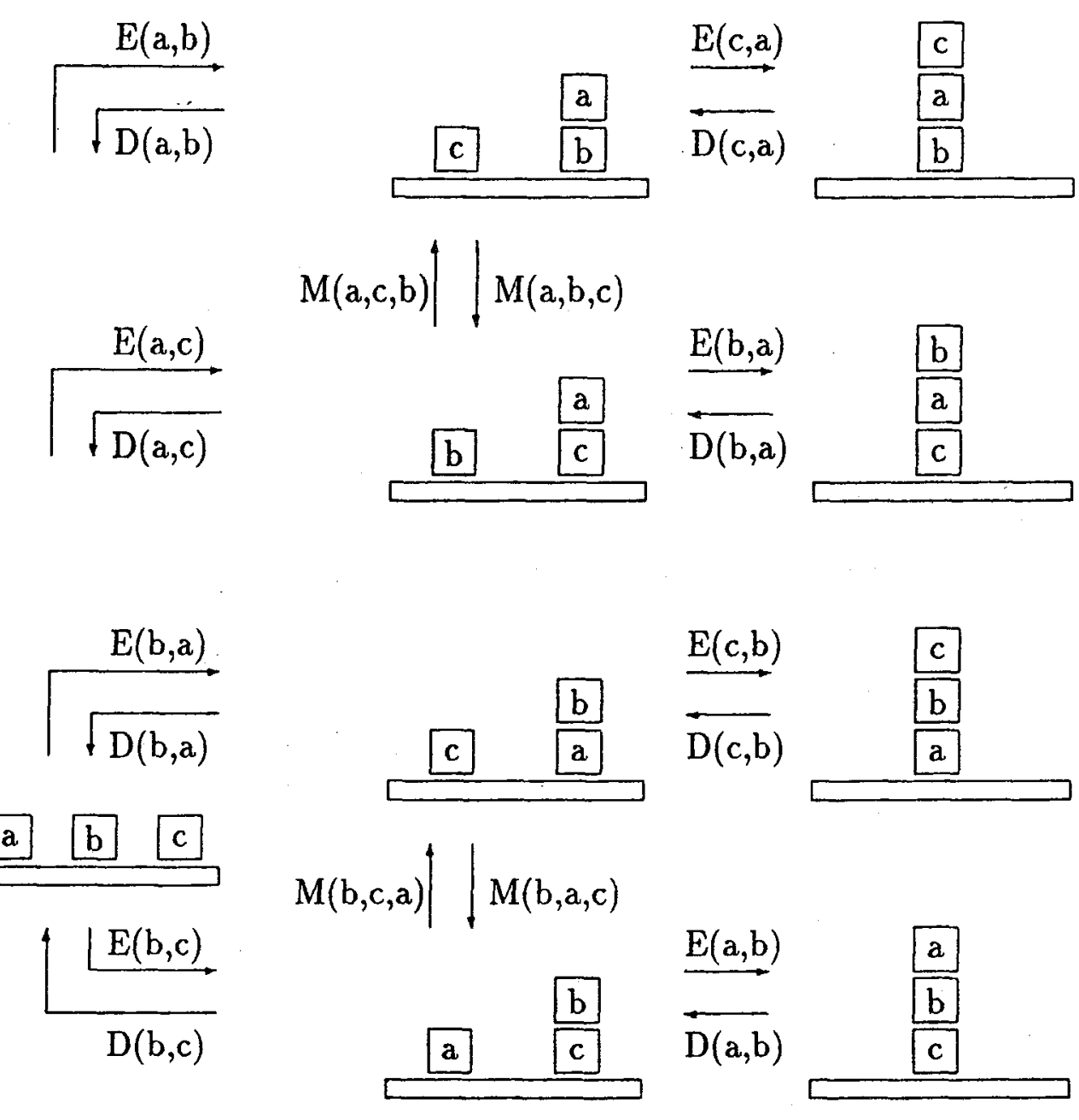

$a \quad b \quad c$

$\frac{\lfloor\stackrel{\mathrm{E}(\mathrm{b}, \mathrm{c})}{\longrightarrow}}{\mathrm{D}(\mathrm{b}, \mathrm{c})}$

$\frac{\lfloor\underline{L(c, a)}}{D(c, a)}$
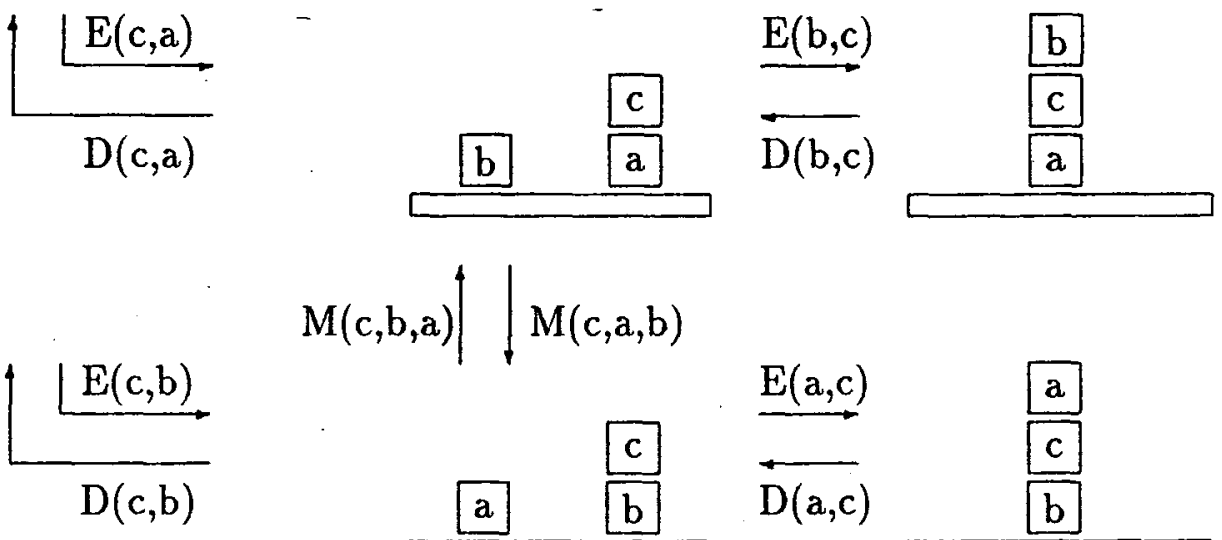

$$
M(c, b, a) \mid\rfloor M(c, a, b)
$$

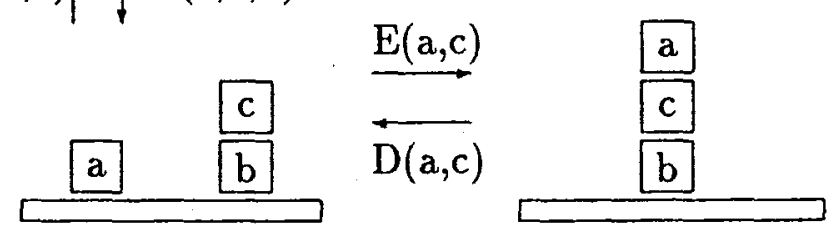

Figura 2.5: Ações e Estados Possíveis para o Mundo dos Blocos 


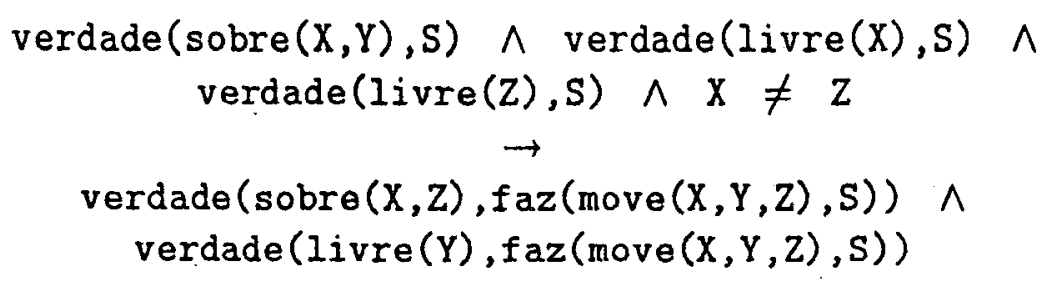

O efeito do operador desempilha é descrito pela seguinte sentença:

Se X está sobre $\mathrm{Y}$ no estado $\mathrm{S}$ e $\mathrm{X}$ tem seu topo livre, então, depois da operação desempilha, $\mathrm{X}$ ficará sobre a mesa e $\mathrm{Y}$ terá seu topo livre.

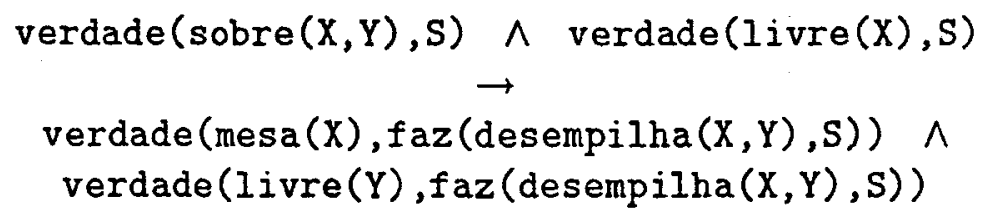

Para o operador empilha vale a seguinte sentença:

Se $\mathrm{X}$ está sobre a mesa, $\mathrm{X}$ e $\mathrm{Y}$ tem seus respectivos topos livres e $\mathrm{X} \dot{e}$ diferente de $Y$, então, após a operação empilha, X ficará sobre $Y$.

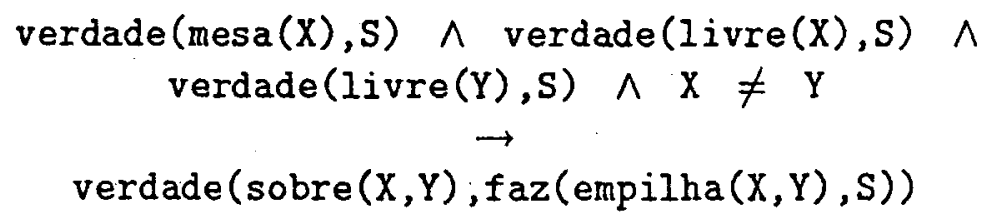

Com isto, é possivel deduzir quais são os fatos que se tornam falsos após a execução de uma ação.

\subsection{O Problema do Frame}

As descrições dos operadores cobrem apenas os fatos que se tornam verdadeiros -e indiretamente os que se tornam falsos - após a execuçâo de instâncias de cada operador, deixando sem especificar como ficam os fatos que não sofrem alterações. Ou seja, fatos que antes eram verdadeiros (falsos) e permanecem verdadeiros (falsos).

Para exemplificar, usando o Mundo dos Blocos, ibasta verificar o que ocorre se o operador empilha (b,a) for aplicado ao estado dado na Figura 2.2, ou seja, quando os três blocos estão sobre a mesa. Nesta situação, o fato de o bloco a estar sobre a mesa é válido antes e 
após a execução de empilha $(b, a)$, sem que isso possa ser obtido da descrição do operador empilha.

O problema de se caracterizar os aspectos - de um estado- que não sofrem mudança após uma ação é chamado de problema do frame. Ele é uma tentativa para formalizar as alterações que ocorrem na representação de domínios complexos [Hayes 81]. Um meio de caracterizar estes aspectos é escrever os axiomas do frame, os quais indicam as propriedades que permanecem inalteradas depois de cada ação.

A seguir são descritos os axiomas do frame para os operadores move, empilha e desempilha [Genesereth 87]:

- Para o operador move: um objeto permanece com seu topo livre depois de uma ação move, a menos que ele seja o objeto destino da ação. Um objeto que está sobre a mesa permanece sobre a mesa. Um objeto que está sobre outro objeto permanece sobre outro objeto, exceto para o objeto que é movido.

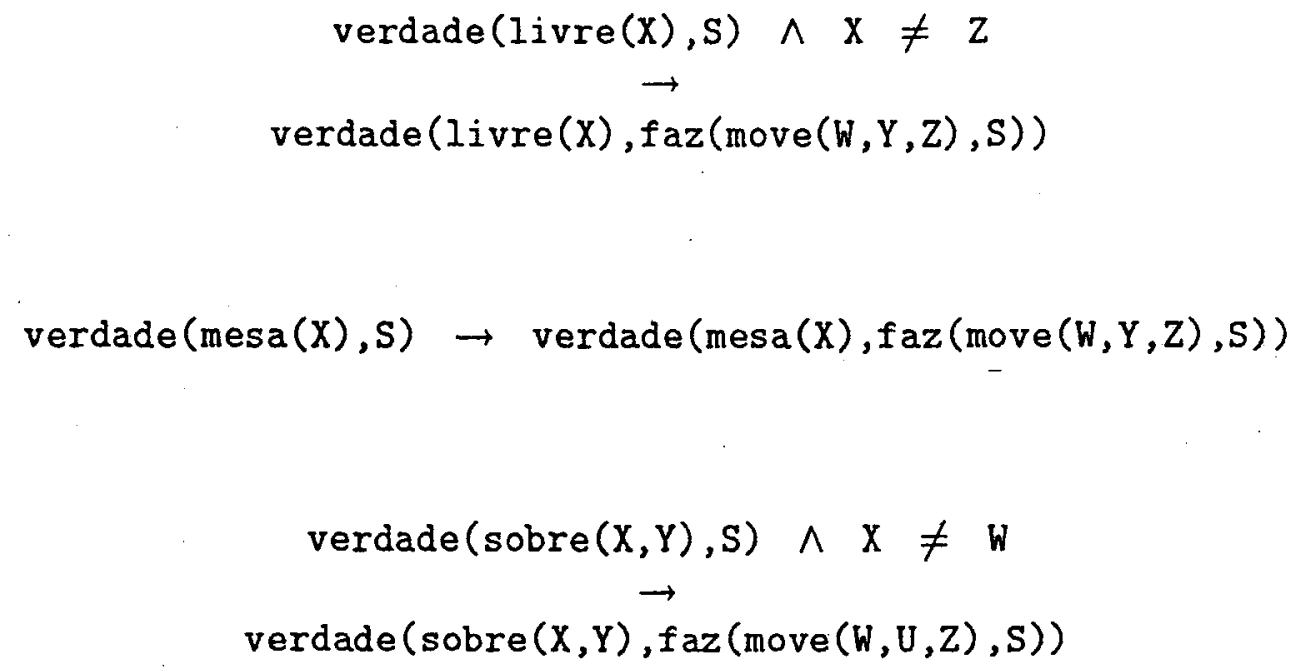

- Para o operador empilha: um objeto permanece com o seu topo livre, exceto se ele for o destino da ação. Um objeto permanece sobre a mesa, exceto se ele for o objeto a ser empilhado. Um objeto que está sobre outro objeto permanece sobre o mesmo objeto.

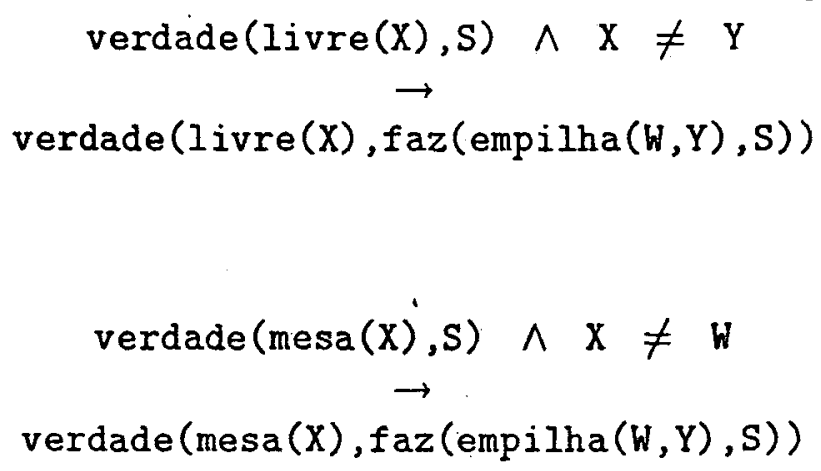




$$
\begin{gathered}
\operatorname{verdade}(\operatorname{sobre}(X, Y), S) \\
\operatorname{verdade}(\operatorname{sobre}(X, Y), \underset{f a z}{ }(\operatorname{empilha}(W, U), S))
\end{gathered}
$$

- Para o operador desempilha: um objeto que tem o seu topo livre permanece com o topo livre. Um objeto que está sobre a mesa permanece sobre a mesa. Um objeto que está sobre outro objeto permanece sobre o mesmo objeto, exceto se o objeto que está em cima for o objeto que será desempihado.

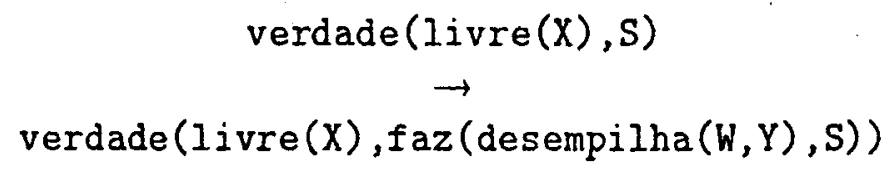

- Para a ação nula: tudo que é verdade permanece verdade.

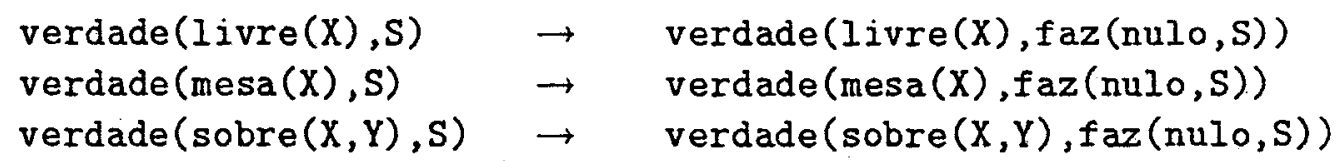

O número de axiomas do frame é proporcional ao produto do número de operadores pelo número de relações. No caso do exemplo considerado, são doze axiomas.

A grande dificuldade a respeito do problemã do frame é que, em universos complexos, existem muitas ações e relações, sendo portanto necessário muitos axiomas. Como grande parte das ações alteram apenas uma pequena parcela dos fatos, entâo, muitos axiomas simplesmente descrevem aquilo que não acontece. Este problema é alvo de contínua pesquisa [Hayes 81].

Porém, tem sido verificado que o problema do frame não constitui um impedimento para o desenvolvimento de planejamento, pois há formas eficientes de implementar planejadores sem fazer uso de um provador de teoremas de propósito geral, que manipula ações de primeira ordem e axiomas do frame [Barr 81]. 


\subsection{Considerações Finais}

Neste capítulo foram vistos alguns conceitos básicos que são muito utilizados dentro de. planejamento.

Inicialmente, foi visto como representar uma determinada instância do mundo físico - em um dado instante no tempo- através do conceito de estado; estado este que permite descrever as possíveis mudanças que possam ocorrer no mundo. Foi também mostrado que é possivel representar as propriedades que sejam imutáveis, bastando para isso conceituá-las como funções e relações independentes do estado.

A seguir foi visto que, para ocorrer uma mudança no estado, é essencial a execução de alguma ação nesse sentido. Foi mostrado também que os efeitos provocados por uma ação podem ser descritos através de sentenças lógicas.

Finalmente, foi abordado o problema do frame, mostrando como representar os fatos que não sofrem alterações - devido a execução de uma ação específica- através de axiomas. 


\section{Capítulo 3}

\section{Planejamento}

\subsection{Considerações Iniciais}

Neste capítulo é apresentada uma visão geral de planejamento, mostrando os conceitos e terminologias usados nesta área de pesquisa. Apresenta, também, uma visâo sobre decomposição de problemas, mostrando como isso é possível e qual a sua importância em planejamento.

A seguir, é enfocado o aspecto da ocorrência de falha durante o planejamento, apresentando alguns exemplos práticos para melhor entendimento. Uma descrição das etapas de planejamento, as quais devem ser realizadas para a elaboração de um plano, também é vista.

Finalmente, é apresentado um problema prático simplificado para exemplificar o uso de planejamento.

\subsection{Planejamento e Resolução de Problemas}

Em termos gerais, planejamento significa decjdir um caminho de ação antes de agir, ou - seja, é o processo de calcular diversos passos de um procedimento de solução para um problema antes de executar qualquer um deles [Rich 83]. Um plano é, então, a representação de um curso de ação que leva a uma possivel solução para um problema específico. $O$ plano gerado será composto por uma sequência de operadores. Estes operadores fazem parte do conjunto de operadores fornecidos ao sistema para cada domínio de aplicação.

As entradas para um planejador são um conjunto de operadores e um problema específico, o qual é caracterizado pela descrição de um estádo inicial e de um estado meta. O estado inicial descreve o estado do mundo antes de ser executado o plano, enquanto que o estado meta descreve como o mundo deve ficar após a execução do plano, para que se tenha 
sucesso na solução do problema.

Os operadores são especificados de acordo com o problema a ser resolvido, e são eles que caracterizam as ações através de pré-condições e efeitos. As pré-condições são, na verdade, as condições que o estado corrente deve satisfazer para que se possa executar determinada ação através do uso de um operador. Os efeitos são os fatos que se tornam verdadeiros e os que se tornam falsos, após a ação ter sido executada. É através do uso de fatos que se torna possível a descrição dos estados [Arariboia 89],[Vere 87].

Quando se trata com problemas simples, a manipulação da descrição completa de um estado é facilmente obtida. Já em domínios mais complexos é importante trabalhar com pequenas partes do problema separadamente, e depois combinar as soluçôes parciais para se ter uma solução completa do problema. Se isso não for possívél, será inviável tratar o problema dentro de um tempo razoável, pois o número de combinaçóes dos estados componentes do problema ficará muito grande.

\subsubsection{Decomposição do Problema}

Existem duas situações onde é importante decompor o problema: uma delas é quando há uma transição de um estado do problema para outro, mas não é necessário recalcular todo o novo estado, pois apenas uma parcela do estado foi alterada. Neste caso, em vez de traçar regras que descrevem transformações da totalidade de um estado para outro, são escritas regras que descrevam apenas as transformações das partes afetadas da descrição do estado, assumindo o restante como constante. Para maior clareza, é considerado o exemplo de guiar um robô em uma casa. A descrição completa do estado é muito grande, pois deve descrever onde cada objeto está localizado na casa, bem como onde o robô está. Uma ação, por parte do robò, irá modificar apenas uma pequena parte do estado total. No caso dele empurrar uma mesa, é necessário apenas descrever a nova localização da mesa, pois a posição dos outros objetos permanece inalterada de um estado para outro.

Outra situação de decomposição, que facilita a solução do problema, é quando se divide um único problema em diversos subproblemas completamente independentes entre si. Embora esta independência seja possível, na maioria dos problemas o que realmente se consegue, na verdade, é uma decomposição em subproblemas onde exista apenas uma pequena quantidade de interação e não uma completa independência [Simon 81]. Nestes casos, seria necessário um método de planejamento que permitisse trabalhar em cada um dos subproblemas separadamente, e só depois tratar as interações.

Ao ser detectado um caminho sem saida, um novo caminho pode ser explorado voltando-se atrás até o último ponto de opção. Entretanto, se os passos de soluçâo do mundo real não puderem ser ignorados ou desfeitos, o planejamento torna-se extremamente importante [Shirai 86]. 


\subsubsection{Simulação do Mundo Real}

Embora os passos do mundo real possam ser irrevogáveis, a simulação por computador não o é. Assim, é possível rastrear as restrições do mundo real ao buscar uma solução completa num mundo simulado —onde a volta atrás é permitida- e, apenas após ter sido encontrada uma solução, é que se retorna ao mundo real para executar o plano. Para isso, o universo deve ser previsível, pois assim é possível ter a certeza de que o resultado será - mesmo do planejado. No caso de ter um universo imprevisivel -planos são executados em um universo cheio de surpresas- não é possivel saber qual será o resultado de um passo de solução com a simples simulação no computador. Neste contexto, só é possível fazer uso de planejamento para monitorar o progresso durante a resolução do problema, e para detectar erros antes que eles provoquem danos [Charniak 86].

Estas características são muito importantes quando se está tratando com problemas do mundo real, onde uma retomada após um erro é impossível. Alguns exemplos deste tipo de problema são:

- Rota aérea: com o uso de planejamento, um piloto pode saber se uma determinada rota aérea irá ou não levar ao destino, isso muito antes de segui-la.

- Robótica: um robô, antes de passar por uma porta fechada, deve saber, através de planejamento, que deve abrí-la, caso contrário poderá danificar a porta ou a ele próprio.

Deve ser considerado, ainda, a existência de um certo "feedback" entre o mundo real e o mundo representado pelo planejador, pois da mesma forma que uma ação baseada em uma decisão do planejador pode afetar o mundo real, uma mudança expontânea -ou gerada por uma ação feita por um agente estranho externo- do mundo real, também afeta o mundo do planejador, obrigando o mesmo a fazer um novo planejamento a partir desta nova realidade (estado).

\subsubsection{Geração de Planos}

Em alguns casos, devido à impossibilidade de se prever todas as variáveis do mundo real, o planejador deve se limitar a encontrar, ou gerar, um único plano até seu objetivo e, quando alguma variável externa tornar impossível executar este plano, o planejador deve então assumir o estado atual como sendo o estado inicial e, a partir daí, traçar um novo plano para chegar ao seu objetivo. Por exemplo, seja um piloto pilotando um avião do Rio de Janeiro para São Paulo. Sua primeira opção é o Campo de Marte; se no meio do vôo é notificado que o Campo de Marte está fechado, ele deve traçar uma nova rota até um aeroporto alternativo, no caso, Congonhas.'

Por outro lado, existem casos onde uma consequência inesperada não invalida todo o resto do plano e, com uma pequena mudança, é resolvido o problema. Por exemplo, na 
confecção de um bolo se, no momento de separar a clara da gema, ocorrer de a gema cair junto, basta fazer o bolo utilizando uma nova receita, onde não seja necessária a separação entre a clara e a gema.

Se, no caso acima, não fosse aceitável ter um boló com uma nova receita -onde a gema pudesse ficar misturada com a clara - então a soluçâo seria refazer a etapa de separação entre a gema e a clara até que nâo ocorressem mais falhas. Isso é possível quando se consegue decompor um problema em vários subproblemas. Com isso, diminuiria o impacto da falha, pois esta só afetaria o restante do plano relacionado com o subproblema.

Para facilitar as eventuais correções de um plano, é útil, durante o processo de planejamento, registrar os passos que deverão ser realizados e as razões do porquê de sua realização. Com isso, quando ocorrer uma falha, é mais fácil voltar atrás e determinar quais partes restantes do plano eram dependentes dela.

Outra maneira de planejar dá-se passo a passo. Neste caso, a desvantagem é que se uma ação inapropriada for escolhida, então suas consequências não poderão mais ser ignoradas voltando-se atrás. Um plano pode, também, ser uma lista desordenada de objetivos, porém, usualmente, tem uma ordem implícita. Muitos planos tem uma rica estrutura de subplanos, pois cada objetivo em um plano pode ser trocado por um subplano mais detalhado para obtê-lo.

Portanto, um plano acabado é uma ordenação linear ou parcial de operadores resolvedores do problema, e os objetivos atingidos pelos operadores têm frequentemente uma estrutura hierárquica. Este aspecto de planos é oriundo da definição de que um plano é algum processo hierárquico no organismo, que pode controlar a ordem na qual uma sequência de operações será executada [Galanter 60].

Um aspecto que deve ser considerado é que, como na maioria dos problemas, o fator de ramificação é menor indo da meta para o estado inicial, então é conveniente o planejamento trabalhar nesse sentido para que ocorra uma minimização de esforços.

Os maiores benefícios do planejamento podem ser vistos na redução da busca, na resolução de objetivos conflitantes e no fornecimento de uma base para a recuperação de erros.

\subsection{Etapas do Planejamento}

Um sistema de planejamento, para obter a solução de um determinado tipo de problema, deve realizar basicamente as seguintes etapas [Rich 83]:

- Escolher a regra mais adequada baseado na informação heurística disponível: escolher um operador que compôe a sequência dè operadores que levará a solução do problema; 
- Aplicar a regra escolhida, originando um novo estado: para cada ação, deve ser descrita cada uma das alterações ocorridas na descrição do novo estado em função de sua aplicação;

- Detectar a obtençã́o de uma solução: para poder verificar isto em sistemas mais simples, basta fazer o casamento direto entre as descrições de estado. Porém, existem casos onde os estados não são representados de maneira explícita em sua totalidade, mas são, na verdade, descritos apenas por um conjunto de propriedades relevantes. Nesse caso, fica mais complexa a tarefa de detecção da solução. Para qualquer esquema representacional utilizado, deverá ser possível raciocinar com representaçóes para descobrir se uma delas é equivalente à outra;

- Detectar becos sem saída: para que eles possam ser abandonados e o esforço do sistema posicionado em direções mais proveitosas. Um sistema de planejamento deve ser capaz de detectar quando o caminho que está sendo percorrido é incapaz de levar à uma solução. No caso de se partir do estado inicial, algumas vezes é possível eliminar caminhos que não levem ao estado meta. Também podem ser eliminados caminhos que, aparentemente, não reduzem as diferenças entre o estado inicial e o estado meta. Já no caso de se partir do estado meta, é possivel eliminar caminhos que não levem ao estado inicial. Neste tipo de processo, cada meta é dividida em submetas e cada submeta poderá levar a um novo conjunto de submetas adicionais. Às vezes, torna-se fácil detectar que não há como satisfazer um conjunto de submetas;

- Detectar soluções parcialmente corretas: após encontrar uma solução parcialmente correta, fazer a correção para torná-la totalmente correta.

\subsection{Um Exemplo Prático}

Para melhor perceber a idéia geral de planejamento, visualize o problema de viajar entre as localidades de São Carlos, estado de São Paulo, para a localidade de Itabuna, estado da Bahia. Não levaria muito tempo para se formular o seguinte plano:

Ir de ônibus de São Carlos para São Paulo;

Ir de avião de São Paulo para Salvador;

Ir de ônibus de Salvador para Itabuna.

Este plano seria formado por três subplanos:

1) viagem pará São Paulo;

2) viagem para Salvador;

3) viagem para Itabuna. 
Resumindo, o problema é dividido em etapas e tenta-se resolver cada etapa utilizando os melhores recursos para cada uma delas. Uma idéia básica de como resolver o problema de viajar entre estas localidades pode ser vista na Figura 3.1.

Este problema poderia ser generalizado para poder atender quaisquer outras localidades, bem como resolver o problema com um número maior de subplanos. Nesse caso, em vez de usar o nome das localidades, são usadas variáveis X e Y quaisquer para representá-las. Os nomes dos lugares desejados devem ser instânciados de acordo com a viagem específica [Ford 87].

Uma possível solução geral deste problema pode ser vista na Figura 3.2.

As locações específicas, bem como as propriedades relevantes, podem ser definidas logicamente pelos seguintes fatos Prolog:

proximo(sao_carlos, sao_paulo).

proximo(salvador, itabuna).

rota_aerea(sao_paulo, salvador).

rota_onibus(sao_carlos, sao_paulo).

rota_onibus(salvador, itabuna).

Onde:

proximo significa que as localidades são próximas uma da outra;

rota_aerea significa que existe uma rota aérea entre as duas localidades referenciadas;

rota_onibus significa que existe uma rota de ônibus entre as duas localidades referenciadas.

Devem também ser definidos os operadores ir_aviao e ir_onibus, cuja representação, seguindo o padrão Prolog, ficaria:

operador(ir_aviao, $Y, Z$, pre_cond $(\operatorname{rota}$ _aerea $(Y, Z), \operatorname{not}(\operatorname{proximo}(Y, Z))))$.

operador(ir_onibus, $Y, Z$, pre_cond(rota_onibus $(Y, Z)$, proximo $(Y, Z)$ )) .

Onde, o primeiro predicado indica que, para aplicar o operador ir_aviao é necessário existir uma rota aérea entre as localidades e que elas não sejam próximas. Já o segundo predicado indica que, para aplicar o operador ir_onibus, é necessário existir uma rota de ônibus entre as localidades e que elas sejam próximas. 


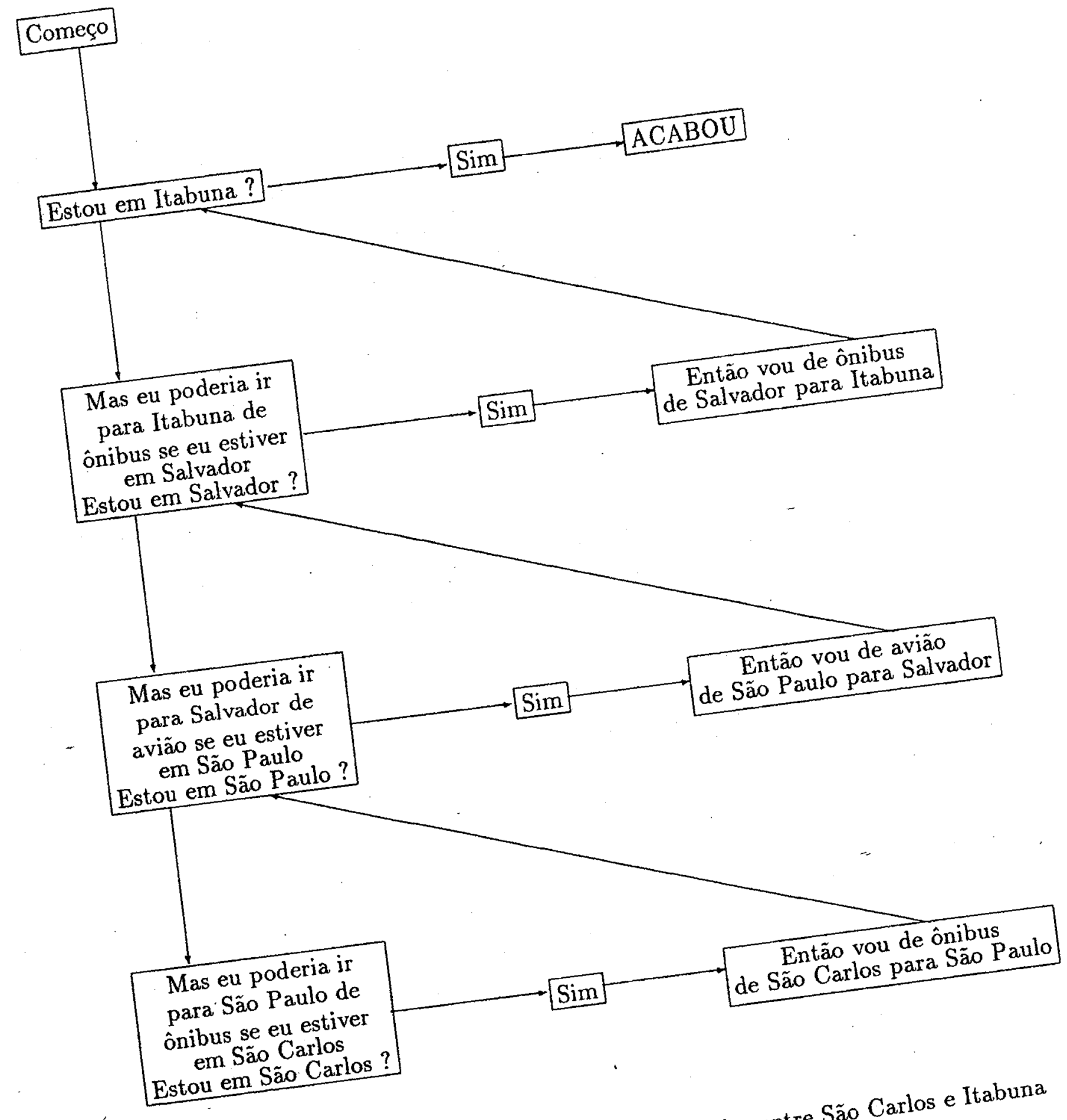

Figura 3.1: Diagrama Básico para o Problema 


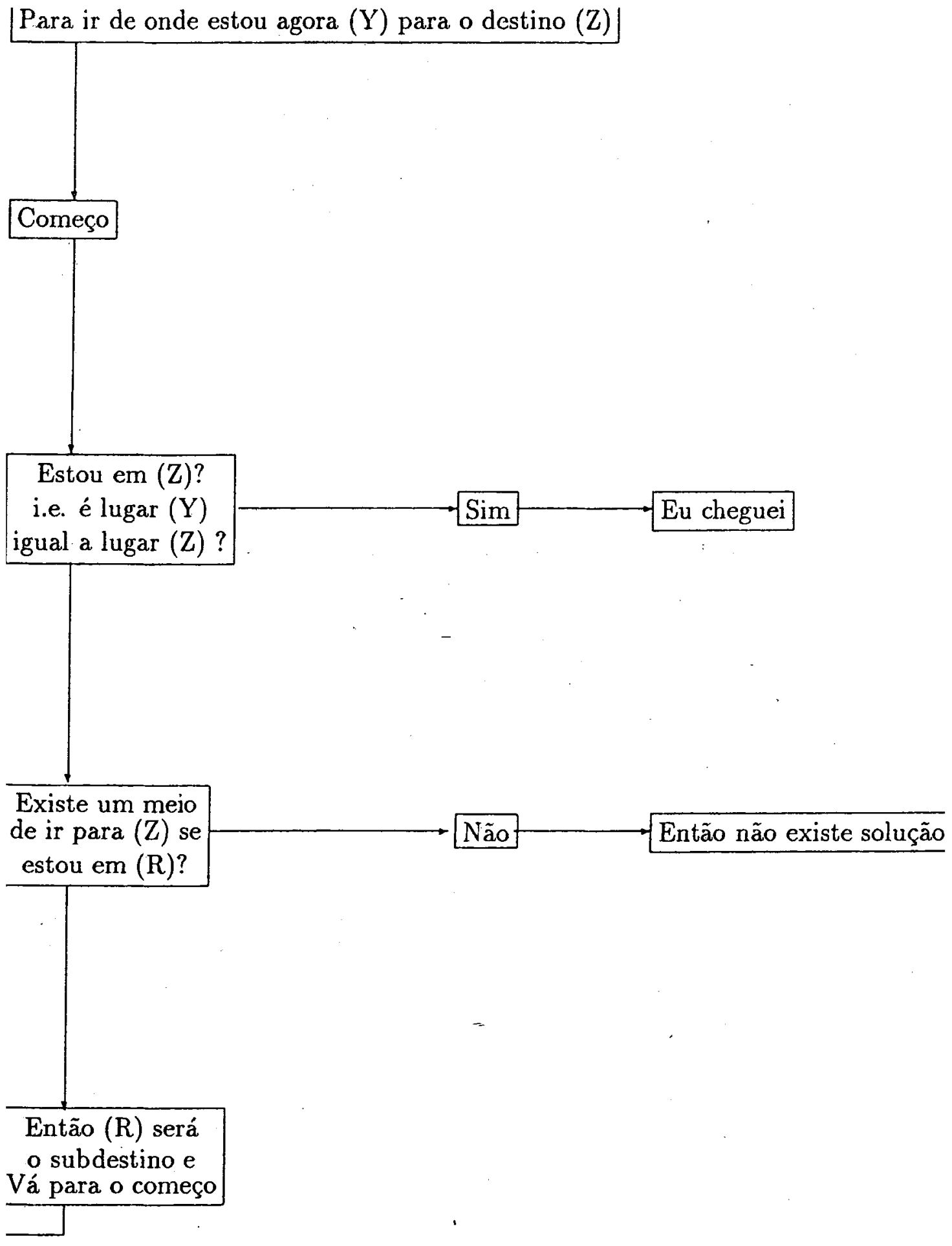

Figura 3.2: Generalização para o Problema de Viagem 
Um resolvedor simples, em Prolog, para o problema de viagens seria: viagem $(Z, Z)$.

Se já estou onde quero ir então nada é preciso ser feito.

viagem $(Y, Z):-$

Se não estou, então devo viajar.

operador $\left(A, R, Z, p r \epsilon_{-} \operatorname{cond}(B, C)\right)$,

Encontro um operador (A) que leve

para $(Z)$ a partir de $(R)$.

call (B), $\operatorname{call}(C)$,

Verifico se as pré-condições

(B) e (C) são satisfeitas.

viagem $(Y, R), n I$,

Aplico a regra viagem recursivamente, só que agora tentando encontrar uma viagem entre $(Y) e(R)$.

write ( $[A$,' de ', $R$,' para ', $Z]$ ).

$O$ trecho de viagem de $(Y)$ até $(R)$

só será feito quando for atingida

a regra vi agem $(Z, Z)$. Pela recursâo, serão escritos todos os trechos da viagem.

Voltando para o exemplo específico de ir de São Carlos para Itabuna, para resolver o problema, o programa deve ser interrogado com:

?- viagem(sao_carlos, itabuna).

A primeira regra não é bem sucedida pois as localidades são diferentes. Com a segunda regra ocorre a instanciação dos argumentos e tem-se como saída o seguinte:

ir_onibus de sao_carlos para sao_paulo;

ir_aviao de sao_paulo para salvador;

ir_onibus de salvador para itabuna.

\subsection{Considerações Finais}

Foi visto neste capítulo que os sistemas de planejamento são utilizados, basicamente, na geração de uma sequência de ações para um agente que possa efetuá-las - por exemplo um robô. As entradas essenciais para o sistema são constituídas por um repertório de ações, por um estado inicial e por um estado meta. 
Outro ponto abordado neste capítulo foram as duas situações possiveis de decomposiçâo de problemas. Uma delas ocorre quando uma transição de um estado para outro não provoca a alteração de todo o estado, ou seja, apenas uma pequena parcela do estado sofre alteração, permanecendo constante todo o reștante do estado. A outra situação de decomposição ocorre quando se tem problemas que podem ser divididos ern subproblemas independentes, ou que tenham um mínimo de interação entre eles.

Foi mostrado, também, que nem sempre uma falha invalida todo o restante do plano, e que devem ser registrados os passos a serem realizados, bem como as razôes de sua utilização, para tornar mais fácil a tarefa de correção desse plano.

Outro aspecto importante tratado é que o sistema de planejamento deve, basicamente, escolher uma ação, aplicar esta ação -originando um novo estado-, detectar a obtenção -parcial ou total - do objetivo desejado e detectar becos sem saídas, para obter a solução de um problema.

Para melhor representar o conceito básico de planejamento, foi escolhido um exemplo muito simples de viagem entre localidades, onde foi mostrado como um problema pode ser decomposto em subproblemas independentes, além de mostrar a adequação da linguagem de programação Prolog para resolver esse tipo de problema. 


\section{Capítulo 4}

\section{Abordagens para Planejamento}

\subsection{Considerações Iniciais}

Neste capitulo são apresentadas as quatro principais abordagens de planejamento. Elas são:

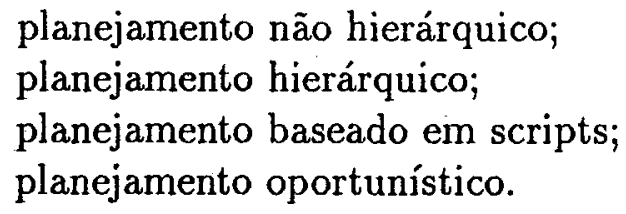

Uma confusão muito comum é com relação a palavra hierárquico. Isso acontece porque a maioria dos planos tem aninhadas estruturas hierárquicas. Contudo, a palavra tem outra interpretação, a qual fornece a base necessária para se distinguir planejamento hierárquico de planejamento não hierárquico. A distinção está no fato de que planejadores hierárquicos geram uma hierarquia de representação do plano, no qual o nível mais alto é uma simplificação ou abstração do plano, enquanto que o nível mais baixo é um plano suficientemente detalhado para resolver o problema. Em contraste, planejadores não hierárquicos têm somente um nível de representação do plano. Em resumo, ambos os tipos de planejadores geram planos com estruturas de sub-metas hierárquicas, mas somente planejadores hierárquicos utilizam uma hierarquia na representação do plano.

\subsection{Planejamento Não Hierárquico}

O planejador não hierárquico desénvolve uma sequência de ações para resolver cada uma de suas metas. Partindo do estado inicial, o planejador não hierárquico reduz suas metas para metas mais simples, ou faz uso da técnica de análise de meio e fins - descrita 
adiante- para diminuir a diferença entre o estado corrente e aquele que representa a solução desejada.

A maior desvantagem do planejador não hierárquico é que ele não distingue entre ações que são relevantes e as que são de pouca importância para o sucesso do plano. Este fato faz com que os planos possam ficar enroscados em detalhes sem importância, além de um possível aumento no tempo necessário para se obter a solução final. Essa incapacidade de distinção entre as possiveis ações é devido ao fato de que um planejador não hierárquico, embora desenvolva uma hierarquia de sub-objetivos, representa esses sub-objetivos no mesmo nivel de representação do plano original.

\subsubsection{O Sistema Strips}

O planejador não hierárquico mais difundido é o sistema Strips [Fikes 71]. Esse sistema utiliza a técnica de pilha de meta, a qual contém objetivos e operadores propostos para satisfazer a meta. O seu resolvedor procura sempre satisfazer os objetivos na ordem em que estão empilhados. Inicialmente, a pilha contém somente a meta. Quando uma sequência de operadores que satisfazem a meta - ou parte dela - for encontrada, essa sequência será aplicada à descrição do estado - resultando em uma nova descrição-e o objetivo satisfeito é desempilhado. O passo seguinte é satisfazer o objetivo que está agora no topo da pilha, sendo que, agora, o estado corrente passa a ser o estado gerado no passo anterior. Este processo continua até que a pilha de meta esteja completamente vazia. Quando isso ocorrer, é verificado se o estado final produzido coincide com a meta desejada. Se coincidir, tem-se a solução do problema, caso contrário, os objetivos componentes da meta que não aparecem no estado obtido serão reinseridos na pilha e o processo continua.

Para exemplificar o uso de Strips, será usado o Mundo dos Blocos, pois seu domínio é considerado suficientemente complexo para exigir que cada um dos mecanismos de resolução de problemas seja aparente e, por outro lado, simples o bastante para que se possa encontrar exemplos de fácil compreensão.

Como já foi visto, neste mundo tem-se que: existe uma mesa na qual se pode colocar blocos, há também blocos quadrados do mesmo tamanho que podem ser empilhados um sobre o outro. Há um braço de robô para manipular os blocos. As ações que podem ser realizadas serão representadas da seguinte forma:

desempilha $(\mathrm{a}, \mathrm{b})$ : Pegar o bloco a que está sobre:o bloco b. O braço deverá estar livre e o bloco a não poderá ter outros blocos em cima dele.

empilha $(a, b)$ : Colocar o bloco a sobre o bloco b. O braço deverá estar segurando a, e o bloco b não poderá ter outros blocos em cima dele.

apanhar(a): Pegar o bloco á da mesa e segurá-lo. O braço deverá estar livre e nada deverá estar em cima do bloco a.

colocar_mesa(a) : colocar o bloco a sobre a mesa. O braço deverá estar segurando o 
bloco a.

Restrições:

- O braço do robô só pode segurar um bloco de cada vez;

- Um bloco só poderá ter, no máximo, um outro bloco diretamente sobre ele.

Para caracterizar um estado corrente num dado momento, serão utilizados os seguintes predicados:

livre(a) : não há nada em cima do bloco a.

segurando(a) : o braço está segurando o bloco a.

mesa(a) : o bloco a está sobre a mesa.

$\operatorname{sobre}(a, b)$ : o bloco a está sobre o bloco b.

Para escolher os operadores que serão aplicados, a técnica utilizada pelo sistema Strips é a análise dos meios e fins.

Supondo que se quer partir do estado inicial Estado 1 e chegar ao estado meta Estado 2, da Figura 4.1.

- Etado 1: $\operatorname{sobre}(b, a), \operatorname{livre}(b), \operatorname{livre}(c)$, mesa (a), mesa(c), bracolivre.

- Etado 2: sobre(c,a), livre(c), livre(b), mesa (a), mesa(b), bracolivre.

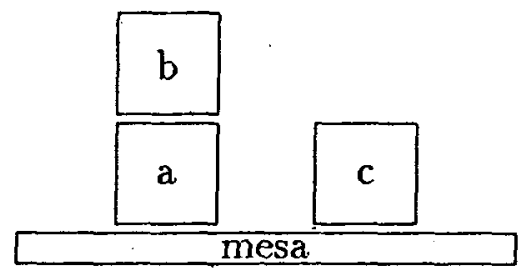

Estado 1 (inicial)

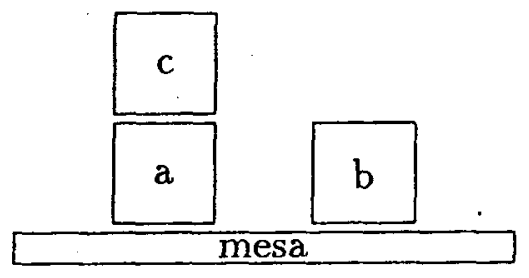

Estado 2 (meta)

Figura 4.1: Representação de Estados - 3 
Pode-se observar que é impossivel atingir o Estado 2 através de uma única ação. A técnica. de análise de meios e fins especifica que a decisâo na escolha deve ser tomada em função da ação que provoque a maior redução nas diferenças entre Estado 1 e Estado 2. Nc exemplo considerado seria primeiro desempilhar o bloco b de a, para então empilhar c em a e atingir a meta desejada.

Como já foi visto, para cada ação devem ser descritas cada uma das alterações ocorridas na descrição do estado em função de sua aplicação. No sistema Strips, cada operação é descrita por uma lista de novos fatos que o operador torna verdadeiros e uma lista de fatos antigos que ele torna falsos. Para estas listas dá-se os nomes de adiciona-fato (AF) e remove-fato (RF). Existe, ainda, uma lista pré-condição (PC) para cada operador, onde se tem todos os fatos que deverão ser verdadeiros para tornar possivel a aplicação desse operador. Qualquer fato que não esteja incluído, seja na lista adiciona-fato, seja na lista remove-fato, não será afetado por elas. Com isto, ao se especificar cada operador, não é preciso considerar aspectos do domínio que a eles não estejam relacionados. Operadores, no estilo Strips, podem ser representados da seguinte maneira:

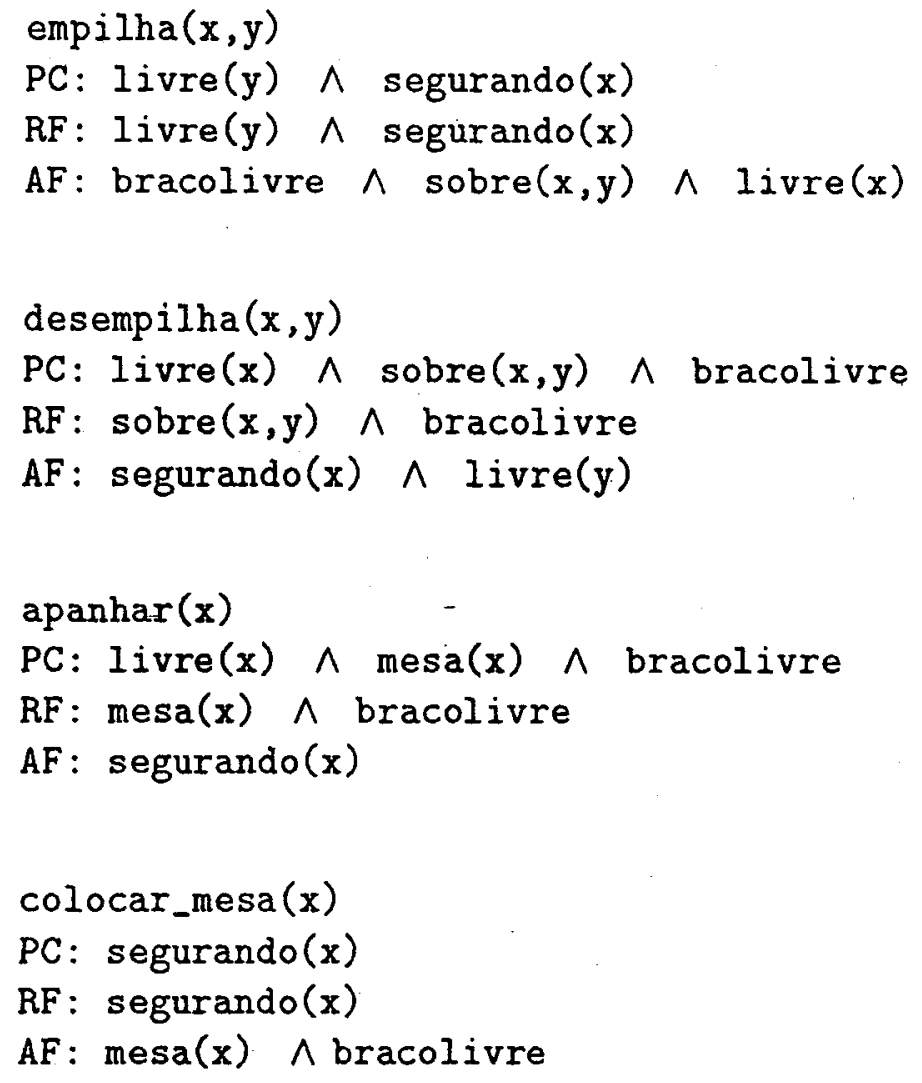

É observado que, em muitos casos, a lista de pré-condições e a de fatos a serem removidos são idênticas. Por exemplo, para apanhar um bloco, o braço do robô deverá estar vazio e, tão logo ele apanhe um bloco, não estará mais vazjo. Mas nem sempre isso é verdade, pois, para que o braço apanhe um bloco, este não poderá ter outro bloco em cima, e isto ainda continua sendo válido após o bloco ter sido apanhado. Esta é a razão pela qual as 
lista PC e RF devem ser especificadas separadamente.

No que se segue, estas listas serão trabalhadas em cima de uma única base de dados, onde será descrito apenas o estado atual do mundo.

Seja o caso da Figura 4.2:

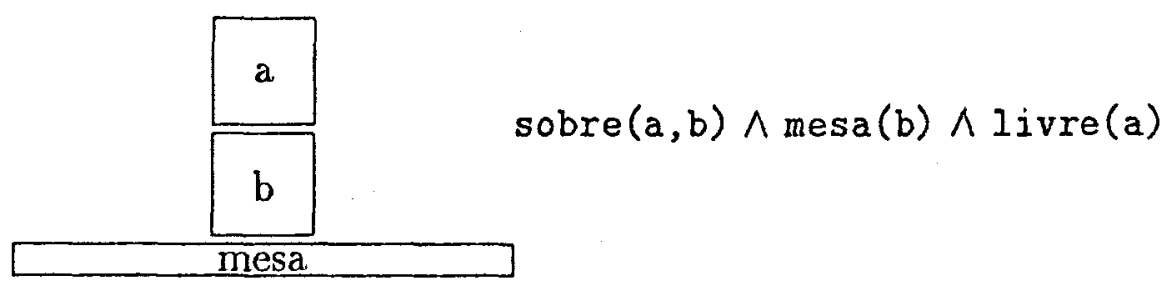

Figura 4.2: Estado Atual

Aplicando-se os operadores desempilha $(a, b)$ e colocar_mesa (a), tem-se a nova descrição.do estado, mostrada na Figura 4.3:

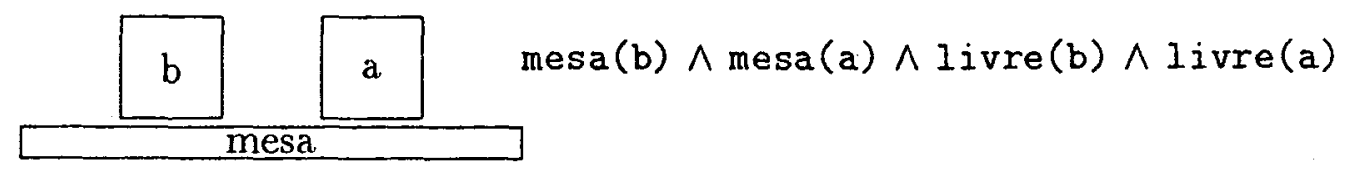

Figura 4.3: Estado Resultante da Execução das Ações

As alterações sofridas na descrição do estado atual são oriundas da aplicação das listas $\mathrm{RF}$ e AF, relativas aos operadores que foram aplicados.

A simples atualização de uma única descrição de estado funciona como um meio de manter o controle dos efeitos de uma sequência dada de operadores. Se ocorrer uma falha, ou seja, for escolhida uma sequência incorreta de operadores, então deverá ser possivel retornar ao estado original para que uma sequencia diferente seja tentada. Para isto, torna-se necessário registrar, em cada estado, as mudanças que foram feitas na base de dados quando ocorreu a passagem através do mesmo. Como as mudanças estão descritas com exatidão nas listas adiciona-fato e remove-fato de cada operador, basta somente registrar qual operador foi utilizado e, assim, tem-se quais as mudanças relativas àquele passo de solução do problema.

Para observar como são os passos de execução em Strips, é escolhida a situação mostrado na Figura 4.4:

- estado inicial : sobre(c,a), Iivre(b), Iivre(c), mesa(a), mesa(b), bracolivre.

- estado meta: $\operatorname{sobre}(c, b), \operatorname{sobre}(a, c)$. 


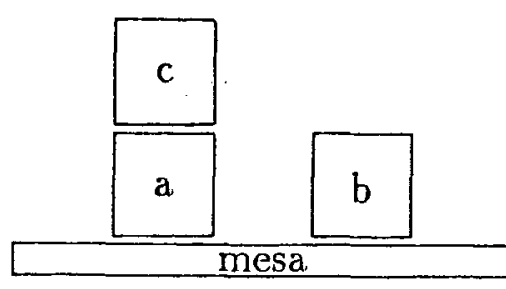

Inicial

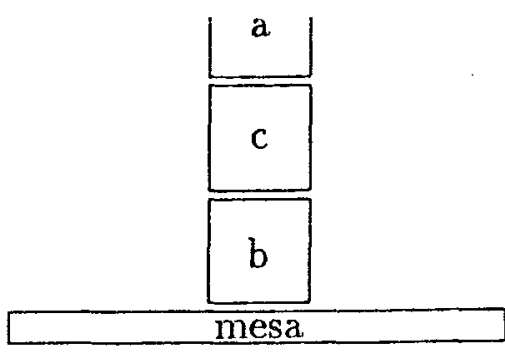

Meta

Figura 4.4: Representaçâo de Estados - 4

A Figura 4.5 mostra um diagrama de solução para essa situação [Nilsson 82]. 


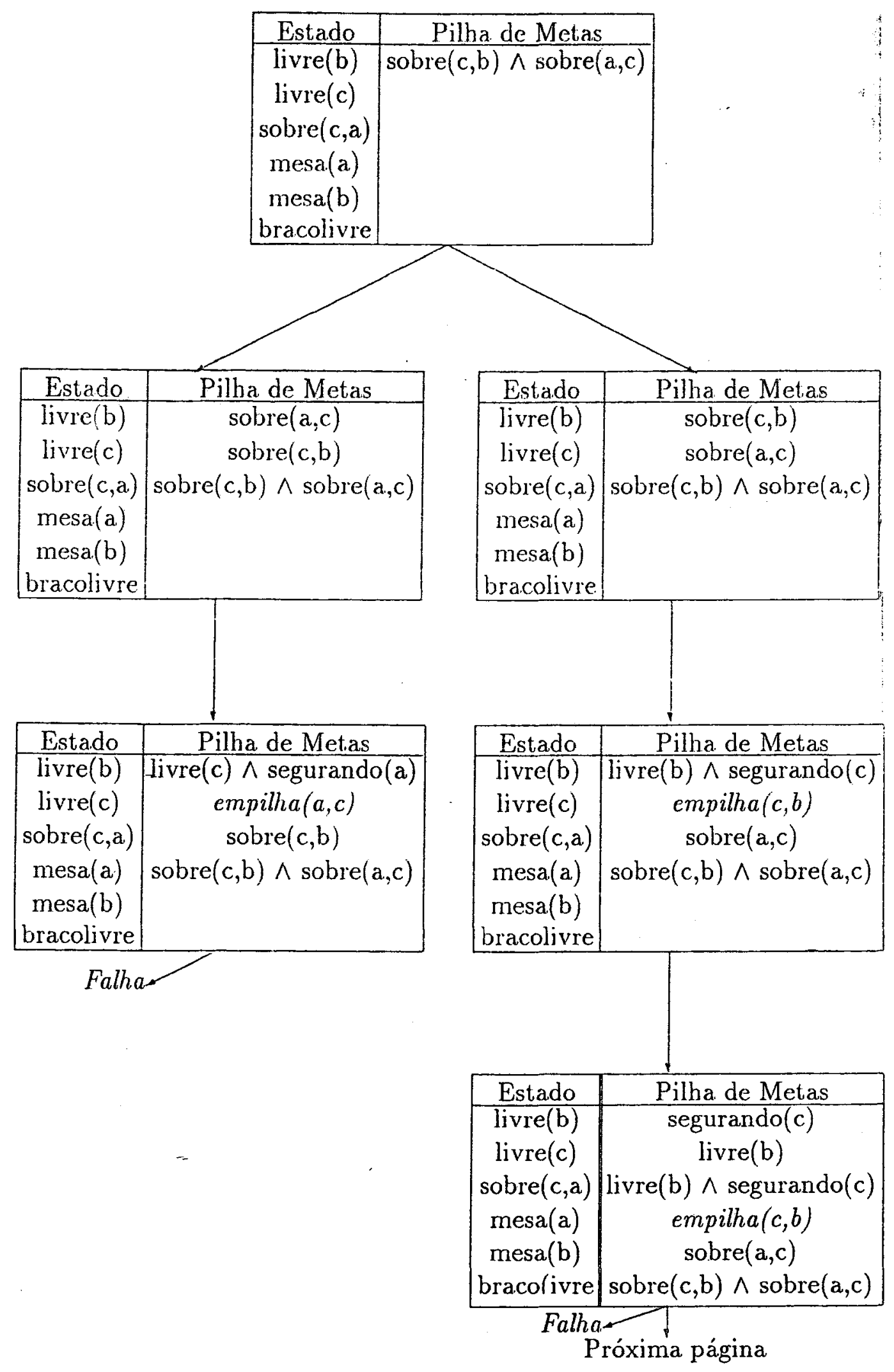

Figura 4.5: Diagrama de Execução do Strips (Parte 1) 


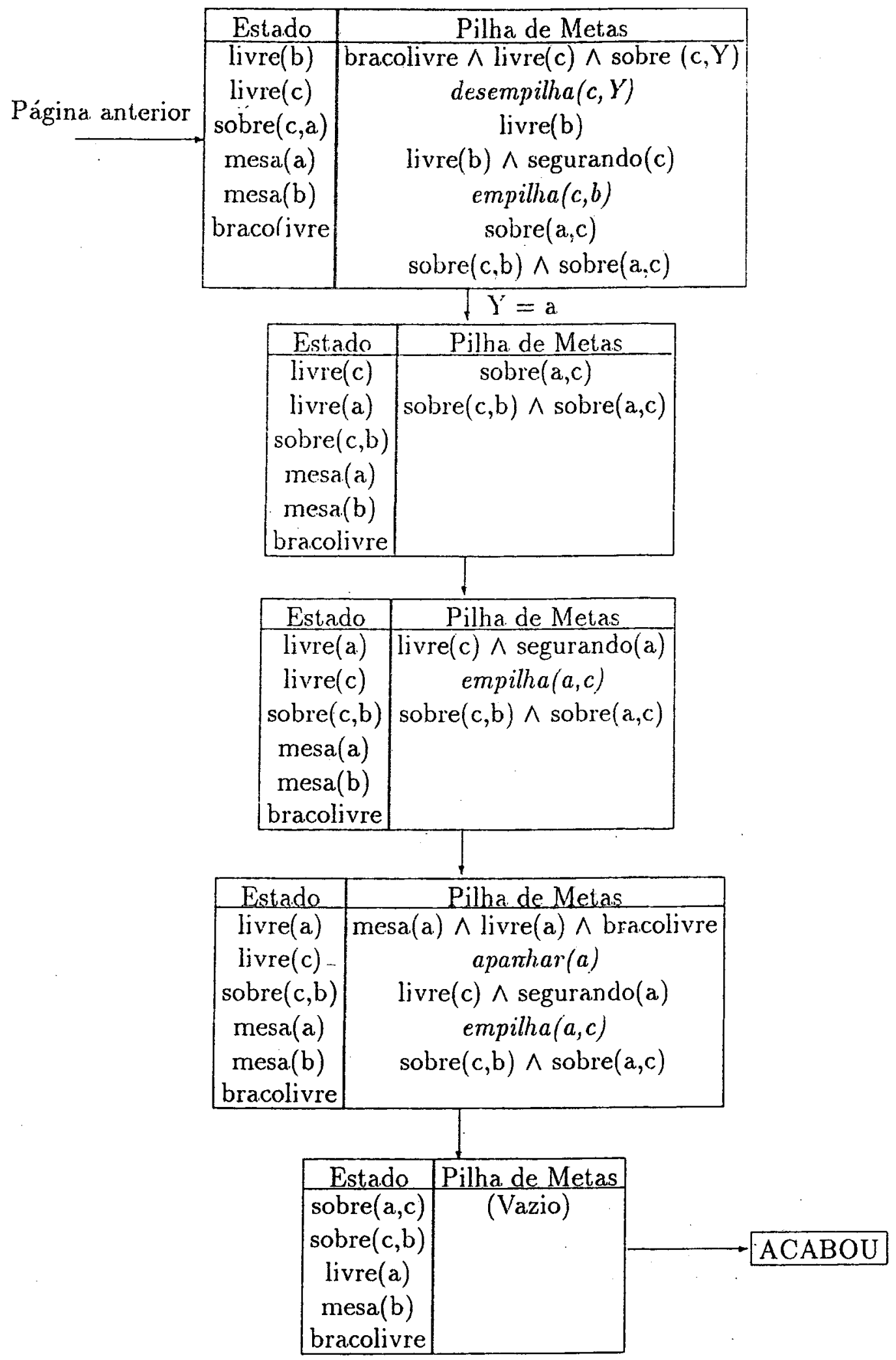

Figura 4.5: Diagrama de Execução do Strips (Parte 2) 


\subsubsection{Uma Implementação Lógica do Sistema Strips}

A fim de mostrar a adequação da linguagem de programação lógica Prolog para implementar planejadores, é mostrado a seguir uma implementação simplicada do sisţema Strips extraída de [Arariboia 89], onde pequenas modificaçôes foram introduzidas para contornar problemas que foram constatados durante os testes realizados.

O domínio de aplicação escolhido é o mesmo definido anteriormente na seção 4.2 , ou seja, o Mundo dos Blocos. A linguagem usada para a implementação é Arity Prolog 5.1 [Arity 88]. No que se segue, é considerado um conhecimento inicial da linguagem Prolog.

Para representar os predicados é adotado o formato onde os predicados são identificados pelo seu nome e aridade. Por exemplo, a notação plano/3 representa um predicado de nome plano que tem 3 argumentos -aridade 3.

Os operadores são representados pelo predicado operador/1 que, no dominio de aplicação escolhido, são definidos por:

operador (empilha $(X, Y)$ ).

operador (desempilha $(X, Y)$ ).

operador (apanhar $(X))$.

operador(colocar_mesa $(X))$.

Para representar as pré-condições que devem ser satisfeitas antes da execução de um operador, é usado o predicado pre_cond/2 como se segue:

pre_cond ( $0 \mathrm{p}$, Cond) .

Onde:

- Op: instancia com o operador;

- Cond: instancia com uma estrutura contendo todos os fatos que devem ser válidos antes da aplicação do operador.

Para exemplificar, seja o caso em que se deseja praticar uma ação de empilhar. Nesse caso, Op instancia com empilha $(X, Y)$ e Cond instancia com livre $(Y)$ \& pegando $(X)$, que indicam as condições prévias de $Y$ não ter nenhum outro bloco sobre seu topo e de que o robô deve ter pego o bloco X, para só aí realizar a operação de empilhar X em Y. A seguir tem-se a definição de pre_cond/2:

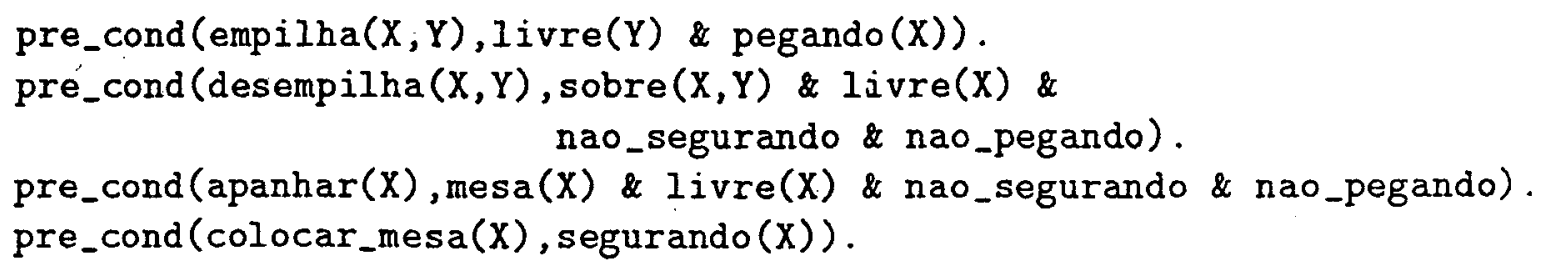


Para representar os fatos que serão acrescidos à descrição do estado após a execução de uma ação - através de um operador- é usado o predicado adiciona_fato/2, como se segue:

adiciona_fato(Op, Adiciona).

Onde:

- Op: instancia com o operador;

- Adiciona: instancia com o fato que será incorporado à descrição do estado.

Para exemplificar, é usado o exemplo visto acima, onde se deseja praticar uma ação de empilhar. Nesse caso, Op instancia com empilha( $X, Y)$ e Adiciona instancia com nao_pegando e com sobre $(X, Y)$, que indicam os fatos válidos de o robô não estar mais pegando o bloco e de o bloco $X$ estar empilhado sobre o bloco $Y$, após ter sido executado o operador. A seguir, tem-se a definição de adiciona_fato/2:

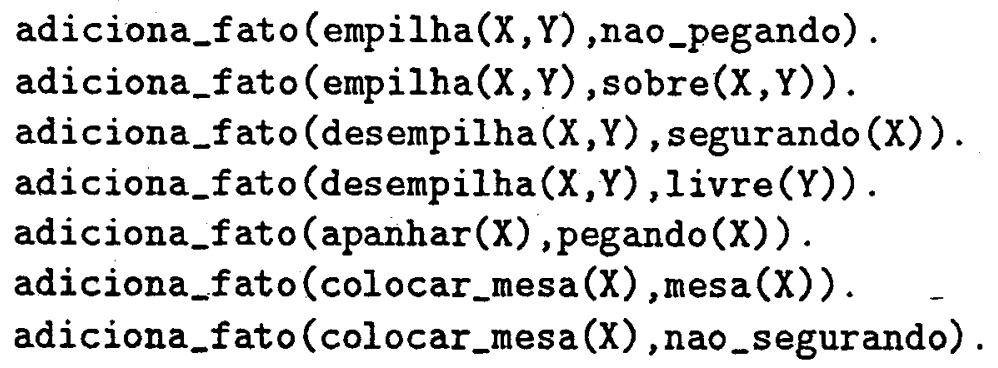

Para representar os fatos que serão removidos da descrição do estado após a execução de uma ação - através de um operador- é usado o predicado remove_fato/2, como se segue:

remove_fato(Op, Remove).

Onde:

- Op: instancia com o operador;

- Remove: instancia com o fato que será removido da descrição do estado.

Para exemplificar, é usado novamente o caso em que se deseja praticar uma ação de empilhar. Nesse caso, Op instancia com empilha $(X, Y)$ e Remove instancia com livre $(Y)$ e com pegando $(X)$, indicando que, os fatos de $Y$ não ter nenhum outro bloco sobre seu topo e de que o robô deve ter pego o bloco $X$, não são mais válidos após realizar a operação de empilhar $X$ em $Y$. A seguir tem-se a definição de remove_fato/2: 


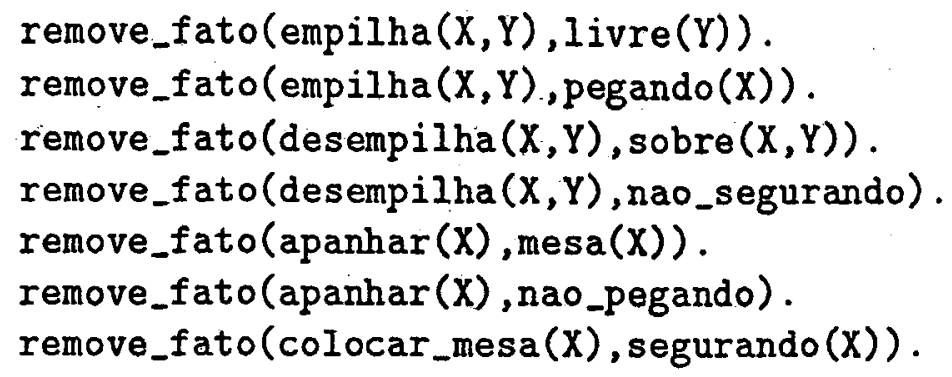

Para descrever o estado corrente, é usada uma única base de dados onde estão especificados os fatos que descrevem o estado. Portanto, após cada ação, essa base é alterada em função das informações contidas no segundo argumento de adiciona_fato/2 e remove_fato/2. Os predicados usados para representar esses fatos são:

\begin{tabular}{|l|l|}
\hline mesa $(X)$. & indica que o bloco X está sobre a mesa \\
sobre $(X, Y)$. & indica que o bloco $X$ está sobre o bloco $Y$ \\
livre $(X)$. & indica que o bloco X tem seu topo livre \\
pegando $(X)$. & indica que o robô pegou um bloco que estava sobre a mesa. \\
segurando $(X)$. & indica que o robô está segurando um bloco que estava empilhado \\
\hline
\end{tabular}

Uma vez mostrado como o domínio de aplicação - Mundo dos Blocos- pode ser implementado, o passo seguinte é apresentar o resolvedor propriamente dito.

O nivel mais alto está definido pelo programa metas/1, que é composto de duas cláusulas. A primeira cláusula constitui a chamada para o resolvedor, e a segunda serve para indicar os casos em que é impossivel encontrar um plano que resolva a meta desejada.

$\operatorname{metas}(\mathrm{C}):-\operatorname{meta}(\mathrm{C})$.

metas(C):- write('Plano impossivel'), nl.

Onde:

- C é o grupo de fatos que descrevem o estado meta.

A seguir, tem-se o predicado meta/1 que é, basicamente, a entrada para o resolvedor de problemas. É passado o grupo de fatos que descrevem o estado meta e, então, é montado uma sequência de operadores - que constituem o plano. O plano, assim construído, é verificado para saber se satisfaz a meta. Caso não a satisfaça, é montado um outro plano, que também é verificado. No caso de sucesso, é mostrado a sequência de operadores que formam o plano.

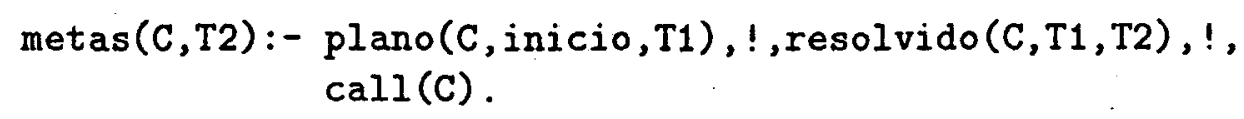


Onde:

- C instancia com o grupo de fatos que descrevem o estado meta;

- T1 instancia com a sequência de operadores que compoem o plano.

Para exemplificar, é considerado o caso em que se tem, inicialmente, os quatro blocos sobre a mesa. É desejado obter um estado meta onde se tenha o bloco a sobre o bloco c, como mostrado na Figura 4.6. Para executar o programa, deve ser feita a seguinte interrogação:

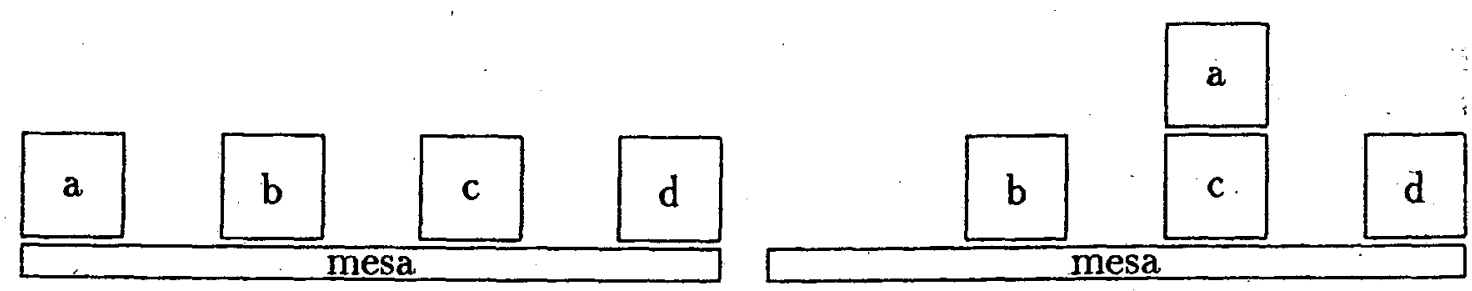

Figura 4.6: Representação de Estados - 5

?- $\operatorname{metas}(\operatorname{sobre}(a, c))$.

Obtendo a seguinte resposta:

Plano $=\operatorname{apanhar}(a) \Rightarrow \operatorname{empilhar}(a, c)$

Se, por outro lado, o estado meta especificado fosse:

?- $\operatorname{metas}(\operatorname{sobre}(\mathrm{a}, \mathrm{c})$ \& livre(c))

Seria obtido o seguinte resultado:

Plano impossivel.

Isto porque é impossível ter o bloco c com seu topo livre e ao mesmo tempo ter o bloco a sobre ele.

O programa plano/3 é o elaborador do plano, e ele é composto de duas cláusulas. A primeira cláusula serve para os casos onde o estado meta seja composto de mais de um fato, e a segunda cláusula serve para os casos onde o estado meta possua apenas um fato. Ele procura resolver os fatos que compõem a meta - sub-metas- um por um.

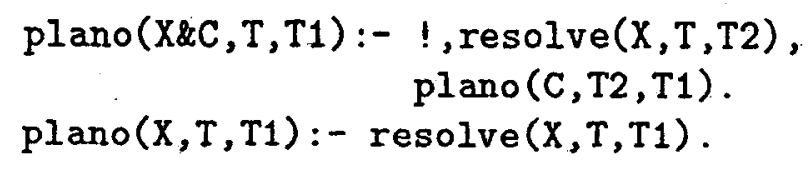


Onde:

- X\&C instancia com o grupo de fatos que descrevem o estado meta;

- $\mathrm{X}$ instancia com a primeira sub-meta;

- T instancia com o plano parcial até o momento;

- T1 instancia com o plano final.

O programa resolve/3 é o resolvedor de sub-metas, pois a ele é fornecida uma sub-meta e o plano parcial até o momento. Ele é composto de duas cláusulas, onde a primeira serve para verificar se a sub-meta passada já foi resolvida anteriormente e a segunda procura resolver a sub-meta.

Para resolver a sub-meta, a segunda cláusula é composta de alguns predicados: operador/1 serve para instanciar um operador candidato a resolver a sub-meta, adiciona_fato/2 verifica se o operador instanciado pode resolver a sub-meta, isto é conseguido ao se verificar na lista de fatos que serão adicionados pelo operador se existe a sub-meta em questão.

Uma vez constatado que o operador pode resolver a sub-meta, então, suas pré-condições são obtidas por pre_cond/2. Depois, plano/3 é chamado para resolver as pré-condições e, após terem sido satisfeitas as pré-condições, ocorre a alteração na base de dados, que contém a descrição do estado. Isso é feito pelos programas adiciona_lista/1 e remove_lista/1.

O programa resolve/ 3 está definido por:

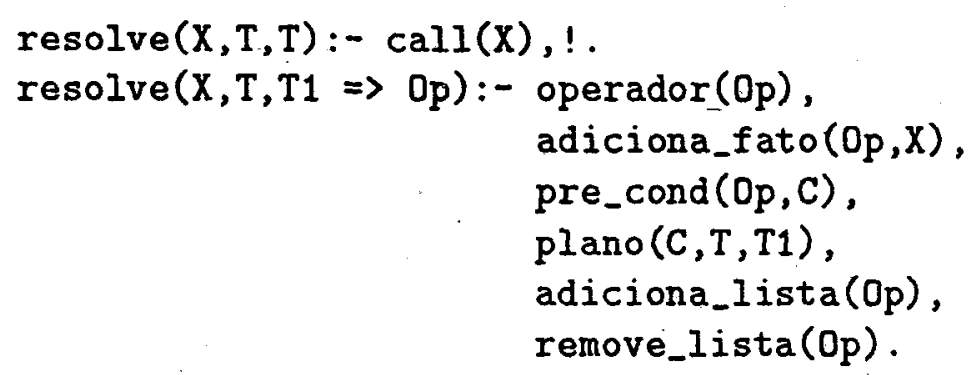

Onde:

- $\mathrm{X}$ instancia com a sub-meta;

- T instancia com o plano parcial até o momento;

- T1 instancia com o plano incluindo a sub-meta resolvida;

- Op instancia com o operador; 
- C instancia com a lista de pré-condições.

O programa resolvido/3 verifica se o plano proposto por plano/3 resolve a meta desejada. Se o plano não resolve, então ele inverte -através de inverte/2- a ordem de atendimento das sub-metas, e monta outro plano usando essa nova ordenação nas submetas.

resolvido (C, T, T):- call(C),!. resolvido(C,T1,T2):- inverte(C,CI), plano(CI, T1, T2).

Onde:

- C instancia com o grupo de fatos que descrevem o estado meta;

- T1 instancia com o plano parcial até o momento;

- T2 instancia com o plano final;

- CI instancia com a nova ordenação no grupo dos fatos que descrevem a meta.

\subsection{Planejamento Hierárquico}

Para se ter uma maior eficiência em planejamento, é necessário poder fazer um balanceamento entre um plano muito detalhado - que provoca desperdício de esforço- e planos tão vagos que não é possível especificar quais os operadores que deveriam ser utilizados. É nesse contexto que surge o planejamento hierárquico.

No planejamento hierárquico, inicialmente é esboçado um plano completo, porém ainda muito vago. A seguir, este plano é refinado em subplanos mais detalhados, até que o plano tenha sido refinado ao ponto de tornar-se uma sequência completa e detalhada de operadores que resolvem o problema. A grande vantagem nessa abordagem é que o plano só é detalhado até um ponto onde a execução ainda seja viável. $O$ uso desse tipo de abordagem proporciona uma redução no tamanho do espaço de busca [Kautz 88].

Dentro de planejamento hierárquico existe uma abordagem, exemplificada no sistema Abstrips [Sacerdoti 73], onde determina-se quais objetivos são críticos para o sucesso do plano, e ignora-se - pelo menos inicialmente - todos os outros objetivos. Sua vantagem está no fato de que, sabendo quais os sub-objetivos críticos, é possível reduzir o espaço de busca.

O planejamento hierárquico foi implementado inicialmente por Newell e Simon no sistema GPS [Newell 63]. A abordagem usada em GPS é levemente diferente de Abstrips. Em Abstrips, uma hierarquia de abstração de espaço é definida pela escolha de objetivos que 
sejam mais importantes que outros, enquanto que no GPS existe uma simples abstração do espaço definida pela escolha de uma representação do problema como mais geral que outra.

Um plano gerado por Abstrips é uma hierarquia de abstração do espaço, a qual contém tudo sobre os objetos e operadores dados na especificação inicial do problema, só que algumas pré-condições de alguns operadores são julgadas como mais importantes que outras.

Por exemplo, para pintar uma parede, ter as paredes limpas não é tão importante como ter uma loja que venda tintas. Para isso, são atribuídos níveis de criticabilidade ${ }^{\mathbf{1}}$, ou seja, especificar através de valores arbitrários qual condição é mais crítica que outra. Quando Abstrips inicia o planejamento, as pré-condições escolhidas são aquelas que tenham o maior valor de criticabilidade, ou seja, aquelas que sejam críticas para o sucesso do plano. Esse conjunto de pré-condições formarão o nível mais alto do espaço de abstração. A seguir, são escolhidas as pré-condições dos passos, nesse nivel mais alto, que tenham o próximo nivel de criticabilidade, e assim se repete o processo até que todas as pré-condições tenham sido atendidas.

O primeiro passo nesse processo é associar valores de criticabilidade às pré-condições. Para isso, uma pessoa esboça uma ordem parcial de pré-condições através do julgamento intuitivo de sua importância e, então, Abstrips segue um algorítmo para ajustar as criticabilidades.

Supõe-se que a pré-condição mais importante é a existência de um lugar, pois se ele não existir, os operadores que dependem dele não poderão ser utilizados no plano: A seguir, ter alguma coisa é a pré-condição mais importante entre as restantes, e estar em algum lugar é a menos importante, com os seguintes indices de criticabilidade:

\begin{tabular}{|l|c|}
\hline \multicolumn{1}{|c|}{ Pré-condição } & Criticabilidade \\
\hline existir lugar & 3 \\
ter alguma coisa & 2 \\
estar algum lugar & 1 \\
\hline
\end{tabular}

Abstrips ajusta estas criticabilidades da seguinte maneira: todas as pré-condições cujos valores não podem ser mudados por algum operador recebem um valor máximo de criticabilidade. Para cada uma das outras pré-condiçôes, se um pequeno plano pode ser encontrado para resolvê-la —assumindo as pré-condições como verdadeiras- então é assumido que ela será um detalhe, e é dado uma criticabilidade igual a que foi especificada na ordenação parcial, caso contrário, será dado uma criticabilidade tão grande quanto a maior criticabilidade existente na ordem parcial.

Para exemplificar como associar criticabilidades as pré-condições, é especificado a seguir o problema de pintar uma parede:

\footnotetext{
${ }^{1} \mathrm{Na}$ ausência de um termo adequado em português, foi adotado o termo criticabilidade para representar o termo em inglês criticability.
} 


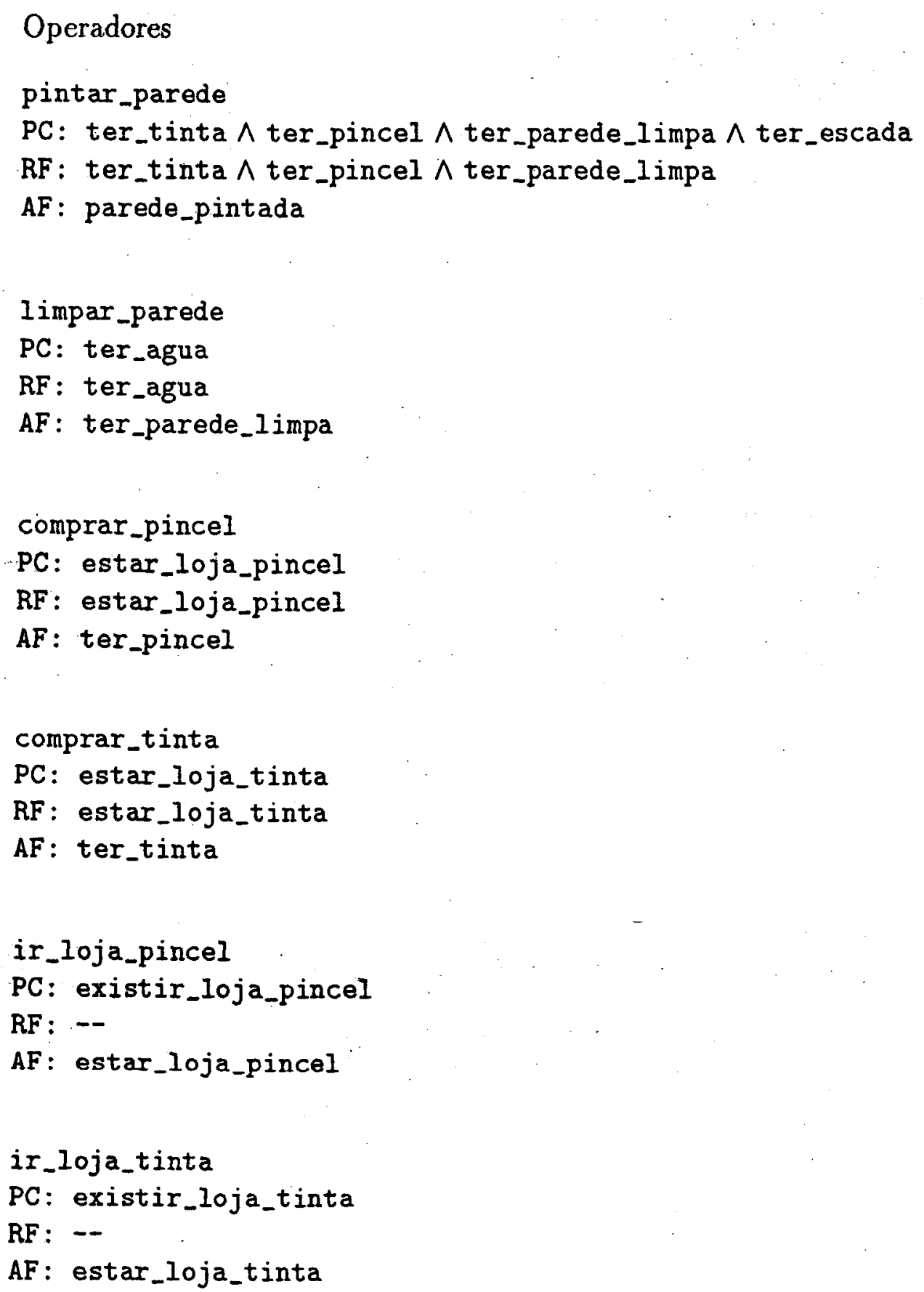

Observação: não existe loja que venda escada.

Seguindo a idéia descrita anteriormente, as pré-condições

$$
\text { existir_loja_tinta e existir_loja_pincel }
$$

recebem criticabilidade máxima, neste caso igual a 5 (cinco), pois elas não podem ser mudadas por qualquer operador. As pré-condições 
ter_agua, ter_pincel, ter_tinta e ter_parede_limpa

podem ser obtidas por um pequeno plano, dado que suas pré-condições sejam verdadeiras. Por exemplo, se existe uma loja de tintas, um pequeno plano pode ser feito para satisfazer ter_tinta. Com isso, é dado valor igual a 2 (dois) para suas criticabilidades.

Já a pré-condição ter_escada não pode ser satisfeita por um pequeno plano, pois não existe uma loja que venda escadas e, portanto, sua criticabilidade recebe valor igual a 4 (quatro), que é maior do que qualquer outro dentro da ordem parcial ter alguma coisa. Finalmente, estar_loja_tintas e estar_loja_pincel recebe o menor valor de criticabilidade, que nesse caso é igual a 1 (um).

\begin{tabular}{|l|c|}
\hline \multicolumn{1}{|c|}{ Pré-condição } & Criticabilidade \\
\hline existir_loja_tinta & 5 \\
existir_loja_pincel & 5 \\
ter_escada & 4 \\
ter_pincel & 2 \\
ter_tinta & 2 \\
ter_agua & 2 \\
estar_loja_tinta & 1 \\
estar_loja_pincel & 1 \\
\hline
\end{tabular}

Como Abstrips tenta resolver primeiro as pré-condições que possuem maior criticabilidade, então, ele consegue resolver os problemas com muito menos busca e "backtracking" - voltar atrás- que Strips. Por exemplo, se não houver um escada disponível na descrição do estado inicial, isso será detectado antes de dispender algum esforço no sentido de comprar tinta e pincel, ou mesmo limpar a parede, para só então descobrir que o plano é inviável por causa da falta de uma escada.

\subsection{Planejamento Baseado em Scripts}

Este tipo de planejamento faz uso de planos já criados e armazenados anteriormente, ao invés de gerá-los. O processo é-o seguinte: primeiramente um esqueleto de plano já existente é encontrado em função do tipo de problema que se deseja solucionar. A seguir, os passos de abstração são executados através da utilização de operadores específicos que estejam dentro do contexto do problema. Essa escolha de operadores requer grande conhecimento do domínio do problema e, se essa escolha for satisfatória para cada passo de abstração, o plano como um todo poderá ter sucesso.

$\mathrm{O}$ conceito de esqueletos de plano tem um precedente direto no trabalho de Schank e Abelson para compreensão de linguagem natural. Eles introduziram o conceito de scripts, que são representações declarativas de sequências ordenadas de eventos [Abelson 77]. 
Existem distinções entre as abordagens vistas anteriormente e a abordagem baseada em -scripts. As primeiras procuram construir uma abstração inicial do plano, enquanto que a abordagem baseada em scripts seleciona um plano inicial já existente. Outra diferença é que, enquanto as outras abordagens se concentram na interação dos passos do plano, em scripts os passos são considerados o suficientemente independentes a ponto de ser possivel resolvê-los por subplanos relativamente menores.

Em scripts, os esqueletos de plano são especificados em muitos níveis de generalidade. No nível mais geral existem somente alguns planos básicos, que são usados como reserva para o caso de não ser possível encontrar planos mais específicos e que sejam fáceis de refinar. O problema não é, especificamente, encontrar um plano que deve fornecer uma solução satisfatória, mas sim, encontrar um plano que necessite menos trabalho de refinamento. Quando acontece de se ter um problema que já foi resolvido anteriormente, a escolha de um plano se resume a uma procura simples. Já, para os casos em que o problema é inédito, a escolha fica em fazer a opção entre um plano detalhado para o problema relatado, ou um plano mais geral para uma classe de problemas.

Para ocorrer o refinamento de um esqueleto do plano, deve ser selecionado um nível apropriado de instanciação para cada passo em um plano abstrato.

Vale salientar que, embora a tarefa de planejamento se torne mais simples em scripts, os planos gerados não conterão inovações, pois a solução será baseada em planos já elaborados anteriormente.

\subsection{Planejamento Oportunístico}

A principal caracteristica desta abordagem é que ela permite o uso de uma estratégia mais flexível para a resolução do problema, se comparada com as vistas anteriormente.

Nesta abordagem, o conhecimento para a resolução do problema - elaboração do planose encontra dividido em módulos isolados, denominados especialistas. As decisões são tomadas em função do conhecimento específico de cada especialista.

Para resolver um problema, não existe uma ordem pré-estabelecida para a atuação dos diversos especialistas, bem como não é necessário a atuação de todos os especialistas. É esta liberdade, na tomada das decisões, que levou Barbara Hayes-Roth [Hayes-Roth 79] a empregar o termo oportunístico para denominar esta abordagem, pois, o planejador procura sempre tomar a decisão mais oportuna para um dado instante no processo de planejamento.

A flexibilidade do planejador oportunístico é caracterizada por ele poder resolver um problema específico como um planejador hierárquịco ou, conforme a conveniência, como um planejador baseado em script ou, ainda, fazer uso de uma estratégia totalmente diferente das que foram vistas nas três abordagens anteriores. 
Desta forma, durante o processo de resolução do problema, o planejador pode desenvolver o plano em uma forma top-down -usando refinamentos sucessivos como na abordagem hierárquica - até um certo nivel de detalhamento e, a partir daí, adotar uma estratégia de gerar sequências de ações que resolvam as sub-metas deste nível -como na abordagem não hierárquica.

Planejamento oportunístico encontra-se bem discutido em [Prado 91]

\subsection{Considerações Finais}

Neste capítulo foram vistas quatro abordagens de planejamento, que são: planejamento não hierárquico, planejamento hierárquico, planejamento baseado em scripts e planejamento oportunístico. Procurou-se dar uma visão geral e simplificada de cada abordagem mostrando as características básicas de cada uma delas.

Pode ser observado que, se por um lado é mais amena a tarefa de implementar planejadores não hierárquicos, por outro lado, não se consegue distinguir quais são os passos fundamentais e quais são apenas detalhes para a obtenção da solução desejada.

Já nos planejadores hierárquicos, é possivel determinar o nível de refinamento mais adequado ao plano, evitando, assim, que a execução fique enroscada em detalhes sem importância.

Nos planejadores baseados em scripts tem-se, em princípio, a vantagem da obtenção mais rápida da solução do problema, isso porque scripts faz uso de planos já elaborados, bastando apenas aplicar um certo nível de refinamento para se ter o plano desejado. Por outro lado, o uso de planos já elaborados anteriormente traz a desvantagem de que não existirão inovações na soluçâo de um problema que jả foi resolvido em aplicações anteriores.

Finalmente, nos planejadores oportunísticos tem-se a vantagem da maior flexibilidade que ele permite na escolha da estratégia de planejamento. Porém, se torna extremamente complexa a tarefa de implementar um controlador responsável por esta escolha. Outro aspecto é que o tempo gasto para examinar as possiveis intervencões de cada especialista pode inviabilizar a obtenção de um plano em tempo hábil. 


\section{Capítulo 5}

\section{Principais Aspectos e Sistemas de Planejamento}

\subsection{Considerações Iniciais}

As pesquisas em planejamento têm introduzido alguns problemas no campo de Inteligência Artificial. Exemplos destes problemas são: restrições físicas nas soluçôes mais convenientes, incerteza na execução de planos, percepção do mundo real, múltiplos agentes que podem cooperar ou interferir na elaboração do plano, restrições de tempo e interações entre objetivos.

Neste capítulo é apresentada uma rápida visão de como alguns planejadores procuram resolver alguns destes problemas. Para mostrar isso são observados os aspectos de busca, de objetivos conjuntivos, de representação de operadores, de mudanças no ambiente, de aprendizado, de condições e interações, bem como de incerteza no planejamento.

\subsection{Técnicas de Redução de Busca}

Como já visto, planejamento é, essencialmente, um problema de busca. O planejador deve percorrer um espaço de busca potencialmente grande e encontrar um plano que, sendo aplicado no estado inicial, leve a uma solução para o problema. A busca pode ser muito complexa nos casos onde o espaço de busca envolva muitas interações entre diferentes estados. É interessante fazer uso do algorítmo $A^{*}$ (ou variações) para realizar a busca [Rich 83].

O problema de organizar a'busca heuristica, a fim de encontrar caminhos nos quais se tenha uma maior quantidade de informação, está entre os aspectos mais discutidos em planejamento. Uma discussão mais aprofundada pode ser encontrada em [Korf 87]. 
Os primeiros esforços para reduzir o espaço de busca foram baseados em aplicar ações possiveis para alguns estados iniciais a fim de satisfazer um dado objetivo - meta. A função heurística, nesse caso, era determinar um custo para as ações necessárias até que se chegasse à meta. Contudo, essa abordagem não teve sucesso devido a dificuldade de se elaborar boas funções heurísticas e, também, devido ao usual crescimento exponencial do espaço de busca.

Assim, várias técnicas, descritas a seguir, foram desenvolvidas para resolver esses problemas.

\subsubsection{Análise dos Meios e Fins}

A técnica de análise dos meios e fins surgiu para reduzir o número de estados intermediários considerados. Nela, os operadores escolhidos são aqueles que levam a uma redução nas diferenças entre o estado inicial e o estado objetivo. Esta técnica foi usada como base para realizar a busca em muitos planejadores.

Com o sistema Noah [Sacerdoti 75], o problema de busca mudou. Neste sistema, e em seus descendentes, o espaço de busca consiste em um espaço de planos parciais, ou seja, para uma ação de escopo maior, o planejador procura reduzir essa ação em ações menores. Portanto, nesse caso, o planejamento consiste na escolha de reduções apropriadas dentro do conjunto de ações possiveis para eliminar interações danosas.

Uma técnica importante que surgiu nesse contexto foj a técnica do menor comprometimento.

\subsubsection{Menor Comprometimento}

$\mathrm{Na}$ técnica do menor comprometimento são verificadas quais as ações necessárias, bem como a ordem em que elas devem ser executadas, para que se tenha um comprometimento mínimo.

Para exemplificar, usando o Mundo dos Blocos, suponha que é dado um estado inicial onde os três blocos estão sobre a mesa. É desejado como meta que se tenha o bloco b sobre o bloco a, e o bloco a sobre o bloco c. As ações necessárias para a solução-do problema são empilha $(b, a)$ e empilha $(a, c)$.

Usando a técnica do menor comprometimento, é possível observar que se for realizada primeiro a ação empilha $(b, a)$, isso irá comprometer a condição livre(a) necessária para solucionar o objetivo sobre $(a, c)$, como mostrado na Figura 5.1a. Portanto a ordem correta encóntrada é resolver em primeiro lugar o objetivo sobre $(a, c)$, para só depois resolver sobre $(b, a)$. Consequentemente, $a$ ordenação ideal das ações é empilha $(a, c) e$ empilha $(b, a)$, como mostrado na Figura 5.1b. 
Uma ampliação da técnica do menor compromentimento é a técnica denominada fixação de restriçôes.

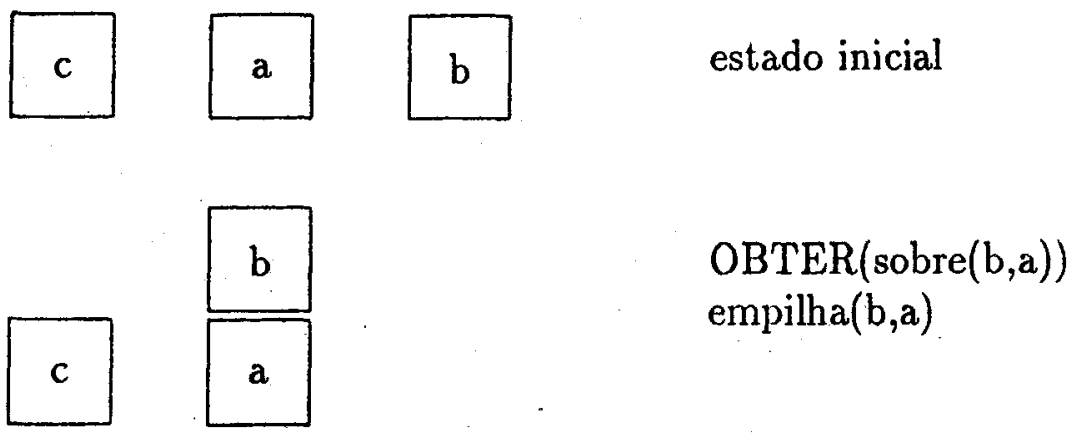

FALHA em OBTER(sobre $(a, c))$

Figura 5.1a: Falha devido a Ordem Inadequada de Solução dos Objetivos

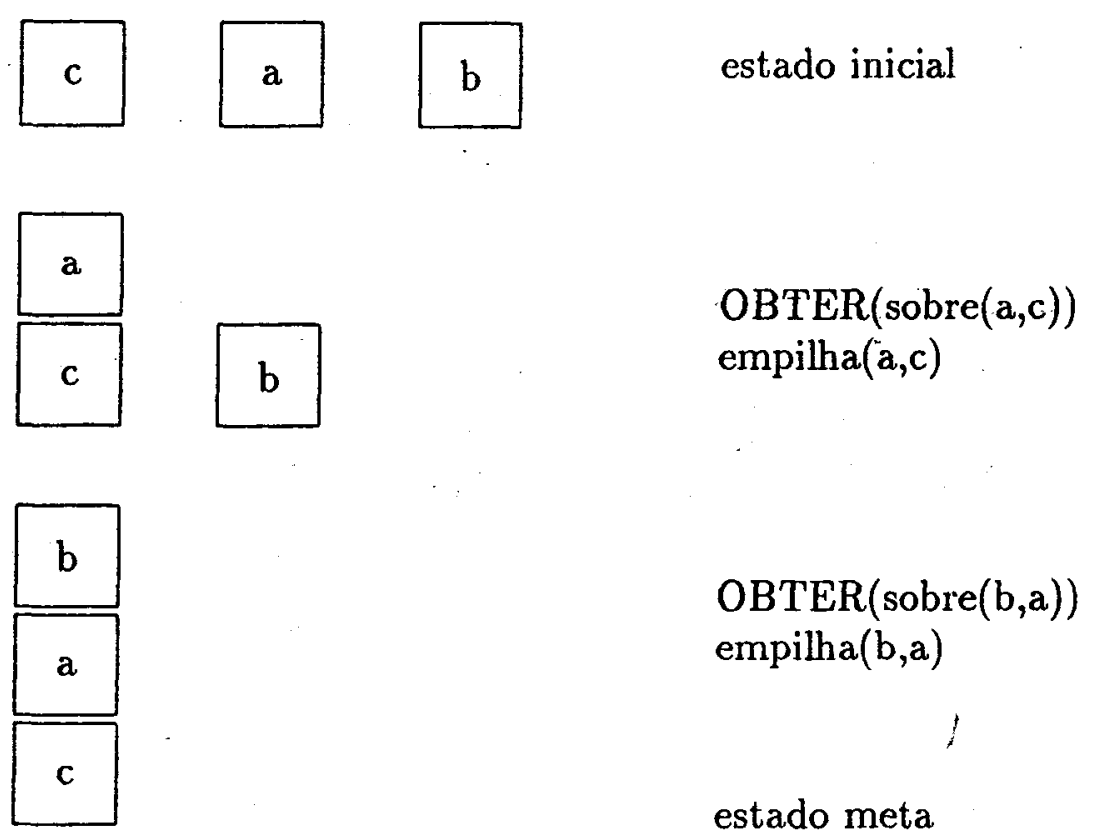

Figura 5.1b: Reordenação para os Objetivos devido ao Menor Comprometimento

\subsubsection{Fixação de Restrições}

$\mathrm{Na}$ técnica de fixação de restrições, as decisões são reduzidas devido ao fato de ser possível fixar restrições a respeito do problema que se quer resolver. As restrições são fixadas com 
- objetivo de eliminar interações danosas, uma vez que, através do uso das restrições, é possível obter independência nạ solução dos objetivos.

Para tornar isso mais claro, é usado o exemplo onde se deseja escolher uma pessoa para ser o Ministro da Economia e outra pessoa para ser o presidente do Banco Central. Por existirem vários fatores a serem considerados na escolha, é desejável evitar a elaboração de uma lista contendo todos os pares possíveis de pessoas. Para tanto, o problema é separado em dois objetivos independentes. Porém, na verdade, existe uma interação que é a necessidade de que as pessoas se relacionem bem. Usando a técnica de fixação de restrição, essa interação é facilmente manipulada. Os objetivos são

$$
\text { ministro_economia(X) e pres_banco(Y). }
$$

São criadas as restrições

$$
\text { bom_relacionamento }(X, Y) \text { e diferentes }(X, Y) \text {. }
$$

Com essas restrições, é agora possível fazer o planejamento de forma independente para os objetivos. O sistema Molgen [Stefik 81] é um exemplo de planejador que opera dessa maneira.

Existem, ainda, alguns sistemas em que as seleções dos operadores são feitas baseadas em informações disponíveis apenas localmente. Nestes casos, o comprometimento é verificado apenas para um caminho particular de solução, fato que tornará o sistema incapaz de resolver alguns problemas. Esta última técnica tem sido bem sucedida em casos onde domínios heurísticos mais robustos podem ser utilizados. Quando tais heurísticas não são possíveis, uma solução mais geral é usar "backtracking" para a recuperação de um outro caminho, no caso de se ter objetivos que não podem ser obtidos baseados nas últimas escolhas.

\subsubsection{Backtracking}

Para realizar "backtracking", o sistema de planejamento deve simplesmente guardar os estados onde ocorreram pontos de escolha - mais de um caminho possível-, podendo assim retornar em caso de falha:- Implementações baseadas em pilha podem ser usadas para esse processo - como é feito em Prolog.

O sistema Nonlin [Tate 77],[Tate 84a] introduz uma variante do "depht-first backtracking" para ser usado em planejamento. Como normalmente existe disponível uma boa. informação local, indicando o caminho preferido de solução, é comum tentar primeiro fazer a melhor escolha - baseada na informação heurística local - antes de se considerar as muitas alternativas que provavelmente poderiam levar a uma escolha ruim. É o que o sistema Nonlin faz, ou seja, ele seleciona a alternativa mais promissora - que foi classificada pelo avaliador heurístico- para continuar o processo. 
A técnica de armazenar os estados onde ocorrem pontos de escolha, utilizada em Nonlin, pode causar um desperdício de esforço de busca para o caso de se estar trabalhando com um problema que tenha uma solução com partes independentes. Se o "backtracking", em uma determinada parte da solução, provocar o retorno além de pontos que fazem parte do trabalho que foi feito em uma outra parte da solução, então, todo o esforço gasto nessa parte será perdido.

Considere-se, por exemplo, que é desejado reformar um banheiro, sendo necessário trocar os azulejos, piso e peças sanitárias. Após comprados os três itens, é feito o assentamento do azulejo e do piso, porém, após ter assentado as peças sanitárias é observado que elas estão com defeito, sendo necessário trocá-las. Neste tipo de problema, as partes relativas ao piso e azulejo são independentes e, portanto, só devem ser refeitos os serviços relativos as peças sanitárias, deixando intacto o restante. Caso contrário, estará ocorrendo um esforço desnecessário ao se refazer também o assentamento do piso e azulejo.

Muitos sistemas resolveram esse problema pelo uso de uma variação do método de "backtracking" utilizado no sistema Nonlin. Nesses sistemas, não são guardados os estados onde ocorreram pontos de escolha, ao invés disso, são registradas as dependências entre as decisões, as suposiçôes nas quais elas estão baseadas e as alternativas das quais uma seleção pode ser feita. Assim, para se recuperar após uma falha, basta desfazer todas as partes dependentes da solução, deixando as partes independentes intactas. Alguns trabalhos que utilizam esta técnica são encontrados em [Hayes 75], [Stallman 77] e [Daniel 83].

Existe, também, uma técnica denominada metaplanejamento, a qual necessita que o operador raciocine não somente sobre o objetivo, mas também sobre as várias técnicas possíveis para a geração do plano. Essa técnica é aplicada nos sistemas OPM [Hayes-Roth 79] e PRS [Georgeff 87].

\subsubsection{Outras Técnicas}

Além dos métodos básicos de redução de busca pela seleção de operadores relevantes, muitos outros métodos têm sido usados em planejadores.

Um exemplo pode ser visto nos sistemas Abstrips [Sacerdoti 73] e Lawaly [Siklossy 75], onde são criados níveis de criticabilidade para os operadores de acordo com sua prioridade de execução.

Outro exemplo é Warplan [Warren 74], onde estados ou planos são rejeitados por serem impossiveis, ou por violarem alguma regra. O sistema Warplan foi refinado para incluir o uso de domínios restritos [Allen 83] e coerência temporal [Drummond 88], fornecendo heurísticas para a rejeição de determinadas ações. Uma variante desta abordagem, usando um modelo de dominio para simular os resultados, foi usado no sistema gerador de teste e depurador feito por Simmons e Davis [Simmóns 87].

Outros sistemas, tais como Deviser [Vere 83], Sipe [Wilkins 83], Nonlin+ [Tate 84b] e 
O-Plan [Currie 85], verificam os níveis de recursos usados e tempo restrito em ações, isso para eliminar algumas possibilidades no espaço de busca.

Uma abordagem mais recente tem envolvido o uso de paralelismo para examinar, de modo simultâneo, as escolhas potenciais para as ações a serem executadas.

\subsection{Tratamento de Objetivos Conjuntivos}

A ordem em que os objetivos conjuntivos são resolvidos pode estar diretamente relacionada com a eficiência do processo de planejamento. Quando os objetivos são atendidos em uma ordem inadequada, é muito provável que seja obtida uma solução redundante, ou seja, contendo passos que poderiam ser retirados sem afetar a correção do plano, ou, ainda, gerar um plano que fique em "loop" tentando resolver sempre os mesmos objetivos. A procura por uma ordem ótima de execução de objetivos conjuntivos é uma área de pesquisa em planejamento que tem recebido muita atenção.

Duas abordagens estão sendo usadas para solucionar parcialmente este problema: uma é ordenar os vários objetivos por níveis de importancia, a outra é analisar e evitar as possíveis interações entre objetjvos conjuntivos.

\subsubsection{Ordenação de Objetivos por Níveis de Importância}

A abordagem de ordenação de objetivos por níveis de importância foi usado em Abstrips e Lawaly. Estes sistemas trabalham, em primeiro lugar, com os objetivos a um nivel mais geral para só depois trabalhar com os objetivos a um nível mais detalhado. Assim, uma solução é encontrada no nível mais geral, e os niveis mais detalhados são obtidos em função do refinamento do nivel imediatamente superior. Vale salientar que nestes sistemas não é possível fazer o "backtracking" para os niveis superiores, ou seja, não é possivel levar em conta os niveis superiores em caso de falha.

Outros sistemas hierárquicos, além de usar níveis de abstração como um guia para a ordenação dos objetivos, são também capazes de mostrar quando uma escolha é satisfatória, determinando assim qual o objetivo ideal a ser atacado naquele momento - como faz Molgen.

Estudos mais recentes tentam construir modelos que possam planejar de modo concorrente pelos diferentes niveis de hierarquia.

\subsubsection{Interação entre Diferentes Objetivos}

Um outro aspecto, na manipulação de objetivos conjuntivos, é tratar as interações que surgem entre os diferentes objetivos. Para exemplicar esse tipo de problema, potte ser 
usado o exemplo de pintar o teto de uma casa e pintar uma escada. Neste problema, se for pintada primeiro a escada, não será possível pintar o teto, pois a escada estará com tinta fresca. Portanto, a solução para um objetivo acaba prejudicando a solução de um outro objetivo.

Os planejadores podem ser categorizados de acordo com o modo com que eles administram as interaçôes entre os objetivos e pelo modo com que eles estruturam os objetivos. Em termos de interações entre objetivos, os primeiros planejadores - por exemplo Strips [Fikes 71] - resolvem sequencialmente os objetivos conjuntivos, e depois fazem uma simples verificação para ver se a conjunção de objetivos ainda é válida. Por outro lado, existem planejadores que fazem uso da chamada suposição linear, que nada mais é do que supor uma solução para um objetivo - fora da conjunção- e então juntá-la com a solução de outros objetivos. Esta suposição mostra-se útil nos casos em que as soluções para os diferentes objetivos, que compõem a meta, podem ser desassociadas.

Muitos planejadores não fazem a suposição linear, ao invés disso, misturam de maneira aleatória os objetivos e sub-objetivos do plano. Esses planejadores são chamados de planejadores não lineares, isso porque não utilizam a suposição linear para garantir a correção da solução. Quando a suposição linear falha, uma interferência mútua entre os objetivos e sub-objetivos pode resultar em ações redundantes, sendo que, no pior dos casos, o planejador pode entrar em um ciclo onde ele sempre tenta satisfazer o mesmo objetivo.

\subsubsection{Reordenação e Regressão de Objetivos}

Alguns sistemas tentam resolver os problemas surgidos em função de objetivos conjuntivos de duas formas. A primeira é permitir que uma ação tenha seu lugar no plano trocado, até que seja constatado que não ocorrem mais interações entre os objetivos — como faz o sistema Warplan. A segunda-forma é fazer a regressão de objetivos quando ocorre uma falha devido as interações [Waldinger 75]. Para melhor compreender o que significa regressão de objetivos, é tomado o seguinte exemplo dentro do Mundo dos Blocos:

A Figura 5.2 apresenta os estados inicial e meta:
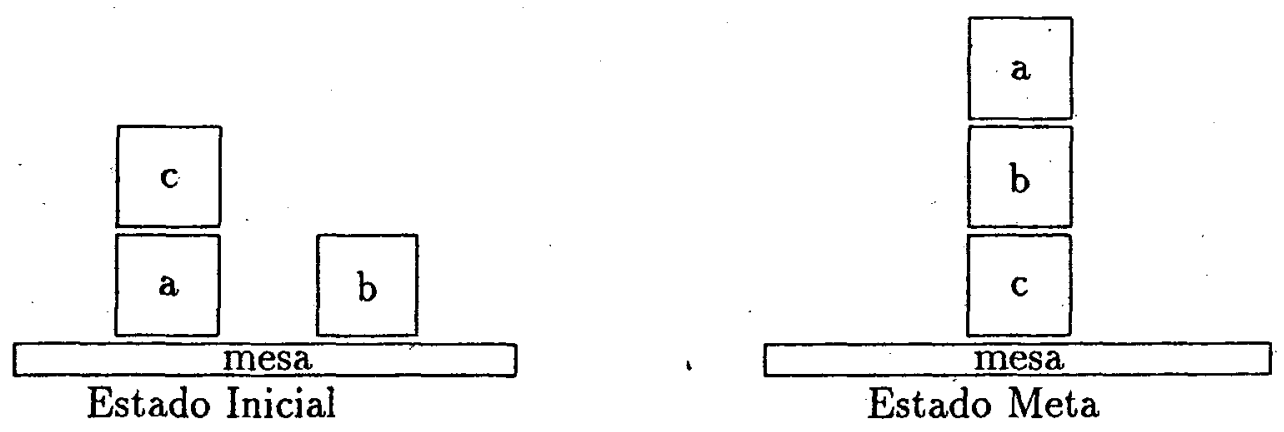

Figura 5.2: Representação de Estados - 6 
Para obter a meta sobre $(a, b)$ e sobre $(b, c)$, primeiro o sistema procura resolver o objetivo sobre $(a, b)$. Para isso, ele remove o bloco $c$ do topo do bloco a, para depois empilhar o bloco a sobre o bloco b. Portanto, o plano parcial consiste de duas açôes,

$$
\text { desempilha(c,a) e empilha }(a, b) \text {. }
$$

Contudo, ao tentar resolver o objetivo sobre (b,c), o sistema "percebe" que não é possível obter a pré-condição livre(b), isso devido a ação empilha (a,b) realizada por último. Nesse momento, ao invés de reordenar os objetivos que compõem a meta, o sistema encontra um lugar no plano parcial onde o objetivo sobre $(b, c)$ não sofre a interferência do outro objetivo. Neste caso, o objetivo $\operatorname{sobre}(b, c)$ é movido para antes da ação empilha (a,b). Para ilustrar, observe a Figura 5.3, que mostra como ocorre a interferência entre os objetivos, e a Figura 5.4, que mostra como a regressão de objetivos contorna o problema.

Objetivos ou Ações
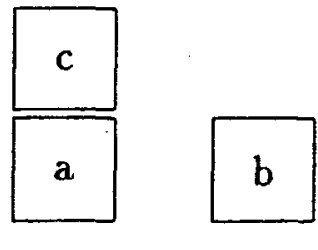

estado inicial
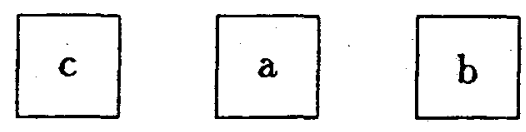

OBTER(sobre $(a, b))$
desempilha(c,a)

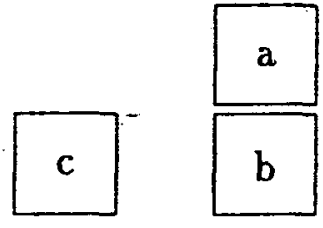

empilha(a,b)

FALHA em OBTER(sobre(b,c))

Figura 5.3: Representação de Falha devido a Objetivos Conjuntivos

A regressão de objetivos leva a vantagem de que ações redundantes não são reintroduzidas se o objetivo for alcançado anteriormente no plano.

O sistema Interplan [Tate 75] procura registrar a ligação entre um efeito de uma ação que é uma pré-condição de uma outra ação posterior. Isso, porque algumas ações causam efeitos que são usados' muito mais tarde no plano [Sussman 73]. As interações são detectadas como uma interferência, entre alguns novos objetivos, que é introduzida por um ou mais objetivos prévios. Um conjunto mínimo de reordenação dos objetivos pode ser proposto para solucionar as interações surgidas. 
Objetivos ou Ações

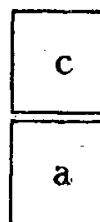

c

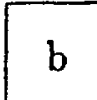

estado inicial
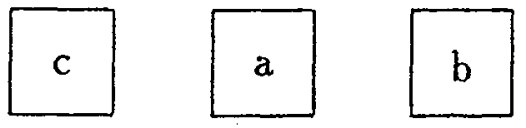

OBTER(sobre(a,b))

desempilha(c,a)
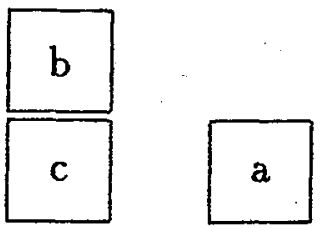

$$
\begin{aligned}
& \text { OBTER(sobre(b,c)) } \\
& \text { empilha(b,c)) }
\end{aligned}
$$

empilha(a,b)

estado meta

Figura 5.4: Representação do Conceito de Regressão de Objetivos

Noah introduz o conceito de críticas para examinar o plano e detectar as interações entre os subplanos. Cada crítica é um pequeno programa que faz observações especificas a respeito de um plano proposto. É possível, por exemplo, ter uma crítica Resolver Conflitos, para resolver todos os conflitos devidos à interações entre os objetivos. Outra crítica poderia ser Elimina Redundância, para retirar todas as redundâncias que porventura possam ocorrer em um plano.

Nonlin é um planejador de ordenação parcial baseado no sistema Noah, mas difere no fato de que ele possibilita voltar atrás além de pontos em que as ordenações foram feitas.

Um refinamento posterior na análise das interações de objetivos foi feito para o sistema Deviser. Nele, é possível limitar o número de soluções, através do uso de restrição no tempo. usado para satisfazer um objetivo, ou, mesmo, para executar uma ação. Por exemplo, determinar o tempo que deve ser gasto para que um robô possa escolher, ou mesmo realizar, uma ação que possibilite colocar um bloco sobre outro. O sistema Deviser possibilitou planejar na presença de eventos externos. 


\subsection{Representação de Operadores}

Os primeiros sistemas de planejamento simplesmente selecionavam os operadores, que seriam aplicados na resolução de um problema, pela avaliação das diferenças existentes entre o estado inicial e o estado meta desejado. É o caso do sistema GPS.

Como já visto, Strips usa a noção de diferenças entre estados, para assumir que o modelo inicial do mundo somente pode ser mudado através de fatos que são adicionados e fatos que são excluídos da descrição do estado - existem ainda fatos que permanecem sem mudanças. Para tanto, Strips define um operador através de uma lista de fatos a serem adicionados, de uma lista de fatos a serem excluídos e de uma lista de pré-condições que devem ser satisfeitas antes da aplicação do operador. Os operadores são escolhidos em função da instanciação entre sua lista de fatos adicionados e a lista de fatos que compõem o objetivo.

Em sistemas mais recentes, novas informações, tais como restrição de tempo, estão sendo adicionadas ao operador.

O sistema Nonlin adiciona a capacidade de representar múltiplos recursos para fazer a seleção das atividades apropriadas com base nesses recursos. A definição de objetos compartilhados como recursos e a declaração do uso de tais recursos em operadores é também fornecida no sistema Sipe.

O sistema Airplan [Masui 83] contém informações no operador que o habilita a raciocinar sobre intervalos de tempo e, também, sobre como podem interagir, durante este intervalo de tempo, as ações concorrentes.

O sistema O-Plan [Bell 85] representa as restriçôes de tempo -e recurso usado- através de pares numéricos (min,max) que delimitam o tempo de duração das atividades, $o$ instante do início da atividade, $o$ instante do término da atividade e o intervalo de tempo entre uma e outra atividade. A razão de existir sempre um valor mínimo e um máximo é devido ao plano ter um certo nível de incerteza na modelagem do domínio.

Os domínios considerados em planejamento foram se tornando muito dinâmicos. Portanto, tornou-se necessário que novas informações fossem incorporadas aos operadores para permitir atender outros aspectos, tais como: monitoramento em tempo de execução [Firby 89], necessidade de escalador em tempo real [Hendler 89], diferentes listas de fatos adicionados e excluídos para o sucesso ou fallha de execução, bem como mostrar a probabilidade de sucesso de um operador [Miller 85].

\subsection{Tratamento de Mudanças no Ambiente}

Muitos sistemas assumem que o planejador possui um conhecimento completo do estado corrente do mundo, bem como dos relacionamentos que governam as mudanças neste 
mundo. Porém, há casos em que esse conhecimento completo não pode ser garantido. Um exemplo disto é quando agentes, que estão fora do controle do planejador, provocam mudanças no ambiente, ou ainda, casos onde somente é possível saber o que irá ocorrer, no momento da execução do plano.

O sistema Strips, por exemplo, foi projetado para planejar o movimento de um robô - chamado Shakey - na tarefa de empurrar uma caixa através de diversas salas interligadas. Para o caso de algum agente externo alterar a descrição do estado - por exemplo mudando a posição da caixa - foi criado um monitor de execução - chamado Planexque utiliza informações mantidas pelo Strips para fazer a adaptação perante a nova descrição do estado [Hart 81].

Essa característica de adaptação com novas descrições provocadas pelo surgimento de uma falha - que normalmente ocorre quando é detectada uma incompatibilidade entre a descrição esperada e a existente para o estado- é conhecida como replanejamento.

Uma alternativa para replanejamento é planejar as falhas potencialmente esperadas. Esta técnica pode envolver planejamento para as possibilidades esperadas, tais como, esperar que a luz se torne verde para poder atravessar uma rua. É possível, ainda, realizar testes em tempo de execução. Um exemplo deste último caso seria um robô verificar se está equidistante de duas paredes ao atravessar um corredor, sendo que, se não estiver equidistante, ele deve replanejar para atingir essa condição, para só depois continuar a travessia [Kaelbling 87].

Uma outra maneira de tratar as mudanças no ambiente é fornecer uma classe diferente de integrāção entre a geração e execução de planos. O sistema NASL [McDermott 78], por exemplo, intercala a geração e execução de planos, ou seja, ele escolhe um passo de solução e o executa em seguida. Isto torna o planejador mais susceptivel a erros causados por interaçôes. Portanto, o sistema NASL trabalha bem em ambientes onde ocorrem poucas mudanças e que não exigem uma resposta rápida. Este sistema foi incrementado posteriormente para que regras fossem usadas para informar a um_sistema de execução que, se necessário, ele poderia agir sem um plano. Nesse caso, o plano serviria apenas para aumentar a capacidade de obtenção de objetivos [Drummond 89].

Vários trabalhos recentes tem usado mecanismos que podem manipular rapidamente as mudanças no ambiente. Firby [Firby 89] propôs o pacote de ação reativa -para manipular as mudanças no ambiente-- que, basicamente, troca os operadores por procedimentos que incluam um componente de reação à mudança. A mbros-Ingerson e Steel [Ambros 83] propõem uma abordagem para a integração entre planejamento e execução, usando uma estrutura de controle de agenda, na qual ações que foram iniciadas podem rodar concorrentemente com ações de aquisição de informação, incluídas pelo monitoramento do ambiente.

Uma parte importante de planejamento em dominios dinâmicos é conseguir uma precisão na decisão do tempo de resposta dos eventos. Nos últimos anos, pesquisadores tentam melhorar a sensibilidade dos sistemas de planejamento nesses domínios [Dean 88], [Horvitz 88], [Russel 89]. Para obter uma maior precisão, é necessário um trabalho en- 
volvendo um exame apurado sobre estas decisões durante a geração e execução do plano [Dean 89], [Heckerman 89].

\subsection{Aprendizado}

A maior parte dos trabalhos em planejamento tem sido na geração de planos que não utilizam conhecimento prévio - não "aprendendo" de experiências anteriores. Recentemente, projetos de sistemas de planejamento que utilizam aprendizado tem se tornado uma opção, devido aos avanços conseguidos na área de aprendizado de máquina [Castainẽira 90].

O pioneiro em fazer uso de aprendizado em planos foi o trabalho para macro operadores, denominado Macrops [Fikes 72]. Ele estendeu o sistema Strips para incluir um aprendizado limitado referente as falhas. A idéia usada é a seguinte: no caso de uma parte do plano ser resolvida, então todos os operadores usados nessa solução são transformados em um único operador, cujas pré-condições e efeitos são idênticos aos da sequência de operadores originais. Os operadores são generalizados usando variáveis no lugar das constantes encontradas na solução específica da qual o macro operador tinha sido derivado.

Uma outra técnica que tem recebido atenção é a de raciocínio baseado em casos. Nos sistemas que utilizam esta técnica, um plano "velho" é escolhido e modificado para rodar em novas situaçóes. Muitos destes sistemas concentram-se em guiar a busca para um plano "velho", e usar um mapeamento relativamente simples para produzir um novo plano.

Exemplos de sistemas deste tipo são Julia [Kolodner 87] e Chef [Hammond 86]. O sistema Plexus [Altermann 88] utiliza informações sobre um novo contexto para guiar a reutilização de um plano existente. O sistema Priar [Kambhamp 89] permite ao planejador anotar planos sendo criados com informações sobre as estruturas de dependência entre operadores e, a seguir, esta informação é usada para guiar a reutilização, recuperação e replanejamento.

\subsection{Condições e Interações}

Muitas técnicas de controle do espaço de busca, ordenação de objetivos e mecanismos de correção para interações desenvolvidos em planejadores, têm sido orientadas para a geração de planos que sejam uma sequencia parcialmente, ou completamente ordenada, de ações primitivas. Contudo, existem alguns esforços na geração de planos que contenham condições -if...then...else...- e interações - repeat...until... .

Condições são manipuladas em Warplan-C [Warren 76] pela ramificação do plano, onde um ramo representa o caso da condição ser ver'dadeira, e o outro ramo representa o caso da condição ser falsa. 


\subsection{Incerteza}

A incerteza é uma fonte de problemas durante a geração de um plano. Se um planejador não pode modelar o mundo real com informações completas, então, ele deve trabalhar com eventos que tenham pequena probabilidade de ocorrer durante a execução. Este problema surge em sistemas que usam sensores reais para a percepção do mundo.

Trabalhos usando estimativas de probabilidade, inseridas durante a geração de planos, são encontrados em [Dean 89]. Os aspectos de falhas nos planos, causadas pela incerteza, também são vistos no trabalho de Segre [Segre 88].

O problema de incerteza também pode ser tratado fazendo uso de lógica nebulosa [Zadeh 65].

\subsection{Alguns Sistemas de Planejamento Existentes}

Ao longo deste capítulo foram citados vários sistemas, sendo que, cada um deles apresentava alguma contribuição para se ter uma maior eficiência em planejamento.

Como os sistemas estão distribuídos segundo as técnicas que eles incorporam, fica difícil ter uma visão geral de quais são esses sistemas. Para tornar isso mais claro, foi montada a tabela que se segue, apresentando os principais sistemas de planejamento, bem como o domínio de aplicação para o qual eles foram desenvolvidos. A principal técnica, em que cada sistema se baseia, também é especificada, facilitando a identificação do mecanismo de execução de cada um.

\begin{tabular}{|l|l|l|l||}
\hline \multicolumn{1}{|c|}{ Sistema } & \multicolumn{1}{|c|}{ Autor } & \multicolumn{1}{c|}{ Dominio } & \multicolumn{1}{c|}{ Aspectos } \\
\hline \hline Strips & Fikes (71) & Contrôle de robôs & $\begin{array}{l}\text { Listas } \\
\text { de pré-condições, fatos } \\
\text { adicionados, fatos re- } \\
\text { movidos }\end{array}$ \\
\hline Abstrips & Sacerdoti (73) & Contrôle de robôs & $\begin{array}{l}\text { Niveis de criticabili- } \\
\text { dade }\end{array}$ \\
\hline Hacker & Sussman (73) & Geração de programas & $\begin{array}{l}\text { Reordenação de obje- } \\
\text { tivos }\end{array}$ \\
\hline Noah & Sacerdoti(75,77) & $\begin{array}{l}\text { Supervisor } \\
\text { para aprendiz em En- } \\
\text { genharia Mecânica }\end{array}$ & $\begin{array}{l}\text { Ordenação parcial, } \\
\text { conceito de críticas }\end{array}$ \\
\hline Nonlin & Tate (77,84) & $\begin{array}{l}\text { Vistoria de turbinas } \\
\text { elétricas }\end{array}$ & $\begin{array}{l}\text { Objetivos são estrutu- } \\
\text { rados baseando-se nas } \\
\text { alternativas mais } \\
\text { promissoras }\end{array}$ \\
\hline \hline
\end{tabular}




\begin{tabular}{|c|c|c|c|}
\hline Sistema & Autor & Domínio & Aspectos \\
\hline Molgen & Stefik (81) & $\begin{array}{l}\text { Experimentos em } \\
\text { genética molecular }\end{array}$ & $\begin{array}{ll}\text { Restrições } & \mathrm{e} \\
\text { metaplanejamento }\end{array}$ \\
\hline NASL & McDermott (78) & $\begin{array}{l}\text { Projeto de circuitos } \\
\text { eletrônicos }\end{array}$ & $\begin{array}{l}\text { Integração } \quad \text { entre } \\
\text { geração e execução de } \\
\text { planos }\end{array}$ \\
\hline $\mathrm{OPM}$ & Hayes-Roth (79) & $\begin{array}{l}\text { Planejamento de Via- } \\
\text { gens }\end{array}$ & Busca oportunística \\
\hline ISIS-II & Fox $(81)$ & $\begin{array}{l}\text { Escalador do trabalho } \\
\text { de oficina (produção } \\
\text { de turbinas) }\end{array}$ & $\begin{array}{l}\text { Restrições do ambi- } \\
\text { ente }\end{array}$ \\
\hline Sipe & Wilkins (83) & $\begin{array}{l}\text { Planejamento para } \\
\text { carregar aeronaves }\end{array}$ & $\begin{array}{l}\text { Recursos usados } \mathrm{e} \\
\text { tempo das ações }\end{array}$ \\
\hline Nonlint & Tate (84) & Logística Naval & $\begin{array}{l}\text { Grafo de decisão, para } \\
\text { fazer a melhor escolha }\end{array}$ \\
\hline Deviser & Vere(83) & $\begin{array}{l}\text { Sequenciamento da } \\
\text { missão } \quad \text { espacial } \\
\text { Voyager }\end{array}$ & $\begin{array}{l}\text { Tempo e eventos ex- } \\
\text { ternos }\end{array}$ \\
\hline Forbin & Miller (85) & $\begin{array}{ll}\text { Controle } & \mathrm{de} \\
\text { manufatura } & \end{array}$ & $\begin{array}{l}\text { Probabilidade de } \\
\text { sucesso }\end{array}$ \\
\hline GPS & Newell (63) & $\begin{array}{l}\text { Resolvedor Geral de } \\
\text { Problemas }\end{array}$ & Análise de meios e fins \\
\hline Interplan & Tate (75) & $t$ & $\begin{array}{l}\text { Efeitos de } \\
\text { açôes prévias em ações } \\
\text { posteriores }\end{array}$ \\
\hline Warplan & Warren (74) & Geral & $\begin{array}{l}\text { Rejeição de planos que } \\
\text { violem alguma regra }\end{array}$ \\
\hline Airplan & McDermott (78) & $\begin{array}{l}\text { Treinamento de pilo- } \\
\text { tos militares }\end{array}$ & $\begin{array}{l}\begin{array}{l}\text { Ação } \\
\text { crítico }\end{array} \\
\end{array}$ \\
\hline PRS & Georgeff (87) & $t$ & $\begin{array}{l}\text { Tempo de reação do } \\
\text { sistema }\end{array}$ \\
\hline Lawaly & Siklossy (75) & $t$ & Criticabilidade \\
\hline O-Plan & Currie (85) & $t$ & $\begin{array}{ll}\text { Recursos usados } & \mathrm{e} \\
\text { tempo de ações }\end{array}$ \\
\hline Priar & $\begin{array}{l}\text { Kambhampati } \\
(89)\end{array}$ & $t$ & $\begin{array}{ll}\text { Reusabilidade } & \text { de } \\
\text { planos prontos }\end{array}$ \\
\hline Chef & Hammond (86) & $t$ & $\begin{array}{l}\text { Adaptação de planos } \\
\text { "velhos" }\end{array}$ \\
\hline Julia & Kolodner (87) & $t$ & $\begin{array}{l}\text { Adaptação de planos } \\
\text { "velhos" }\end{array}$ \\
\hline
\end{tabular}

†Informação não disponível 


\subsection{Considerações Finais}

Neste capítulo, foram mencionados vários do principais planejadores existentes, bem como as suas propostas para a solução de alguns dos problemas encontrados na área de planejamento. Em cada ítem foi enfocado um aspecto importante dentro de planejamento e buscou-se, dentro do possivel, mostrar as linhas de pesquisa tomadas por alguns pesquisadores, mostrando também algumas das soluçôes propostas. 


\section{Capítulo 6}

\section{Algumas Implementações de Técnicas Básicas de Planejamento}

\subsection{Considerações Iniciais}

Neste capítulo, serão vistas com maior detalhes algumas das técnicas básicas mais importantes dentro de planejamento.

Como já mencionado anteriormente, um problema que ocorre com grande frequência sâo os objetivos conjuntivos —onde a solução de um objetivo prejudica a solução de outro objetivo. Para contornar esse problema, serão discutidas diferentes técnicas para o tratamento de objetivos conjuntivos. São elas: reordenação de objetivos e regressão de objetivos. Será apresentada uma implementação em Prolog para cada uma dessas técnicas, utilizando a técnica da análise dos meios e fins para guiar a busca.

\subsection{Domínio de Aplicação}

O domínio de aplicação escolhido, para ilustrar as diferentes técnicas, é o Mundo dos Blocos definido anteriormente. Entretanto, serão feitas mudanças tanto na forma de representar os fatos que descrevem o estâdo, quanto na descrição dos operadores. Essas mudanças têm o intuito de simplificar a manipulação das informações. Com isso, a ação que pode ser realizada é representada da seguinte forma:

move $(X, Y, Z)$ : ação de pegar o bloco $X$ que está sobre o bloco $Y$-ou sobre a mesa-- e colocá-lo sobre o bloco $\mathrm{Z}-$ ou sobre a mesa. Para tanto, $\mathrm{X} \neq \mathrm{Y} \neq \mathrm{Z}$.

Para caracterizar o estado corrente, num dado momento, serão utilizados os seguintes predicados: 
sobre $(X, Y)$ : indica que o bloco $X$ está sobre o bloco $Y$-ou sobre a mesa. Para tanto, $\mathrm{X} \neq \mathrm{Y}$.

$\operatorname{livre}(\mathrm{X})$ : indica que o bloco $\mathrm{X}$ tem seu topo livre.

Como já visto na seção 4.2, as alterações que o operador irá provocar estão especificadas nas listas adiciona-fato ( $\mathrm{AF}$ ) e remove-fato ( $\mathrm{RF}$ ). As pré-condições, necessárias para a. aplicação do operador, estão especificadas na lista de pré-condiçâo (PC).

Com isso, tem-se a seguinte representação para o operador move:

move $(X, Y, Z)$

PC: $\operatorname{sobre}(X, Y) \wedge$ livre $(X)$

RF: $\operatorname{sobre}(X, Y) \wedge$ livre $(Z)$

$\operatorname{AF}: \operatorname{sobre}(X, Z) \wedge \operatorname{livre}(Y)$

Assim, a representação em Prolog do operador mọe fica:

adiciona_fato (sobre $(X, Y)$, move $(X, Z, Y))$.

adiciona_fato ( $I$ ivre $(Z)$, move $(X, Z, Y)$ ).

remove_fato $(\operatorname{sobre}(X, Z), \operatorname{move}(X, Z, Y))$.

remove_fato( $(\operatorname{ivre}(Y)$, move $(X, Z, Y))$.

pre_cond (move $(X, Z$, mesa), sobre $(X, Z) \& l i v r e(X))$.

pre_cond (move $(X, Z, Y), \operatorname{Iivre}(Y) \& \operatorname{sobre}(X, Z) \& I i v r e(X))$.

Considerando que o estado inicial é o mostrado na Figura 6.1:

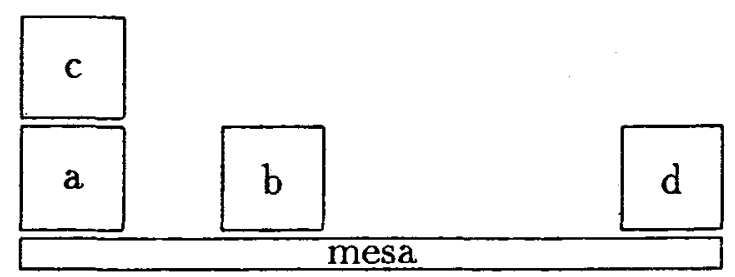

Figura 6.1: Estado Inicial

então, este estado inicial pode ser representado em Prolog como se segue:

dado(inicio, sobre (a,mesa)).

dado(inicio, sobre(b, mesa)).

dado(inicio, sobre(d,mesa)). 
dado (inicio, sobre $(c, a)$ ).

dado(inicio,livre(b)).

dado(inicio, livre(c)).

dado(inicio, livre(d)).

o qual diz que todos os fatos Prolog dado/2 -onde o primeiro argumento é o átomo inicio-compôem o estado inicial.

\subsection{Análise dos Meios e Fins}

A análise dos meios e fins é a técnica clássica para resolver problemas de busca por abstração. Por abstração, entende-se a simplificação na modelagem de um universo, de maneira que se possa racjocinar mais facilmente sobre ele. Vale salientar, ainda, que busca por abstração trabalha melhor quando o problema pode ser decomposto, e quando é possível explorar as pré-condições e efeitos dos operadores.

Para posicionar os operadores em situações específicas, onde eles devem ser utilizados, é necessário que sejam observadas as diferenças entre o estado corrente e o estado meta. Em função disso, é escolhido o operador que minimize ao máximo essas diferenças entre os estados. Como já visto anteriormente na implementação de Strips, para cada operador devem ser especificadas as pré-condições que ele deve satisfazer e os efeitos por ele proporcionados.

Em geral, para ir de um estado inicial I até um estado meta $M$, usando a técnica de análise dos meios e fins, são necessários os seguintes passos de execução:

- São verificadas as diferenças entre esses estados;

- Em função dessas diferenças é escolhido úm operador que as reduza ao mínimo possível;

- São verificadas as suas pré-condições, onde, para serem satisfeitas, pode ser feito o uso de um estado intermediário I1;

- É aplicado o operador escolhido sobre o estado I1, obtendo o estado I2 (devido aos efeitos do operador).

- O processo é repetido, partindo agora do estado 12 até chegar ao estado meta $\mathrm{M}$.

É possível observar que a análise dos meios e fins é uma busca recursiva, onde existe uma certa hierarquia. A hierarquia existe devido a se partir do geral até ir descendo ao nível de detalhes. Os fins verdadeiramente justificam os meios.

Em resumo, a análise dos meios e fins usa recursão para decompor a solução de um problema em um caminho inteligente e o mais próximo possivel de como uma pessoa 
iria resolvê-lo. Para isto, é necessário que se identifique de modo explícito e completo as pré-condições e efeitos de cada operador, sendo que, quando isso não é conseguido, não é possível usar a técnica de análise dos meios e fins.

A seguir, é apresentada uma implementaçâo em Prolog para melhor representar o conceito de análise dos meios e fins. Nesta implementação, o plano é montado partindo-se da meta em direção ao estado inicial.

O nível mais alto está definido pelo programa amfs/2, que é composto de uma única cláusula. Esta cláusula constitui a chamada para o resolvedor de problemas. O estado atual é definido na base de conhecimento do sistema.

amfs(Objetivos, Plano):- amf(Objetivos, inicio, Plano).

Onde:

- Objetivos é o grupo de fatos que descrevem o estado meta.

- Plano é o plano final.

O predicado amf / 3 é composto de duas cláusulas; a primeira verifica se o estado meta já foi satisfeito e a segunda é a entrada para o resolvedor de problemas. $\mathrm{O}$ primeiro argumento de amf $/ 3$ é o grupo de fatos que descrevem o estado meta e, como resultado, ele devolve o plano completo de açôes no terceiro argumento. Para tanto, inicialmente é selecionado um dos fatos que compõem o estado meta. Com esse fato, é identificado o operador que possa resolvê-lo. Para que esse operador possa ser efetivamente aplicado, é necessário que suas pré-condições sejam satisfeitas. Para isso, é montado um plano que satisfaça as pré-condições. A seguir, o operador é aplicado gerando um novo estado -devido aos seus efeitos. Finalmente, são resolvidos os fatos restantes da meta.

O programa que define amf/3 é:

amf (Objetivos, Plano, Plano):- satisfeito(Objetivos).

amf (Objetivos, Plano, Pos_plano):-

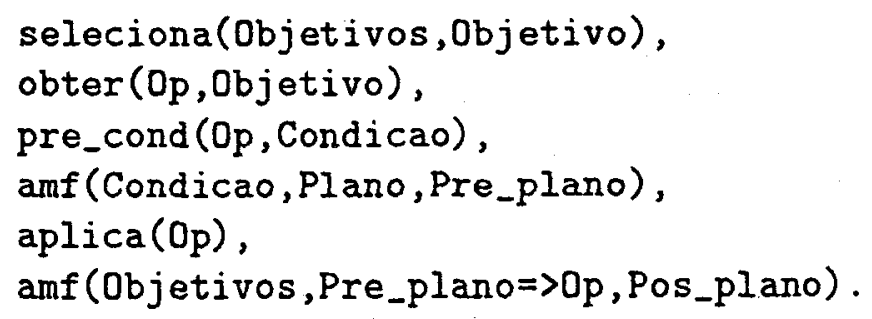

Onde:

- Objetivos é o grupo de fatos que descrevem o estado meta. 
- Plano é o plano inicial.

- Pos_plano é o plano final.

A seguir, são descritos os predicados que definem amf/3.

O predicado satisfeito/1 é responsável por verificar se o estado meta já foi atingido. Para tanto, ele verifica se todos os fatos já. foram satisfeitos.

satisfeito(Objetivo\&Objetivos):-

!, call (Objetivo),

satisfeito(Objetivos).

satisfeito(Objetivo):- call(Objetivo).

Onde:

- Objetivo é um dos fatos que descrevem o estado meta.

- Objetivos é o grupo de fatos restantes que descrevem o estado meta.

O predicado seleciona/2 é responsável por selecionar um dos objetivos que compõem a meta, ou seja, um dos fatos que descrevem o estado meta. Ele garante, também, que o fato escolhido ainda não foi obtido anteriormente.

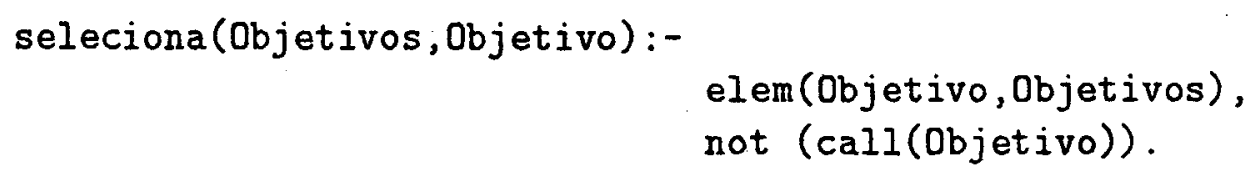

Onde:

- Objetivo é um dos fatos que descrevem o estado meta.

- Objetivos é o grupo de fatos restantes que descrevem o estado meta.

O predicado obter/2 é responsável por obter um operador, do conjunto de operadöres disponiveis para o domínio de aplicação, que resolva o fato especificado. Para tanto, ele verifica qual operador contém, em sua lista de fatos adicionados, o fato em questão. É nele que está embutida a análise dos meios e fins.

obter(Op,óbjetivo):- adiciona_fato(Objetivo,Op).

Onde: 
- Objetivo é um dos fatos que descrevem o estado meta.

- Op'é um operador.

O predicado aplica/ 1 é responsável pela mudança de um estado para outro, devido aos efeitos provocados pelo operador. Para isso, ele remove os fatos que deixaram de ser válidos e adiciona os fatos que passaram a valer após a aplicaçâo do operador.

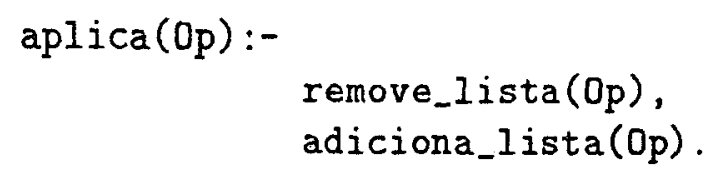

Onde:

- Op é um operador.

Por exemplo, para ir do estado inicial ao estado meta -representados na Figura 6.2-, deve ser feita a interrogação:

?- $\operatorname{amfs}(\operatorname{sobre}(b, d) \& s o b r e(a, c), P l a n o)$.

O resultado dessa interrogação será:

Plano $=$ inicio $=>\operatorname{move}(b, \operatorname{mes} a, d) \Rightarrow \operatorname{move}(c, a, \operatorname{mes} a) \Rightarrow \operatorname{move}(a, \operatorname{mes} a, c)$

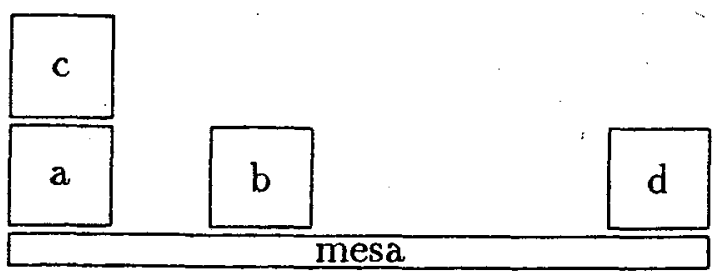

Estado Inicial

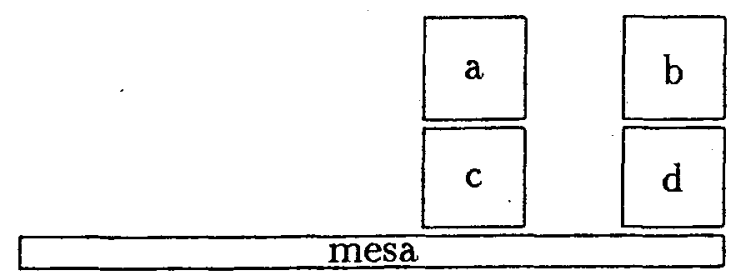

Estado Final

Figura 6.2: Representação de Estados - 7

\subsection{Análise dos Meios e Fins com Reordenação de Objetivos}

Como já mencionado, muitos problemas são formulados como uma conjunção de objetivos. Por exemplo, a faxina em uma casa deve envolver varrimento e lavagem do chão, lavagem das janelas, batimento do tapete etc.. Contudo, estes objetivos não são independentes, ou seja, eles não podem ser obtidos em uma ordem arbitrária. Lavar o chão antes dele ter sido varrido é uma tarefa desaconselhada, pois uma pré-condição para lavar o chão é que 
ele tenha sido varrido. Analogamente, bater o tapete depois de varrer o chão provocaria a perda do efeito de se ter varrido o chão.

Uma idéia óbvia, para evitar que problemas deste tipo ocorram, foi que o planejador tentasse preservar os objetivos que já tivessem sido atingidos. Daí surgiu o conceito de proteção de objetivos. Com isto, antes de ser aplicado um operador, é verificado se esse operador irá afetar algum objetivo já alcançado anteriormente.

Isso pode ser feito pela manutenção de uma lista contendo todos os objetivos anteriormente alcançados e, antes de aplicar o operador, verificar se, em sua lista de fatos que irão ser removidos, consta algum dos objetivos - fatos- já obtidos anteriormente. Caso conste, esse operador não poderá ser aplicado. Caso não exista outro operador possivel, então o plano é rejeitado e o planejador busca outra ordem de atendimento dos objetivos. Daí surge a reordenação de objetivos.

A seguir, tem-se uma implementação em Prolog onde é introduzido o conceito de proteçâo de objetivos na implementação da análise dos meios e fins feita anteriormente, com a diferença de que, agora, o estado é representado através do uso de uma lista, nâo ficando mais gravado na base de dados.

O nível mais alto está definido pelo programa planos_reord/2, que é composto de uma cláusula. Esta cláusula constitui a chamada para o resolvedor do problema. O estado inicial é suposto como dado.

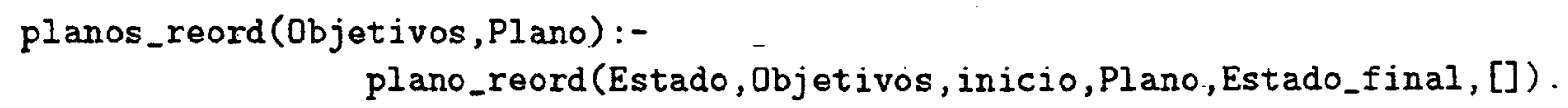

Onde:

- Objetivos é o grupo de fatos que descrevem o estado meta.

- Plano é o plano final.

O predicado plano_reord/6 é composto de duas cláusulas; a primeira verifica se o estado meta já foi satisfeito, e a segunda é a entrada para o resolvedor de problemas. $\mathrm{O}$ segundo argumento de plano_reord/6 é o grupo de fatos que descrevem o estado meta $\mathrm{e}$ como resultado ele devolve o plano completo dé ações no quarto argumento. Para tanto, inicialmente é selecionado um dos fatos que compõem o estado meta. Com esse fato, é identificado o operador que possa resolvê-lo. É, também, verificado se esse operador preserva os fatos já atingidos anteriormente. Para que esse operador possa ser efetivamente aplicado, é necessário que suas pré-condições sejam satisfeitas. Para isso, é montado um plano que satisfaça as pré-condições. A seguir, o operador é aplicado e, devido aos seus efeitos, é gerado um novo estado. Finalmente, sâo resolvidos os fatos restantes da meta.

O programa que define plano_reord/6 é: 


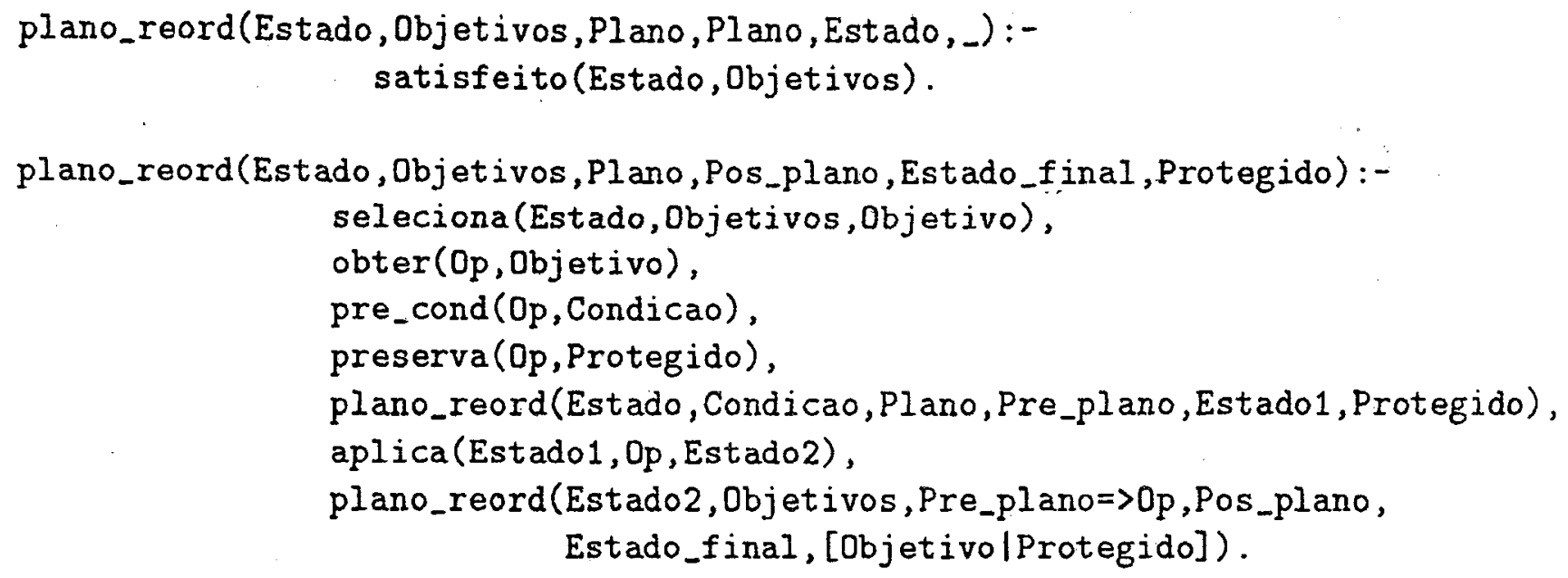

Onde:

- Objetivos é o grupo de fatos que descrevem o estado meta.

- Plano é o planó inicial.

- Pos_Plano é o plano final.

- Estado é o estado inicial.

- Estado_final é o estado final.

- Protegido é o grupo de fatos já resolvidos.

A seguir, são descritos os predicados que definem plano_reord/6.

O predicado satisfeito/1 é responsável por verificar se o estado meta já foi atingido. Para tanto, ele verifica se todos os fatos já foram satisfeitos.

satisfeito(Estado, Objetivo\&Objetivos):-

!, pertence2(Objetivo, Estado), satisfeito(Estado,objetivos).

satisfeito(Estado,Objetivo):- pertence2(Objetivo,Estado).

Onde:

- Objetivo é um dos fatos que descrevem o estado meta.

- Objetivos é o grupo de fatos restantes que descrevem o estado meta.

- Estado é o estado atual.

O predicado seleciona/2 é responsável por selecionar um dos fatos que compõem a meta, ou seja, um dos fatos que descrevem o estado meta. Ele garante, também, que o fato escolhido ainda não foi obtido anteriormente. 


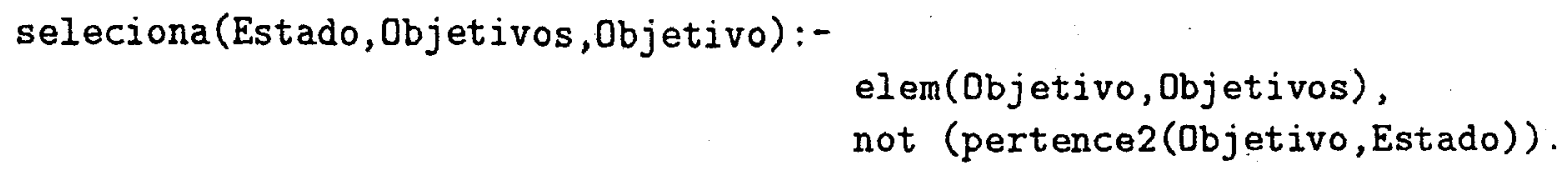

Onde:

- Objetivo é um dos fatos que descrevem o estado meta.

- Objetivos é o grupo de fatos restantes que descrevem o estado meta.

- Estado é o estado atual.

O predicado obter/2 é responsável por obter um operador, do conjunto de operadores disponíveis para o domínio de aplicação, que resolva o fato especificado. Para tanto, ele verifica qual operador contém em sua lista de fatos adicionados o fato em questão.

$\operatorname{obter}($ D , Objetivo):- adiciona_fato(Objetivo,Op).

Onde:

- Objetivo é um dos fatos que descrevem o estado meta.

- Op é um operador.

O predicado preserva/2 é responsável por verificar se o operador não irá afetar um fato já atingido anteriormente. Para representar esses fatos, é usada uma lista denominada Protegido. Sempre que um objetivo é alcançado, ele é acrescido à lista Protegido. Durante a execução, se um operador é rejeitado por afetar um objetivo previamente satisfeito e, não existindo outro operador que o substitua, ocorre o "backtracking" para que outro objetivo seja escolhido. Daí, tem-se a reordenação dos objetivos. A seguinte cláusula define preserva/2:

preserva(Op,Protegido):- not (pertence2(Objetivo,Protegido), remove_fato(Objetivo, Dp)).

Onde:

- Op é um operador.

- Protegido é o conjunto de fatos que ja foram atingidos.

O predicado aplica/1 é responsável pela mudança de um estado para outro - devido aos efeitos provocados pelo operador. Para isso, ele remove os fatos que deixaram de ser válidos e adiciona os fatos que passaram a valer após a aplicação do operador. 
aplica(Estado, Op,Novo_estado):-

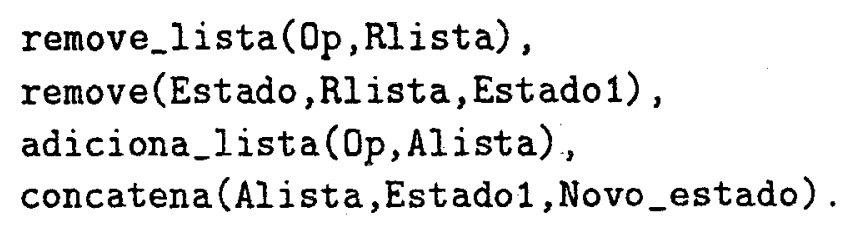

Para melhor visualizar a vantagem que a proteção - e consequente ordenação- de objetivos traz, observe o exemplo mostrado na. Figura 6.3:

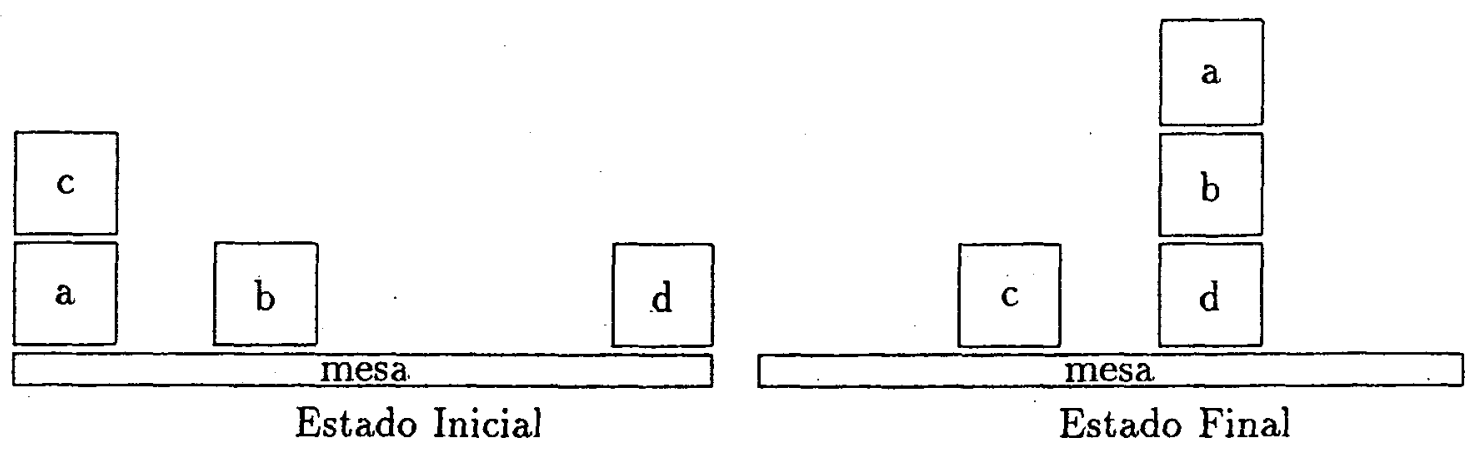

Figura 6.3: Representaçâo de Estados - 8

Para obter essa meta usando a análise dos meios e fins sem proteção de objetivos deve ser feita a seguinte interrogação:

?-amfs (sobre (a,b) \&sobre (b,d), Plano).

Como resultado tem-se:

$\begin{aligned} \text { Plano }=\operatorname{move}(c, a, \operatorname{mes} a) & \Rightarrow>\operatorname{move}(a, \operatorname{mes} a, b) \Rightarrow \\ & \operatorname{move}(a, b, \operatorname{mes} a) \Rightarrow \operatorname{move}(b, \operatorname{mes} a, d) \Rightarrow \text { move }(a, \text { mes } a, b) .\end{aligned}$

Por outro lado, usando o programa com proteção de objetivos deve ser feita a seguinte interrogação:

?-planos_reord (sobre $(a, b)$ \&sobre $(b, d)$, Plano).

Como resultado tem-se:

Plano $=\operatorname{move}(b$, mesa,$d)=>\operatorname{move}(c, a, \operatorname{mes} a) \Rightarrow \operatorname{move}(a, \operatorname{mes} a, b)$.

É notório o fato de que o uso de proteção de objetivos levou o planejador a reordenar o atendimento dos objetivos e, consequentemente, obteve-se um plano mais eficiente. $\mathrm{O}$ planejador atendeu o objetivo sobre $(a, b)$ priméiro. Quando ele tentou atender sobre $(b, d)$ foi verificado que seria afetado o objetivo $\operatorname{sobre}(a, b)$, já resolvido. Com isso, o plano é rejeitado e por "backtracking" é atendido primeiro sobre(b,d), para só então atender sobre $(a, b)$. 


\subsection{Análise dos Meios e Fins com Regressão de Ob- jetivos}

Como já visto na seção 5.3.3, uma outra maneira de se evitar os problemas que surgem devido aos objetivos conjuntivos, é construir um plano que resolva um objetivo conjuntivo por vez, verificando se cada soluçâo nào interfere em outros objetivos que foram alcançados anteriormente. No caso de interferir, o objetivo que provocou essa interferência é deslocado para um outro local dentro do plano. Esse é o conceito de regressão de objetivos.

Imagine um conjunto de objetivos $\mathrm{O}$ e um operador $\mathrm{Op}$. Não é garantido que $\mathrm{O}$ será verdadeiro depois da aplicação de Op. No entanto, é possível encontrar um novo objetivo Or que, sendo obtido antes da aplicação de $O p$, garantirá que $O$ não sofrerá mais a interferência de Op. Or é dito regressão de $\mathrm{O}$ a partir de Op.

Para melhor visualizar as relações entre os vários objetivos e pré-condiçôes, observe a Figura 6.4:

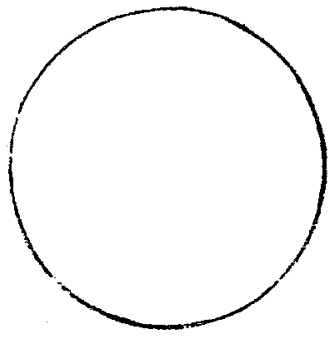

remove-fato ( $\mathrm{RF}$ )

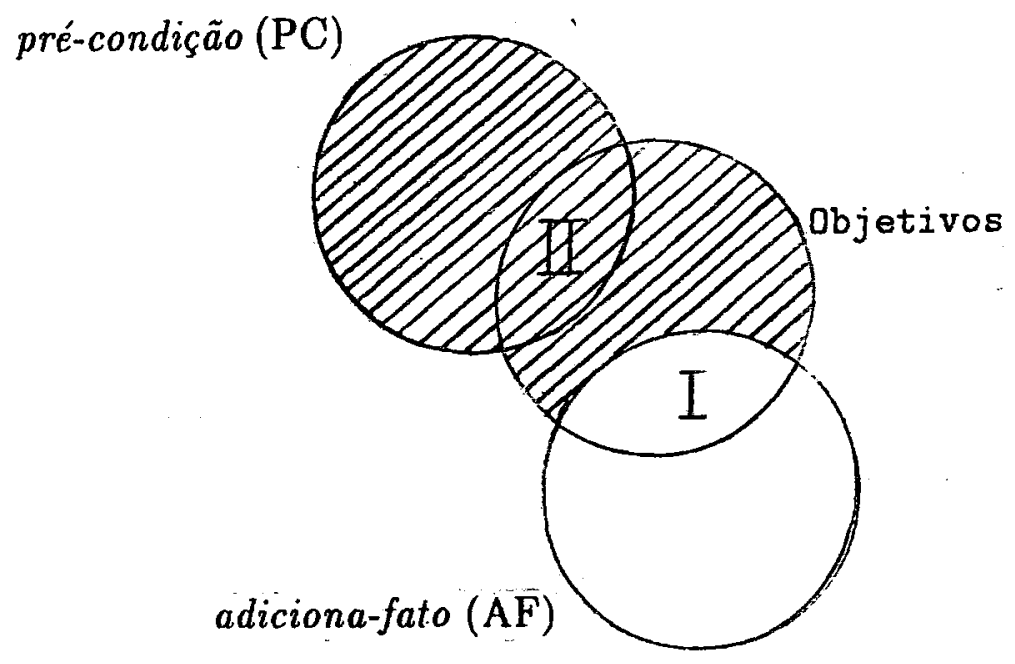

Figura 6.4: Relações entre Objetivos

Note que a intersecção I representa os objetivos que o operador Op resolve dentre os objetivos que compõem $O$. Já a interseç̧ão II mostra os objetivos que são comuns entre os objetivos que compõem as pré-condições de $\mathrm{Op}$ e os objetivos que compõem $\mathrm{O}$. A área hachurada representa Or.

Um problema que pode ocorrer, é o surgimento de um novo objetivo Or que contenha uma combinação de objetivos impossível de existir na prática. Por exemplo, sobre $(c, a)$ \& livre(a) é uma combinação de objetivos que poderá surgir; porém, na prática, é impossível ter um bloco a com seu topo livre e ao mesmo tempo ter um bloco c sobre ele.

Para resolver esse problema, pode ser formuląda uma relação impossivel da seguinte forma:

impossivel (Objetivo,Objetivos) 
a qual diz que Objetivo não pode ser combinado com objetivos, pois eles são incompativeis.

Para o Mundo dos Blocos, o predicado impossivel/2 poderia ser implementado da seguinte maneira:

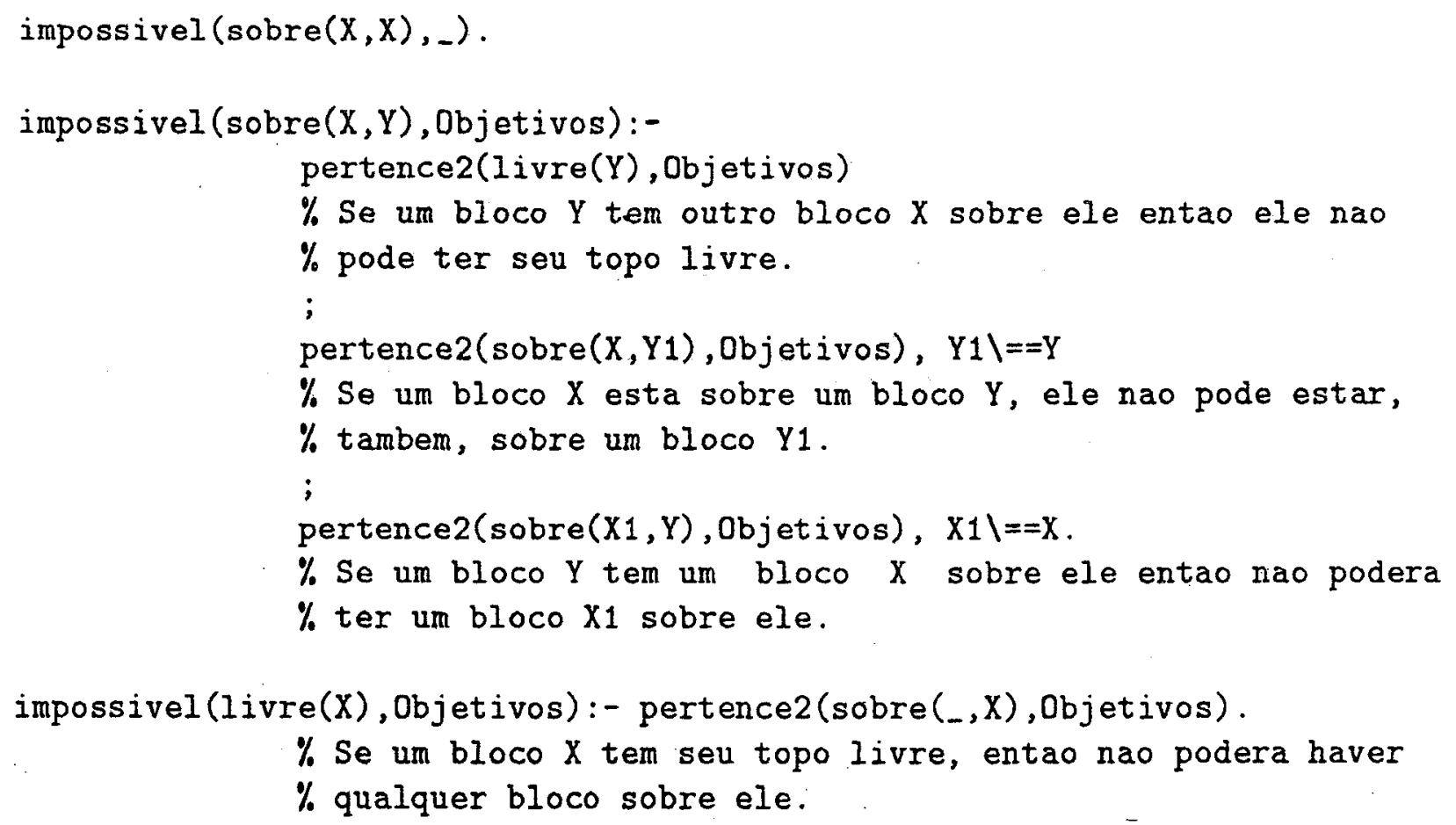

A seguir, tem-se uma implementação em Prolog onde é introduzido o conceito de regressão de objetivos na implementação da análise dos meios e fins feita anteriormente, com a diferença de que tanto o estado, quanto os objetivos, são agora representados através do uso de listas. $O$ estado inicial é suposto como dado.

O nivel mais alto está definido pelo programa planos_regr/2, que é composto de uma cláusula. Esta cláusula constitui a chamada para o resolvedor.

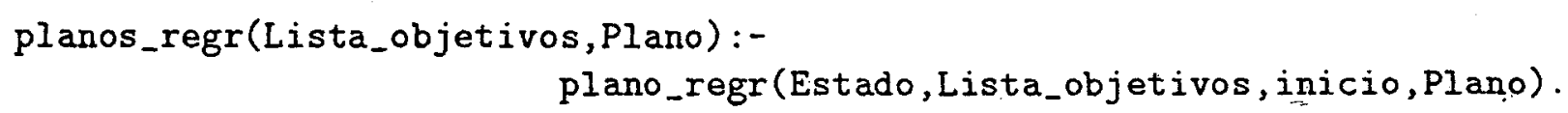

Onde:

- Lista_objetivos é o grupo de fatos que descrevem o estado meta.

- Plano é o plano final.

O predicado plano_regr/4 é composto de duas cláusulas; a primeira verifica se o estado meta já foi satisfeito e a segunda é a entrada para o resolvedor de problemas. $O$ 
segundo argumento de plano_regr/4 é o grupo de fatos que descrevem o estado meta. e, como resultado, ele devolve o plano completo de ações no quarto argumento. Para tanto, inicialmente, é selecionado um dos fatos que compõem o estado meta. Com esse fato, é identificado o operador que possa resolvê-lo. É, também, verificado se esse operador preserva os fatos já atingidos anteriormente. As variáveis livres são instanciadas e ocorre a regressão de objetivos. A seguir, é montado um plano para resolver os objetivos regredidos.

O programa que define plano_regr/4 é:

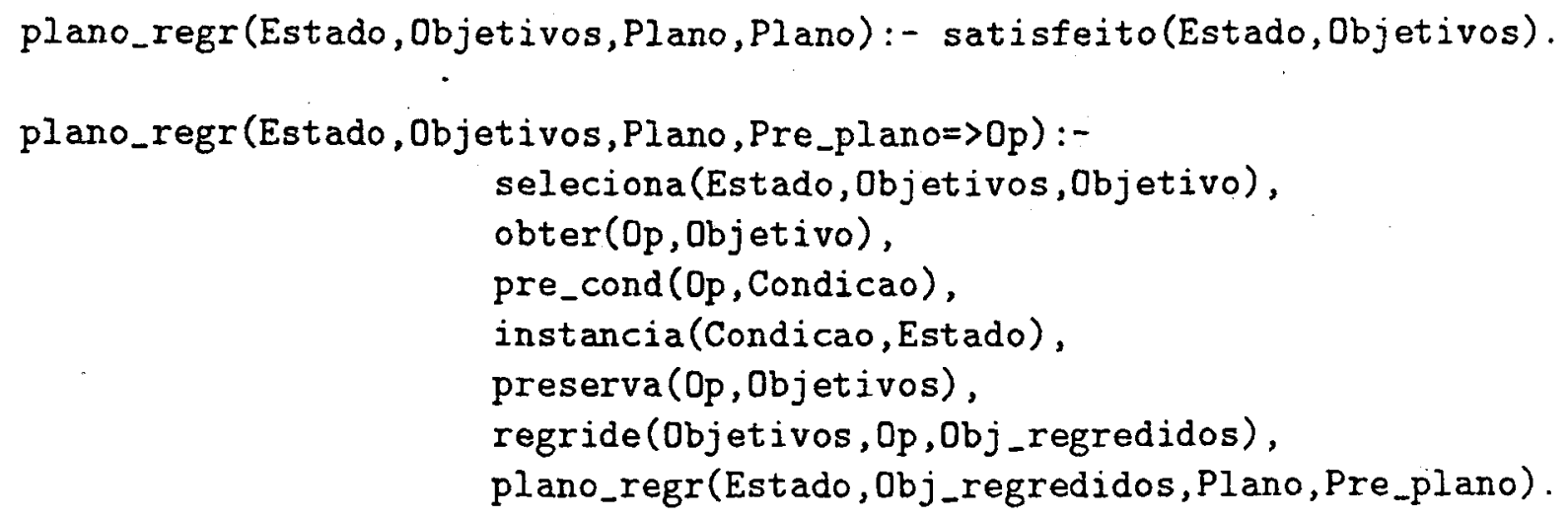

Onde:

- Objetivos é o grupo de fatos que descrevem o estado meta.

- Pre_plano é o plano para os objetivos regredidos.

- Plano é o plano final.

- Estado é o estado inicial.

- Op é o último operador do plano parcial.

A seguir, são descritos os predicados que definem plano_regr/4.

O predicado satisfeito/2 é responsável por verificar se o estado meta já foi atingido. Para tanto, ele verifica se todos os fatos já foram satisfeitos. Isso acontece quando, ao se retirar dos objetivos regredidos os fatos que compõem o estado atual, tem-se uma lista vazia.

satisfeito(Estado, Objetivos):- remove(Objetivos, Estado, []).

Onde:

- Objetivos é o grupo de fatos restantes que descrevem o estado meta. 
- Estado é o estado atual.

O predicado seleciona/3 é responsável por selecionar um dos fatos que compóem a meta, ou seja, um dos fatos que descrevem o estado meta. Ele garante, também, que o fato escolhido ainda não foi obtido anteriormente.

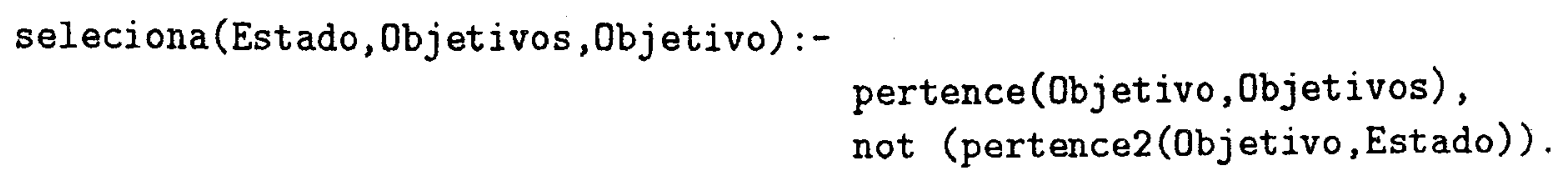

Onde:

- Objetivo é um dos fatos que descrevem o estado meta.

- Objetivos é o grupo de fatos restantes que descrevem o estado meta.

- Estado é o estado atual.

O predicado obter $/ 2$ é responsável por obter um operador, do conjunto de operadores disponiveis para o domínio de aplicação, que resolva o fato especificado. Para isso, ele verifica qual operador contém, em sua lista de fatos adicionados, o fato em questão.

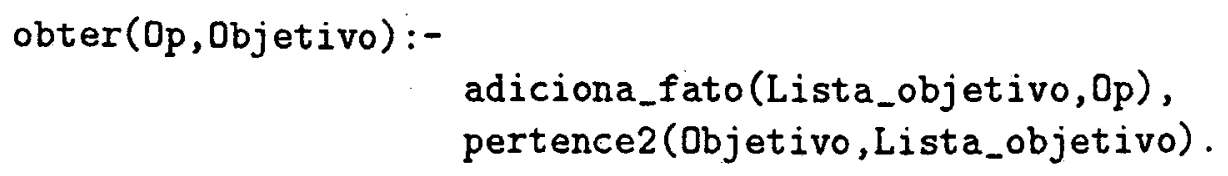

Onde:

- Objetivo é um dos fatos que descrevem o estado meta.

- Op é um operador.

O predicado instancia/ 2 é responsável por verificar se as pré-condições fazem parte do estado atual.

O predicado preserva/2 é responsável por verificar se o operador não irá afetar um fato já atingido anteriormente. Para representar esses fatos, é usada uma lista denominada Protegido. Sempre que um objetivo é alcançado, ele é acrescido à lista Protegido.

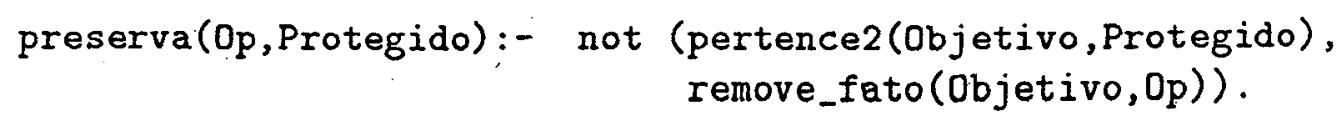

Onde: 
- Op é um operador.

- Protegido é o conjunto de fatos que ja foram atingidos.

O predicado regride/3 é responsável por encontrar a regressão de objetivos. Para isso, ele remove da meta os objetivos que o operador resolve e adiciona ao resultado dessa remoção as pré-condições do operador. No predicado adiciona/3 é verificado se ocorre uma combinação impossível de objetivos.

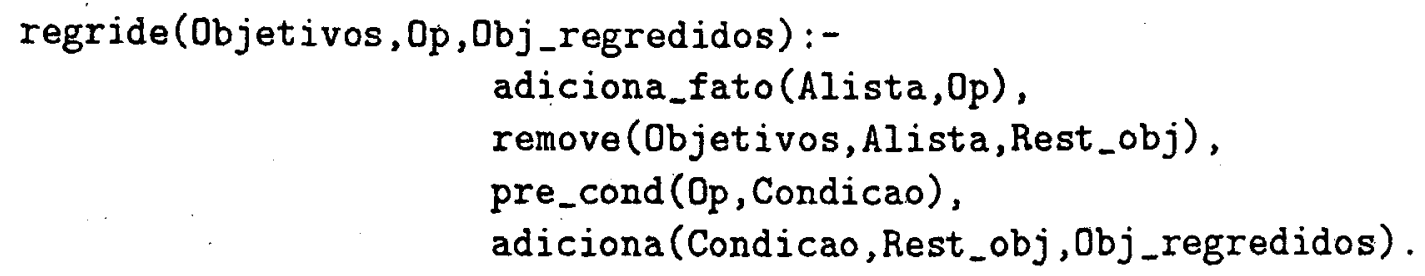

Onde:

- Objetivos é o grupo de fatos que descrevem o estado meta.

- Op é o operador.

- Obj_regredidos é o grupo de fatos que compõem os objetivos regredidos.

Considerando que os estados inicial e final são os definidos na Figura 6.2, a interrogação: ?-planos_regr(sobre(b,d)\&sobre $(a, c)$, Plano).

é bem sucedida com:

Plano $=\operatorname{move}(c, a, \operatorname{mes} a) \Rightarrow \operatorname{move}(a, \operatorname{mes} a, c) \Rightarrow \operatorname{move}(b, \operatorname{mes} a, d)$.

Os passos de resolução são os seguintes:

Inicialmente, é resolvido sobre (b,d) através da aplicação de move(b, mesa,d). Com isto, os objetivos regredidos ficam :

[sobre(b, mesa), livre(d), $\operatorname{livre}(b), \operatorname{sobre}(a ; c)]$

A seguir, é montado um plano para resolver esses objetivos. Apenas sobre $(a, c)$ ainda não está satisfeito. Para resolvê-lo é usado o operador move (a,mesa,c) e tem-se nevos objetivos regredidos, que são:

[sobre(a,mesa), $\operatorname{livre}(c), \operatorname{Iivre}(a), \operatorname{sobre}(b, \operatorname{mes} a), \operatorname{Iivre}(d), \operatorname{Iivre}(b)]$

Destes, livre(a) não é ainda satisfeito, e é escolhido o operador move (c, a, mesa) para satisfazê-lo. Tem-se os novos objetivos regredidos, que são:

[sobre(c,a), sobre(a,mesa), $\operatorname{livre}(c), \operatorname{sobre}(b, \operatorname{mes} a), \operatorname{livre}(d), \operatorname{livre}(b)]$

Todos esses objetivos já estão satisfeitos e, portanto, o plano já está montado. 


\subsection{Considerações Finais}

Neste capitulo foram apresentadas algumas das técnicas básicas mais difundidas em planejamento. Para cada técnica, foi apresentada uma implementação simplificada feita na linguagem de programação lógica Prolog.

O objetivo destas implementações é fornecer ao leitor uma idéia de como implementar as técnicas descritas usando uma linguagem de programação lógica, bem como, possibilitar uma melhor vizualização dos mecanismos de execução embutidos em cada uma das técnicas. 


\section{Capítulo 7}

\section{Implementação de um Sistema Hierárquico e de um Não Hierárquico}

\subsection{Considerações Iniciais}

Após ter visto as implementações das técnicas descritas no capítulo anterior, serão apre. sentadas implementações simplificadas, na linguagem Prolog, para um sistema hierárquico e para um sistema não hierárquico.

Por ser um sistema bastante utilizado, foi escolhido um sistema com as características do sistema Warplan para representar um sistema não hierárquico. No caso de representar um sistema hierárquico, foi escolhido um sistema que contém o conceito de criticabilidades.

\subsection{Sistema Não Hierárquico}

A principal caracteristica de um sistema não hierárquico é que a representação do plano é dada num único nível de abstração. Seu principio básico de funcionamento foi visto na seção 4.2 , com a utilização do sistema Strips.

O sistema Warplan é um sistema derivado do sistema Strips, possuindo, portanto, as mesmas características básicas de funcionamento. Contudo, como visto anteriormente, ele possibilita que estados ou planos sejam rejeitados imediatamente por ser impossível encontrar uma solução. Por exemplo, uma combinação sobre $(a, b) \& l i v r e(a)$ no sistema Warplan é rejeitada imediatamente, ou seja, antes de ser tentada sua solução. Num sistema Strips, seriam primeiro tentados todos os caminhos possíveis de solução para somente aí ocorrer a rejeição. 
A seguir, tem-se uma implementação em Prolog para um sistema não hierárquico com as características do sistema Warplan.

O nivel mais alto está definido pelo programa planos/1, que é composto de uma cláusula. Nesta cláusula, inicialmente, é dada uma lista que contém o estado inicial: Com isso, é chamado o resolvedor de problemas; por fim é apresentado o plano obtido.

planos(Objetivos):-

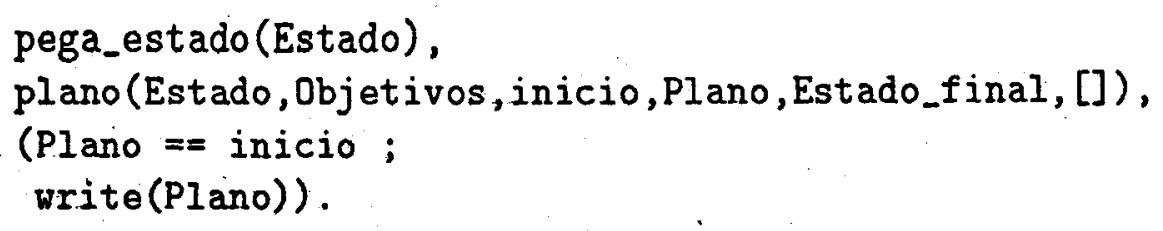

Onde:

- Objetivos é o grupo de fatos que descrevem o estado meta.

A seguir, tem-se o predicado plano/6, que é composto de três cláusulas. A primeira cláusula serve para verificar se existe alguma inconsistência na meta, ou seja, se ocorre uma combinação impossivel de objetivos. A segunda verifica se o estado meta já foi satisfeito, e a terceira é a entrada para o resolvedor de problemas. $\mathrm{O}$ segundo argumento de $\mathrm{plano} / 6$ é o grupo de fatos que descrevem o estado meta e, como resultado, ele devolve um plano completo de ações no quarto argumento. Para tanto, inicialmente é selecionado um dos fatos que compõem o estado meta. É verificado se esse fato não forma uma combinação impossivel. Caso não forme, é identificado o operador que possa resolvê-lo.

O programa que define $\mathrm{plano} / 6$ é:

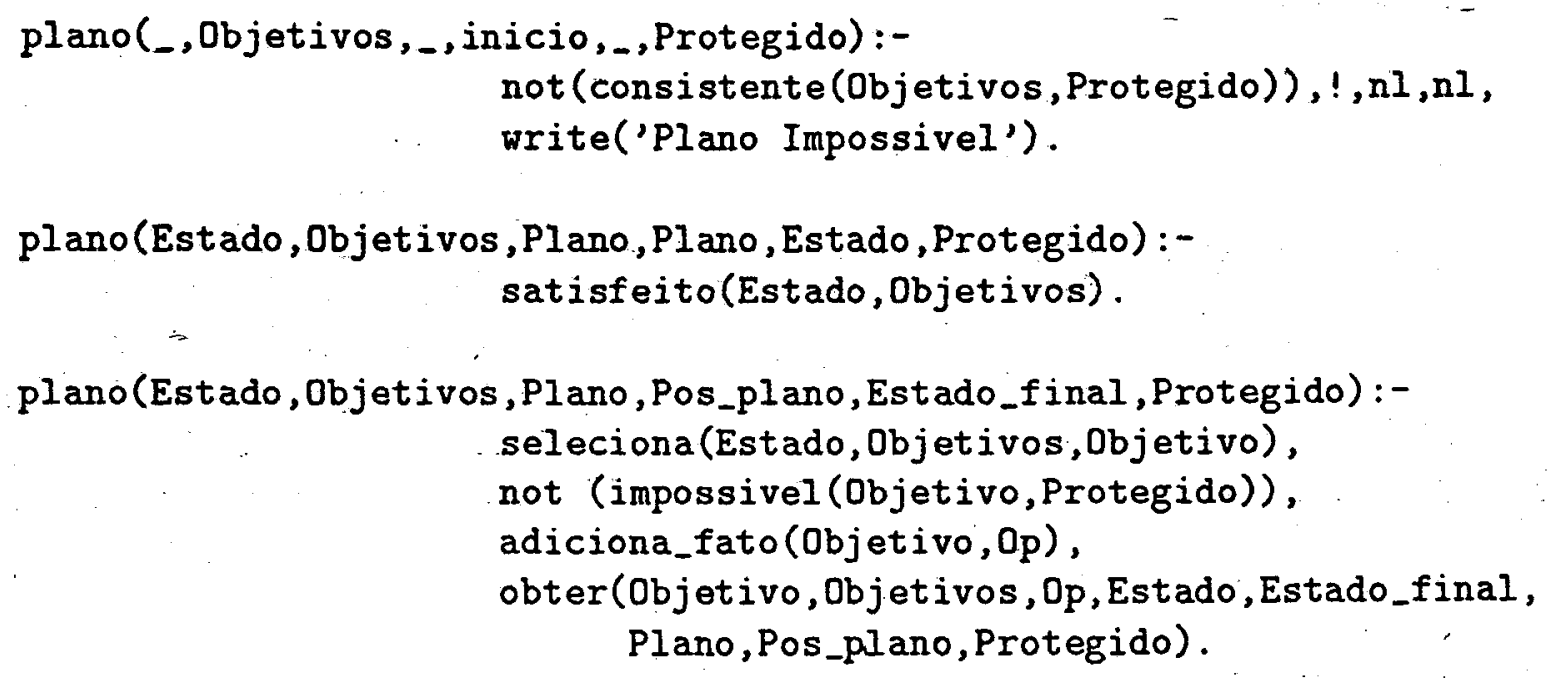

Onde: 
- Objetivos é o grupo de fatos que descrevem o estado meta.

- Plano é o plano inicial.

- Pos_Plano é o plano final.

- Estado é o estado inicial.

- Estado_final é o estado final.

- Protegido é o grupo de fatos que devem ser preservados.

A seguir tem-se a descrição dos predicados que definem plano/6:

O predicado consistente/ 2 é responsável por verificar a consistência entre determinados fatos. Para tanto, ele verifica os casos de combinação impossível entre fatos. Vale salientar que o predicado impossivel/2 deve ser especificado para cada domínio de aplicação.

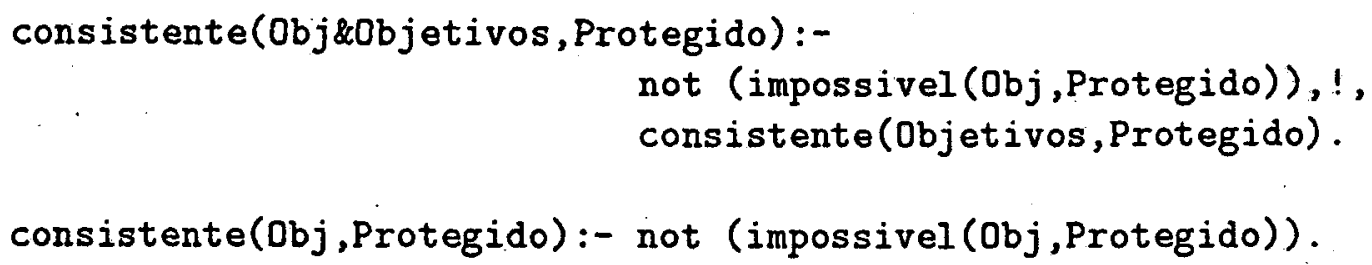

Onde:

- Protegido é o grupo de objetivos preservados.

- Obj\&Objtivos é o grupo de fatos novos.

O predicado satisfeito/2 é responsável por verificar se o estado meta já foi atingido. Para tanto, ele verifica se todos os fatos já foram satisfeitos.

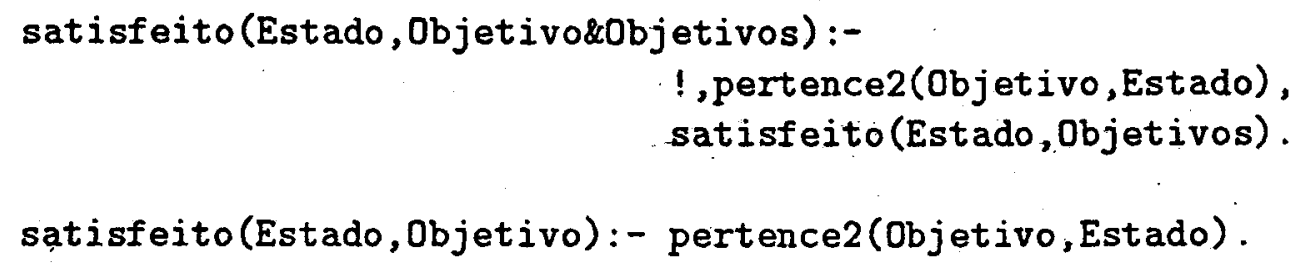

Onde:

- Objetivo é um dos fatos que descrevem o estado meta.

- Objetivos é o grupo de fatos restantes que descrévem o estado meta.

- Estado é o estado atual. 
O predicado seleciona/3 é responsável por selecionar um dos fatos que compõem a meta, ou seja, um dos fatos que descrevem o estado meta. Ele garante, também, que o fato escolhido ainda não foj obtido anteriormente.

seleciona(Estado,Objetivos,objetivo):-

elem(Objetivo,objetivos),

not (pertence2(Objetivo, Estado)).

Onde:

- Objetivo é um dos fatos que descrevem o estado meta.

- Objetivos é o grupo de fatos restantes que descrevem o estado meta.

- Estado é o estado atual.

O predicado obter/8 é responsável pela execução de uma ação, e é composto de duas cláusulas. A primeira verifica, inicialmente, se o operador não irá afetar os objetivos já alcançados, montando um plano para resolver suas pré-condições. Após resolver as précondições, é aplicado o operador Op, que gera um novo estado. Finalmente, monta um plano que resolva os fatos restantes da meta. A segunda clảusula usa, de certa maneira, a idéia de regressão de objetivos. Ela tenta encaixar o operador Op antes do último operador (0p1) dentro do plano parcial. Para que isso seja possível, é necessário que seja recuperado o plano parcial sem o operador Op1, para só então aplicar Op.

O programa que define obter/8 é:

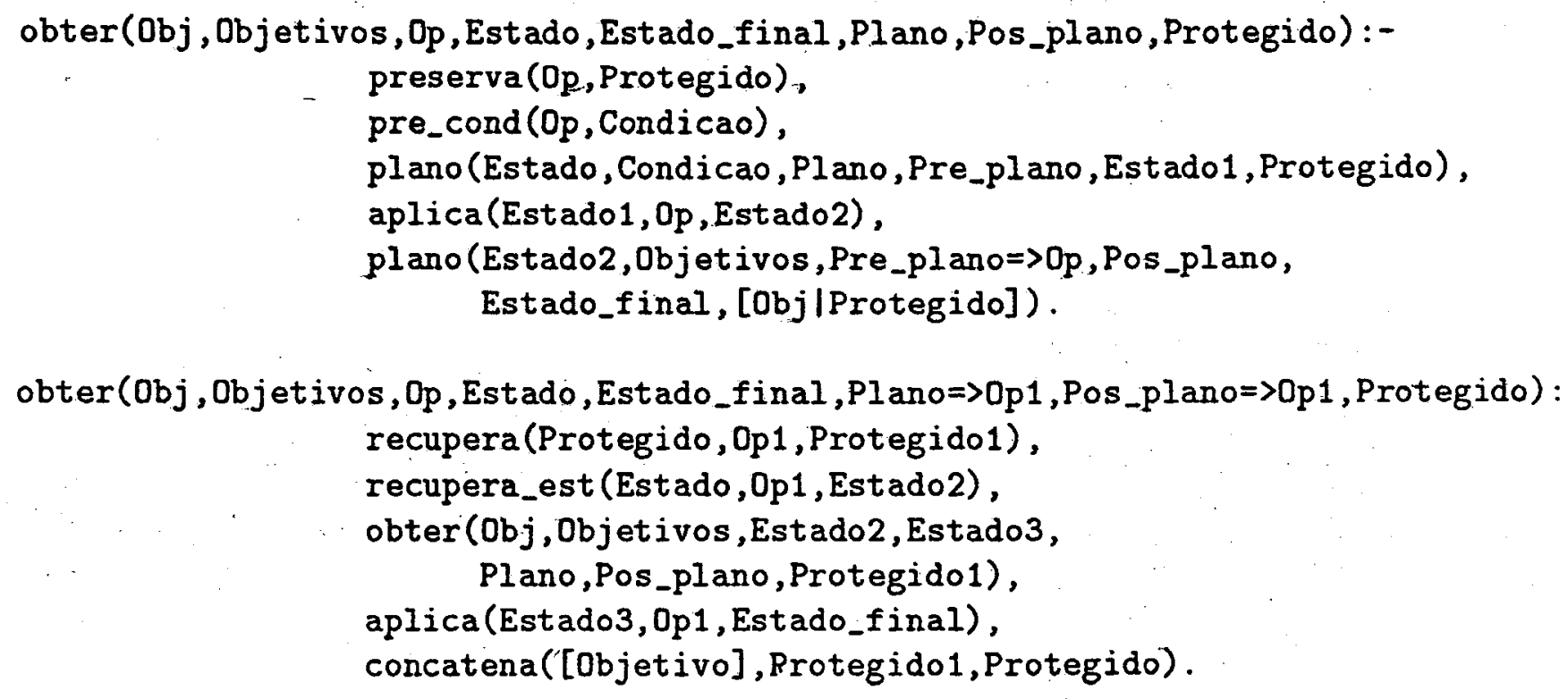

Onde: 
- Obj é o fato que será resolvido.

- Objetivos é o grupo de fatos que serão resolvidos.

- Op é o operador que será aplicado.

- Op1 é o último operador dentro do plano parcial.

- Estado é o estado inicial.

- Estado_final é o estado final.

- Plano é o plano parcial.

- Pos_plano é o plano resultante da aplicação de Op.

- Protegido é o grupo de objetivos já alcançados.

A seguir, tem-se os predicados que definem obter/8:

O predicado preserva/2 é responsável por verificar se o operador não irá afetar um fato já atingido anteriormente. Para representar esses fatos, é usada uma lista denominada Protegido. Sempre que um objetivo é alcançado, ele é acrescido à lista Protegido. Durante a execução, se um operador é rejeitado por afetar um objetivo previamente satisfeito e, não existindo outro operador que o substitua, ocorre o "backtracking" para que outro objetivo seja escolhido.

preserva(Op, Protegido):- not (pertence2(Objetivo, Protegido), remove_fato(Objetivo, Op)).

Onde:

- Op é um operador.

- Protégido é o conjunto de fatos que ja foram atingidos.

O predicado aplica/1 é responsável pela mudança de um estado para outro - devido aos efeitos provocados pelo operador. Para isso, ele remove os fatos que deixaram de ser válidos e adiciona os fatos que passaram a valer após a aplicação do operador.

aplica(Estado,Op,Novo_estado):-

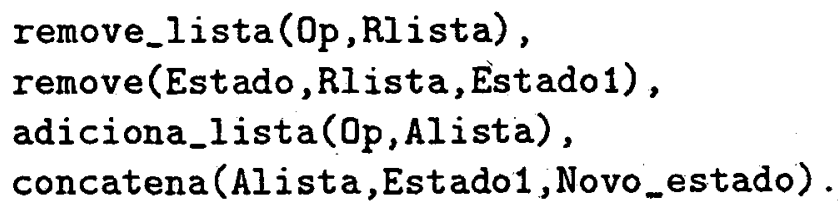

Onde:

- Op é o operador que será aplicado. 
- Estado é o estado inicial.

- Novo_estado é o estado resultante da aplicação de Op.

O predicado recupera/3 é responsável por recuperar os objetivos alcançados antes da aplicação do último operador.

recupera([X|Protegido], Op, Protegido).

Onde:

- Op é o operador que será aplicado.

- [X|Protegido] é o grupo de fatos preservados.

- Protegido é o novo grupo de fatos preservados após ter sido executada a recuperação.

O predicado recupera_est/3 é responsável por recuperar o estado anterior à aplicação do último operador (Op). Para isso, ele remove os fatos que foram adicionados por Op e acrescenta os fatos removidos pelo mesmo 0 p.

recupera_est(Novo_estado, Op, Estado):-

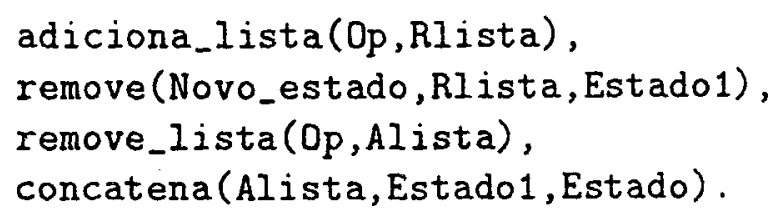

Onde:

- Op é o operador que será aplicado.

- Novo_estado é o estado atual.

- Estado é o estado anterior à aplicação do operador.

Para exemplificar, suponha que é desejado o estado meta sobre(a,d)\&livre(d), que é um caso impossivel. Para executar, deve ser feita a seguinte interrogação:

?-planos (sobre $(a, d) \& \operatorname{livre}(d))$.

Como resultado tem-se:

Plano Impossivel 
Por outro lado, suponha que é desejado o caso mostrado na Figura 7.1, onde tem-se o estado meta sobre $(a, b) \& \operatorname{sobre}(c, d)$.
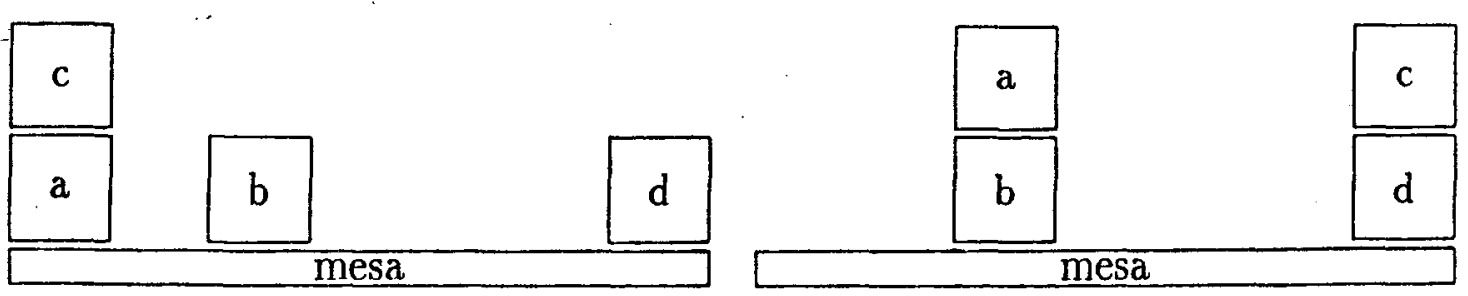

Figura 7.1: Representação de Estados - 9

Para executar, deve ser feita a seguinte interrogação:

?-planos (sobre (a, b)\&sobre $(c, d)$ ).

Como resultado, tem-se:

inicio $\Rightarrow \operatorname{move}(c, a$, mesa $) \Rightarrow \operatorname{move}(a, \operatorname{mesa}, b) \Rightarrow \operatorname{move}(c, \operatorname{mesa}, d)$

\subsection{Sistema Hierárquico}

A essência de um sistema hierárquico é procurar caracterizar quais informações são importantes e quais são apenas detalhes sem importância em um domínio de aplicação.

Uma maneira de se determinar níveis de importância é associando valores que determinem o que deve ser prioritário. Para isso, surgiu o conceito de criticabilidades.

A utilização do conceito de criticabilidades possibilita a ordenação de objetivos por níveis de importância. $\mathrm{O}$ sistema trabalha de modo a representar o plano em vários níveis de abstração, ou seja, ele monta um esqueleto de plano para cada nível de abstração.

O conceito de criticabilidades, bem como a maneira de ser feita a atribuição de seus valores, foram vistos na seção 4.3. Para realizar esta atribuição de valores, deve ser criado um algoritmo que siga a idéia apresentada na seção 4.3. Porém, neste trabalho, a preocupação está concentrada unicamente na elaboração do plano.

Um sistema que faça uso do conceito de criticabilidades trabalha em diferentes niveis de abstração, sem que seja possível realizar o "backtracking" para niveis anteriores - como visto na seção 5.3.1. Com isso, foi feita a opção de guardar os operadores que compôem o esqueleto do plano - para um determinado nível de abstração- na base de dados. Assim, sempre que ocorrer a mudança de nível de abstração, será reinicializada a base de dados, 
apagando o esqueleto do plano anterior, para que possa ser armazenado o novo esqueleto. Além disso, o estado inicial é sempre restaurado ao se iniciar um novo nivel de abstração.

$\mathrm{O}$ processo básico de funcionamento consiste em montar inicialmente um esqueleto do plano para os objetivos que compõem a meta e, então, ir descendo aos niveis mais baixos de abstração, procurando sempre resolver as pré-condições necessárias à aplicação dos operadores que compõem o esqueleto do plano montado para o nivel anterior. As précondições, que não correspondem ao nível que está sendo tratado, são consideradas como satisfeitas. Ao atingir o último nivel de abstração, tem-se o plano final montado.

Nesta seção, será apresentado um exemplo de como seria a elaboração de um plano utilizando-se um sistema como o descrito acima. O Mundo dos Blocos não é o mais adequado para representar o conceito de criticabilidades pois não fica claro a existência de diferenças de prioridade entre suas pré-condições. Assim, a fim de exemplificar, será usado o domínio de aplicação mostrado na Figura 7.2.

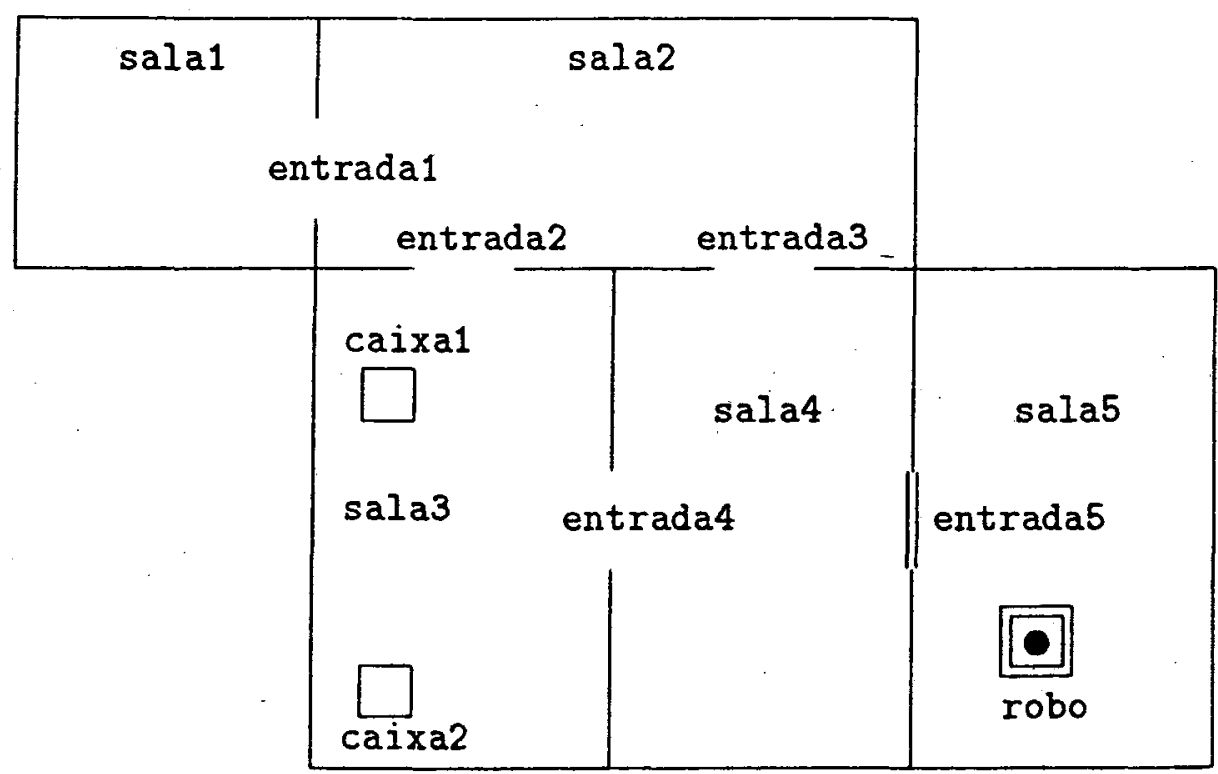

Figura 7.2: Estado Inicial - Problema do Robô

Este domínio consiste de quatro salas interligadas por entradas. Os operadores são definidos a fim de possibilitar que um robô se desloque até um objeto; que um robô empurre um objeto dentro de uma sala; que um robô se desloque por uma entrada e, finalmente, que um robô abra e feche uma porta.

Os operadores, bem como suas listas de pré-condições (PC), fatos adicionados (AF) e fatos removidos $(\mathrm{RF})$, seriam os seguintes: 
empurre (Cx,Cy)

PC: $\{4\}$ tipo(Cx; caixa)

\{3\} dentro_sala(Cx,Sx)

\{3\} dentro_sala $(\mathrm{Cy}, \mathrm{Sx})$

\{3\} dentro_sala(robo,sx)

\{1\} proximo (robo, Cx)

$\mathrm{RF}$ : proximo $(\mathrm{Cx}, \mathrm{V} 1)$

$A F$ : proxima $(C x, C y)$

va_para_porta(Px)

PC: $\{4\}$ tipo(Px,porta)

\{3\} dentro_sala(robo,Sx)

\{4\} conecta (Px,Sx,Sy)

RF : proximo(robo,V1)

$A F$ : proximo(robo, $\mathrm{Px}$ )

va_para_caixa(Cx)

PC: $\{4\}$ tipo(Cx, caixa)

$\{3\}$ dentro_sala(robo, $5 x$ )

\{3\} dentro_sala $(\mathrm{Cx}, \mathrm{Sx})$

RF : proximo(robo,V1)

AF : proximo(robo,Cx)

entre_sala (Px, Sx)

$P C:\{4\}$ conecta $(P x, S x, S y)$

$\{4\}$ tipo(Px,porta)

\{4\} tipo(Sx, sala)

(2\} status ( $\mathrm{Px}$, aberta)

\{3\} dentro_sala(robo,Sy)

RF: proximo(robo, V1)

dentro_sala(robo,V1) 
AF : dentro_sala(robo, Sx)

\section{$\operatorname{abra}(\mathrm{Px})$}

PC: \{4\} tipo(Px,porta)

$\{2\}$ status ( $P x$, fechada)

\{1\} proximo (robo, $P x$ )

RF: status (Px, fechada)

AF : status ( $P x$, aberta)

feche(Px)

PC: $\{4\}$ tipo(Px,porta)

$\{2\}$ status ( $P x$, aberta)

$\{1\}$ proximo (robo, $P x$ )

$\mathrm{RF}$ : $\operatorname{status}(\mathrm{Px}$, aberta)

$A F$ : status (Px, fechada)

Uma observação importante é que o operador va_para_porta(Px) somente é usado quando se deseja abrir ou fechar uma porta, não sendo usado, portanto, para entrar em uma sala cuja porta já esteja aberta.

O problema proposto é que, a partir do estado representado na Figura 7.2, o sistema elabore um plano que possibilite ser atingido o estado representado na Figura 7.3. Portanto, a meta seria:

$$
\text { [proximo(caixa1,caixa2), dentro_sala(robo,sala1)]. }
$$




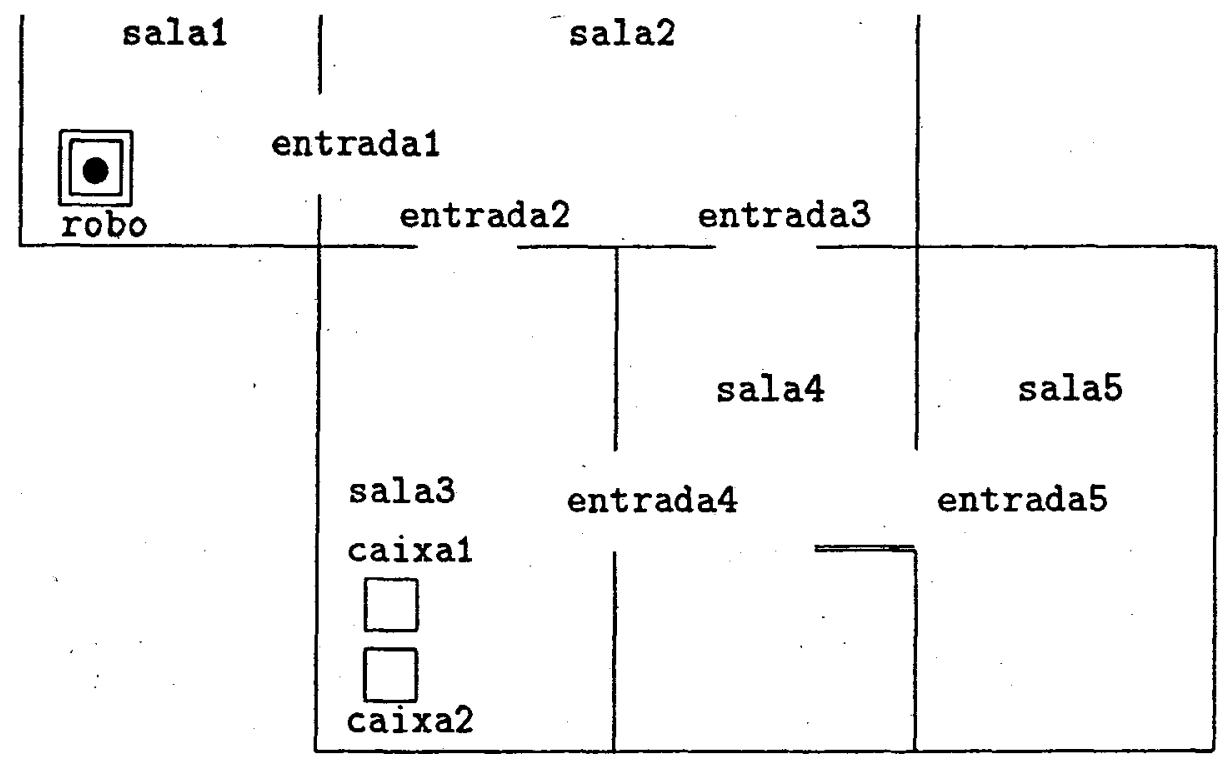

Figura 7.3: Estado Final - Problema do Robô

Segue-se uma descrição dos passos de execução do sistema.

Inicialmente, o sistema trabalha com o nivel de abstração mais alto, ou seja, com valor 4 (quatro) para a criticabilidade.

A diferença entre o estado inicial e o estado final é computada e o operador empurra(caixa1, caixa2) é escolhido e examinado. Como as pré-condiçôes nesse nivel de abstração são verdadeiras no estado inicial, então, o operador pode ser aplicado. 0 estado resultante é um estado onde o robo, caixa1 e caixa2, estão próximos uns dos outros.

A diferença entre este estado e o estado meta é computada como sendo dentro_sala(robo,sala1). O operador entre_sala(X1,sala1) é escolhido e examinado - observe que X1 não está instanciado. Suas pré-condições são satisfeitas quando X1 instancia com entrada1. Com isso, entre_sala (entrada1,sala1) é aplicado, gerando um estado no qual o objetivo é verdadeiro.

Assim, tem-se um esqueleto do plano constituido de dois operadores:

empurra(caixa1,caixa2)

entre_sala(entrada1,sala1)

Agora, é feito o planejamento para o nível de abstração imediatamente inferior, onde o 
valor de criticabilidade é igual a 3 (três).

0 operador empurra(caixa1,caixa2) tem a pré-condição dentro_sala(robo,sala3) não satisfeita. $\mathrm{O}$ operador para resolver esse fato é entre_sala(robo,sala3).

As pré-condições do operador entre_sala (robo, sala3) são testadas e não são completamente satisfeitas. A pré-condição não satisfeita é dentro_sala(robo, sala4).

O sistema tenta resolver esta pré-condição. O operador escolhido é entre_sala (X3,sala4) e suas pré-condições são resolvidas quando $X 3$ é instanciado com entrada5. Então, entre_sala(entrada5,sala4) é aplicado, produzindo um estado onde entre_sala(entrada4,sala3) pode ser aplicado. Com sua aplicação, são satisfeitas as pré-condições de empurre(caixa1, caixa2) que, portanto, pode ser aplicado.

A seguir, o sub-objetivo entre_sala(entrada1, sala1) é verificado e suas pré-condições são verdadeiras neste espaço de abstração. A diferença entre o estado corrente e esse sub-objetivo é dentro_sala(robo,sala2). O operador entre_sala(X4,sala2) é selecionado como relevante, e suas pré-condições são satisfeitas quando $X 4$ é instanciado com entrada2. O operador entre_sala (entrada2, sala2) é aplicado produzindo um estado onde o sub-objetivo é satisfeito. Finalmente, o operador entre_sala(entrada1, sala1) é aplicado e o estado meta é obtido para este nível de abstração.

Çom isto, surge um novo esqueleto de plano composto dos seguintes operadores:

entre_sala(entrada5, sala4)

entre_sala(entrada4, sala3)

empurra(caixa1, caixa2)

entre_sala (entrada2, sala2)

entre_sala(entrada1,sala1)

Este plano, agora, é resolvido para o nível de abstração igual a 2 (dois).

O primeiro sub-objetivo, entre_sala(entrada5, sala4) não foi satisfeito nesse nível de abstração. A diferença é status (entrada5, aberta). Esta diferença pode ser eliminada pela aplicação de abra(entrada5). Isto resulta em um estado que satisfaz o primeiro sub-objetivo. Então, entre_sala(entrada5,sala4) é aplicado.

Cada um dos sub-objetivos remanescentes do processo, neste nível de abstração, são imediatamente satisfeitos e cada operador do esqueleto do plano é aplicado, resultando num estado onde a meta original é satisfeita.

Com isto, um outro esqueleto de plano é montado. Os operadores que compõem este novo esqueleto são os seguintes:

va_para(entrada5)

abra(entrada5) 
entre_sala (entrada5, sala4)

entre_sala (entrada4, sala3)

empurra(caixa1, caixa2)

entre_sala (entrada2, sala2)

entre_sala(entrada1, sala1)

Finalmente, o planejamento é realizado para o último nível de abstração, que, neste exemplo, é de valor igual a 1 (um).

O operador abra (entrada5) tem a pré-condição proximo (robo, entrada5) não satisfeita. Para satisfazê-la, é usado o operador va_para_porta(entrada5). Com isso, pode ser aplicado o operador abra(entrada5). Os operadores entre_sala(entrada5, sala4) e entre_sala(entrada4,sala3) tem suas pré-condições satisfeitas para este nível de abstração.

0 operador empurre(caixa2, caixa1) tem a pré-condição proximo(robo, caixa1) não satisfeita. Para resolvê-la, é usado o operador va_para_caixa(caixa1). Com isso, pode ser aplicado empurra(caixa1, caixa2).

Com uma análise semelhante, o sistema termina o plano com um operador para ir através de entrada2 e entrada1. O plano final é composto dos seguintes operadores:

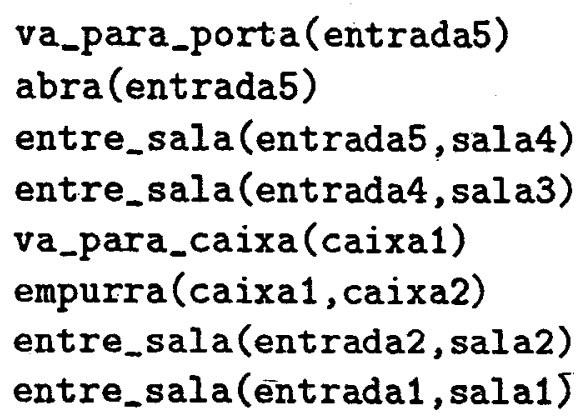

A seguir, tem-se uma implementação em Prolog para demonstrar o conceito de ordenação por niveis de importância usando criticabilidade.

O nível mais alto está definido pelo programa planos_crit/1, que é composto de duas cláusulas. A primeira verifica se existe inconsistência na meta especificada. $\mathrm{Na}$ segunda inicialmente é armazenado o estado inicial na base de dados. A seguir, monta-se o primeiro esqueleto do plano, ou seja, os operadores que resolvem os fatos -objetivos- da meta. É requisitado o valor máximo de criticabilidade. Finalmente, é montado o plano para os vários níveis de abstração e uma interface de saída escreve o plano final e a base de dados é reinicializada. 0 programa que define planos_crit/1 é:

planos_crit([Obj|Objetivos]):-

$$
\text { cria_base, }
$$


not (consistente1 ( $[O b j]$, Objetivos)), !, nl, nl, write('Plano Impossivel'), apaga_base.

planos_crit(Objetivos):-

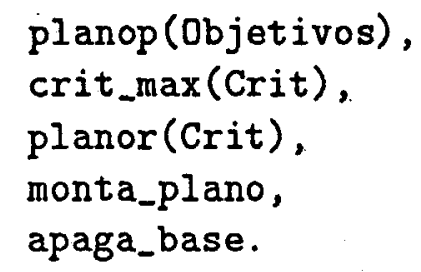

Onde:

- Objetivos é o grupo de fatos que descrevem o estado meta.

- Obj é um dos fatos que descrevem o estado meta.

Segue-se a descrição dos predicados que definem planos_crit/1:

O predicado consistente1/2 é responsável por verificar a consistência entre determinados fatos. Para tanto, ele verifica os casos de combinação impossível entre fatos.

consistente1([Obj|Objetivos], Protegido):-

not (impossivel(Obj, Protegido)), !, consistente1 (Objetivos, Protegido).

consistente1 $([],-)$.

Onde:

- Protegido é o grupo de fatos já resolvidos anteriormente.

- Objetivos é o grupo de fatos que descrevem o estado meta.

- obj é um dos fatos que descrevem o estado meta.

O predicado planop/1 monta o primeiro esqueleto do plano. Para isso, são obtidos e armazenados os operadores que resolvem os fatos especificados na meta.

$\operatorname{planop}([])$.

planop([Objetivolobjetivos]):-

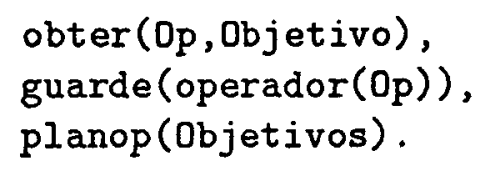


Onde:

- Objetivos é o grupo de fatos restantes que descrevem o estado meta.

- Objetivo é um dos fatos que descrevem o estado meta.

O predicado obter/2 é responsável por obter um operador, do conjunto de operadores disponíveis para o domínio de aplicação, que resolva o fato especificado. Para tanto, ele verifica qual operador contém, em sua lista de fatos adicionados, o fato em questão.

obter(Op,Objetivo):- adiciona_fato(Objetivo,Op).

Onde:

- Objetivo é um dos fatos que descrevem o estado meta.

- Op é um operador.

O predicado crit_max/1 serve para buscar o valor máximo de criticabilidade.

O predicado planor/1 controla a chamada para os diferentes níveis de abstração. Para tanto, ele obtém os operadores que compõem o esqueletó do plano para o nível de abstração imediatamente anterior. Isso é feito através da busca dos operadores que foram gravados na base de dados durante a resolução do nível de abstração anterior. É reinicializada a base de dados, ou seja, é apagado o estado e o esqueletō do plano obtido no nivel de abstração anterior. A seguir, é determinado o próximo nivel de abstração.

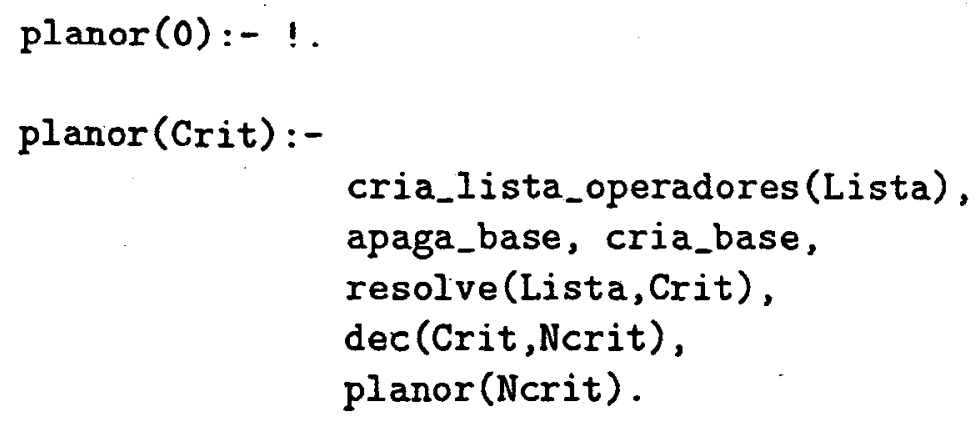

Onde:

- Crit é o valor de criticabilidade, que determina o nivel de abstração.

O predicado cria_lista_operadores/1 carrega o esqueleto de plano, apagando-o da base de dados. Apagar todos os operadores que compõem o esqueleto do plano é um artifício usado para que, ao gravá-los no novo esqueleto obtido no próximo nível de abstração, possa ser respeitada a ordem correta dos operadores dentro do plano. 


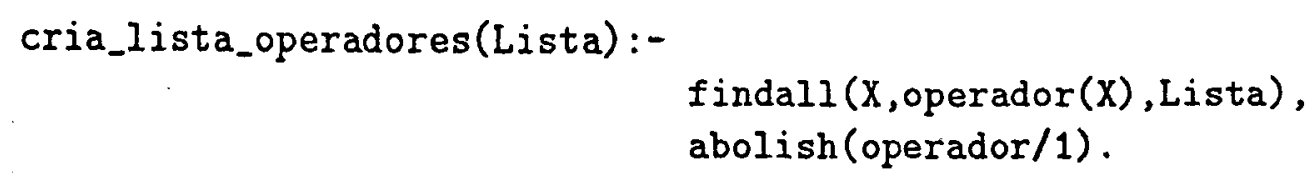

Onde:

- Lista é o esqueleto do plano.

O predicado resolve/ 2 controla a resolução das pré-condições dos operadores que compõem o esqueleto do plano. Para isso, ele seleciona as pré-condições e chama o resolvedor de problemas. Após ter suas pré-condições resolvidas, o operador é armazenado.

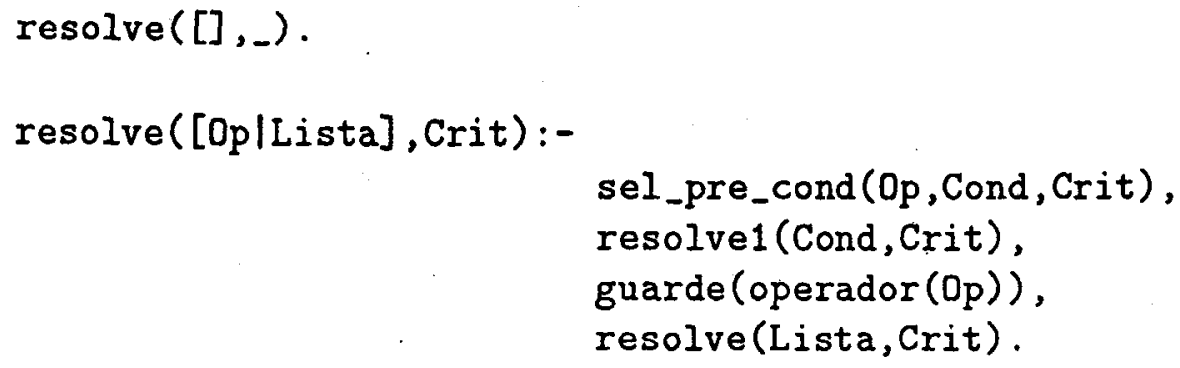

Onde:

- Crit é o valor de criticabilidade que determina o nível de abstração.

- Lista é o esqueleto do plano.

- Op é o operador que está sendo observado.

0 predicado sel_pre_cond/3 seleciona as pré-condições do operador que devem ser resolvidas para o nível de abstração dado.

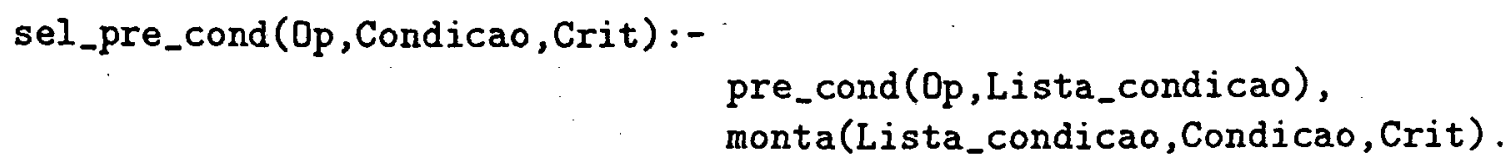

Onde:

- Crit é o valor de criticabilidade que determina o nível de abstração.

- Condicao é o grupo de fatos que compõem as pré-condições.

- Op é o operador que está sendo observado. 
0 predicado resolve1/2 controla a resolução dos fatos que formam as pré-condições dos operadores que compóem o esqueleto do plano. Para isso, ele verifica se o fato faz parte do estado atual. Caso não faça, ele obtém um operador que resolva o fato, selecionando suas pré-condições para este nível de abstração. A seguir, ele resolve essas pré-condições, guardando os operadores usados, para sua solução, na base de dados. Vale salientar que, ao guardar o operador na base de dados, é chamado o predicado aplica/1, que altera o estado atual, também armazenado na base de dados.

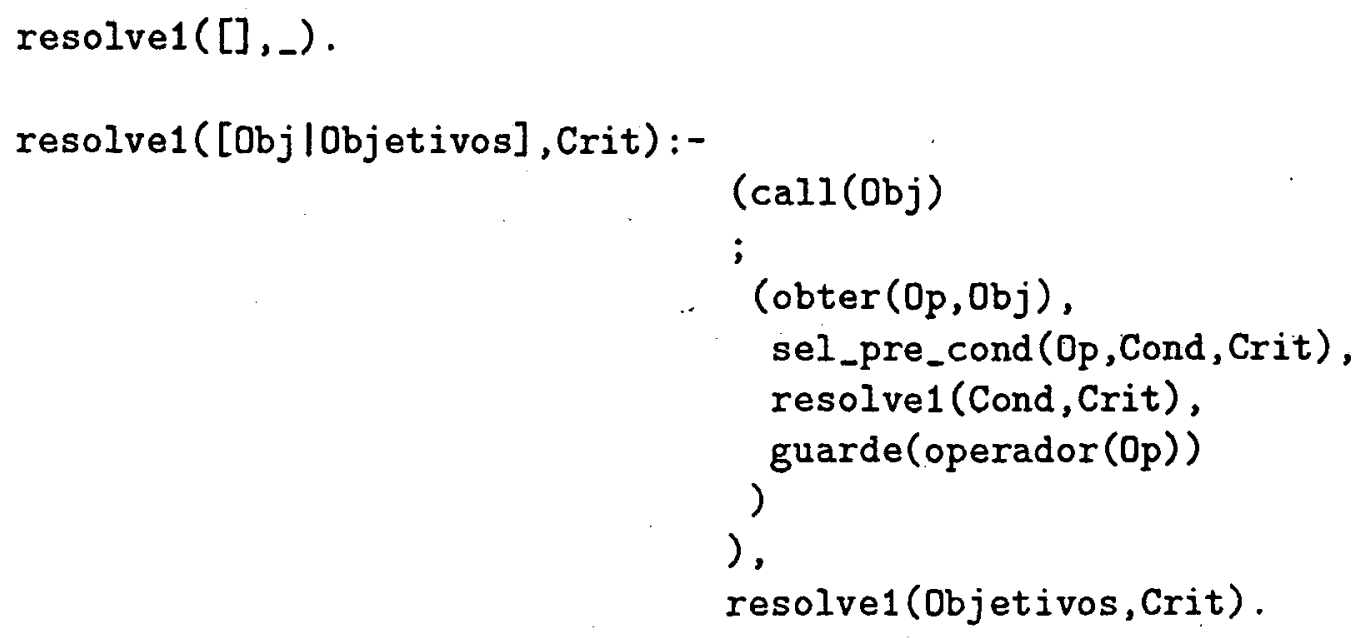

Onde:

- Crit é o valor de criticabilidade que determina o nível de abstração.

- Objetivos é o grupo de fatos restantes que descrevem o estado meta.

- Obj é um dos fatos que descrevem o estado meta.

O predicado monta/3 seleciona as pré-condições para o nível de abstração especificado pelo valor de criticabilidade Crit. Ele é composto de três cláusulas. A primeira é a condição de parada. A segunda percorre a lista de pré-condições, separando as que possuem a criticabilidade desejada. A terceira é para eliminar as pré-condições que não fazem parte desse nível de abstração.

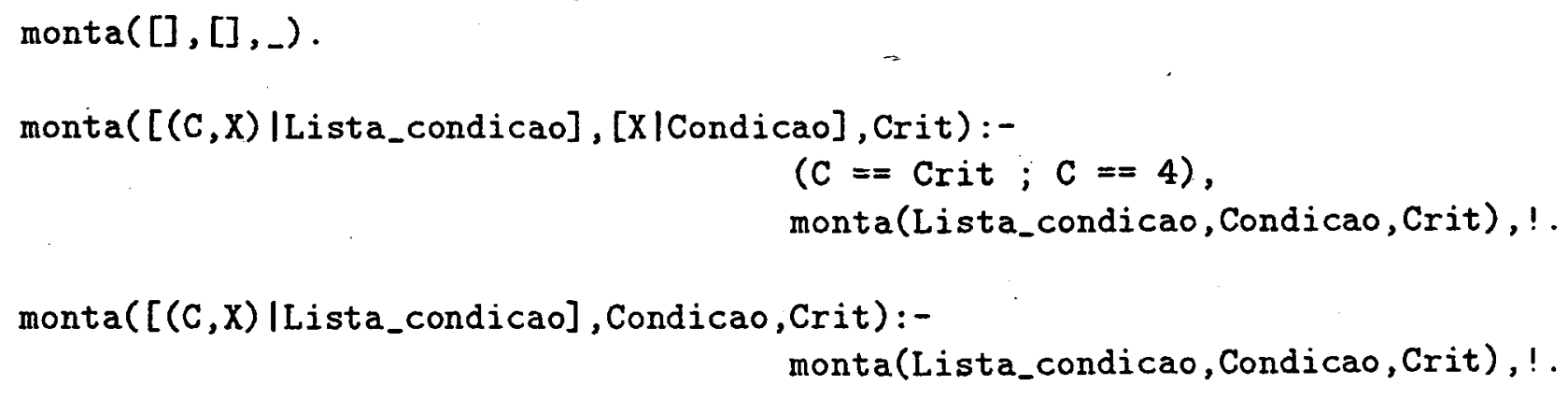

Onde: 
- C determina o valor de criticabilidade para um fato específico.

- X especifica um fato.

- Lista_condicao especifica as pré-condições.

- Crit é o valor de criticabilidade, que determina o nível de äbstração.

Para mostrar a execução deste programa, no caso do problema do Robô, é necessário definir em Prolog as listas adiciona-fato, remove-fato e pre-condição, bem como, os quatro objetos e interligações correspondentes. Elas são:

Lista adiciona-fato:

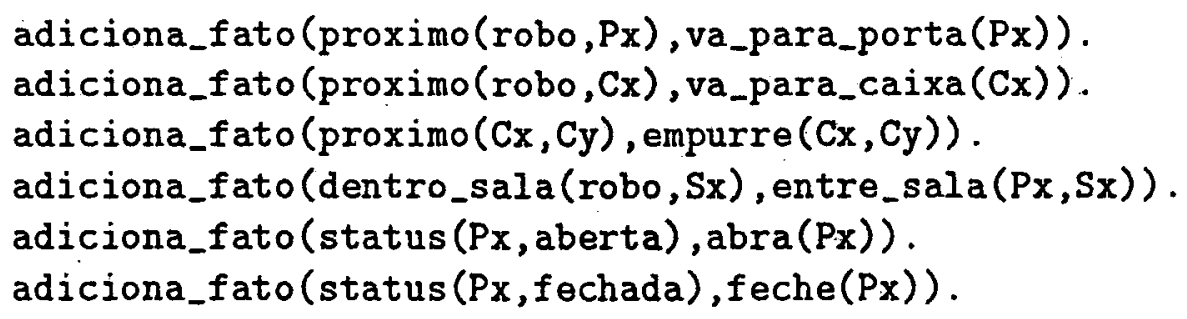

Lista remove-fato:

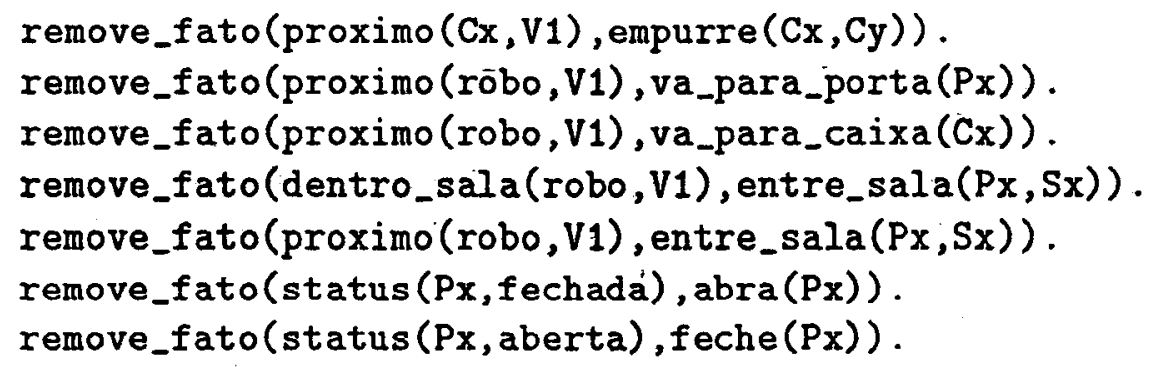

Lista pré-condiçâa:

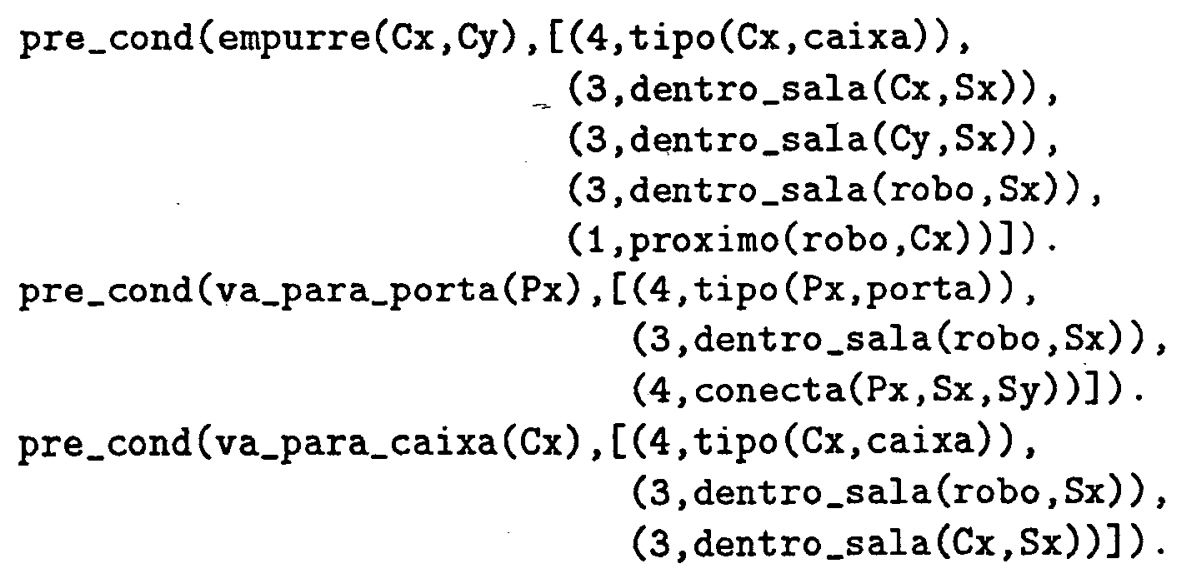




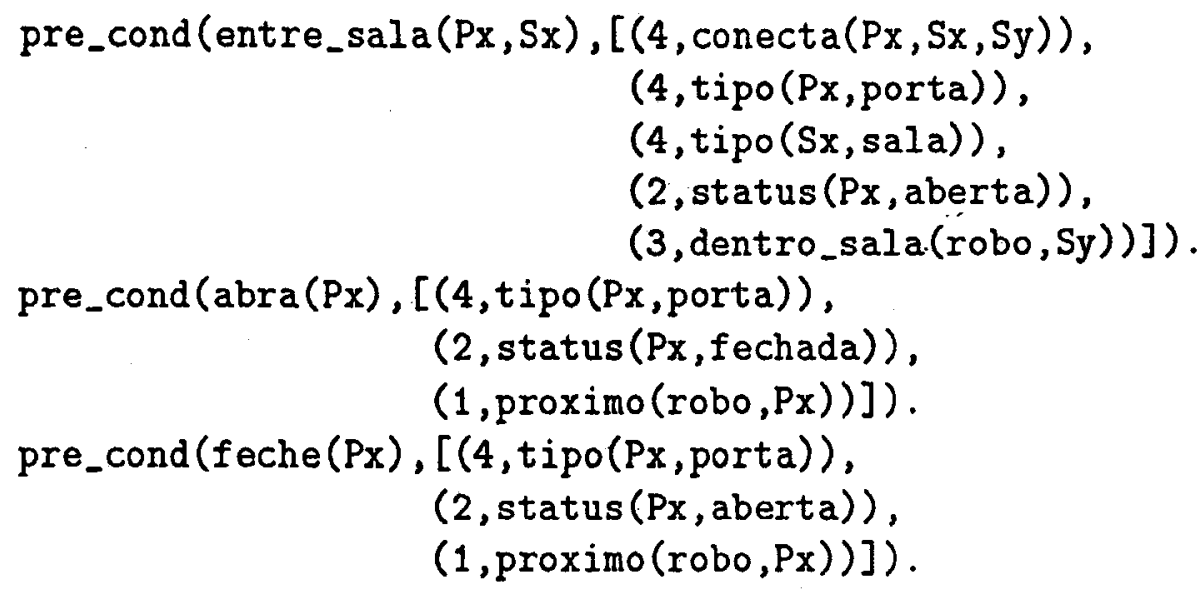

Especificação dos tipos de objetos e interligações:

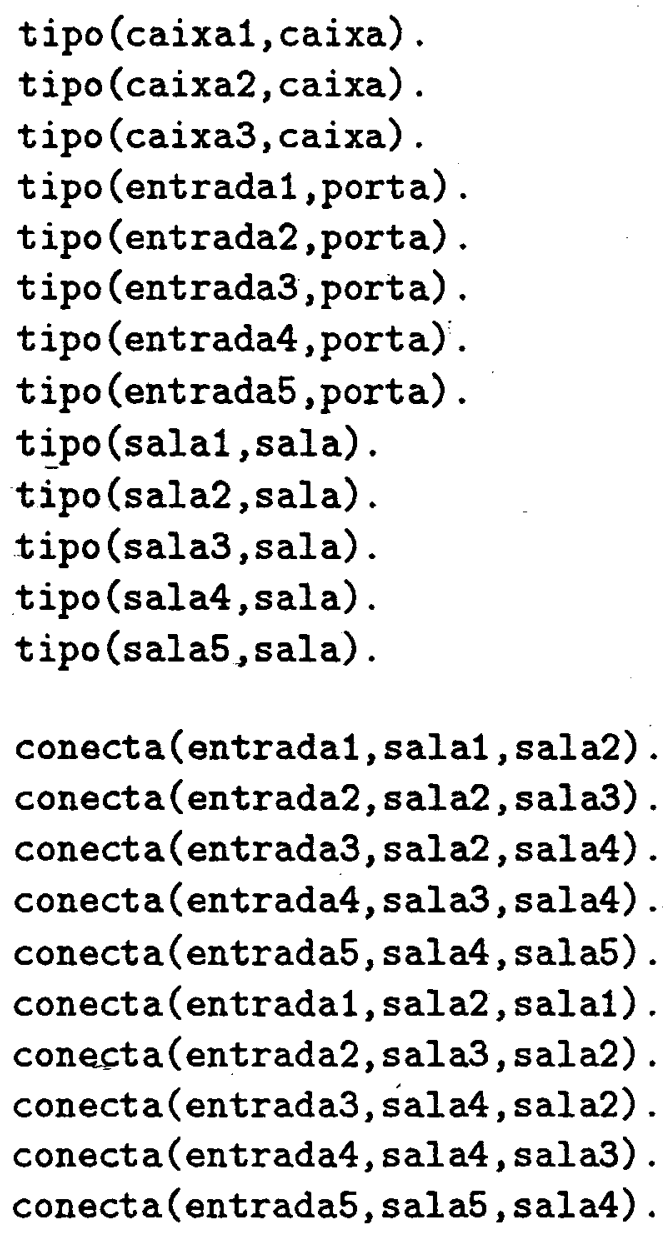

Especificação do estado inicial -Figura 7.2:

dado(inicio, status (entrada1, aberta)). dado(inicio, status (entrada2, aberta)). 


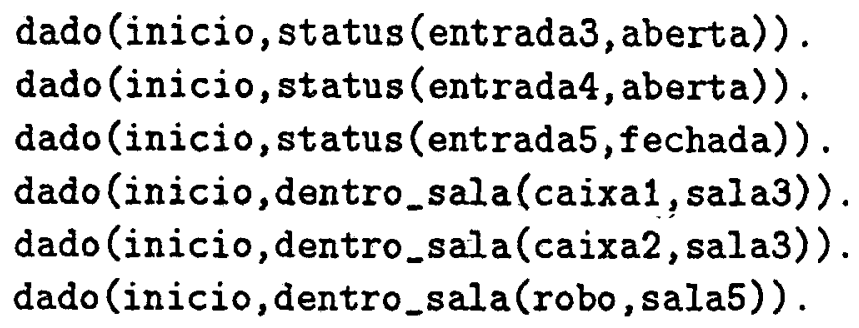

Especificação das metas impossiveis:

impossivel (status ( $P, f e c h a d a)$, Objetivos):- pertence(status( $P$, aberta), Objetivos). impossivel (status ( $P$, aberta), Objetivos):- pertence(status ( $P$, fechada), Objetivos). impossivel(dentro_sala(C,S1), Objetivos):- pertence(dentro_sala(C,S2), Objetivos), S1 $I==S 2$.

Considerando que o estado final a ser atingido é o mostrado na Figura 7.3, então, a interrogação:

?- planos_crit([proximo(caixa1, caixa2), dentro_sala(robo,sala1)]).

leva ao seguinte resultado:

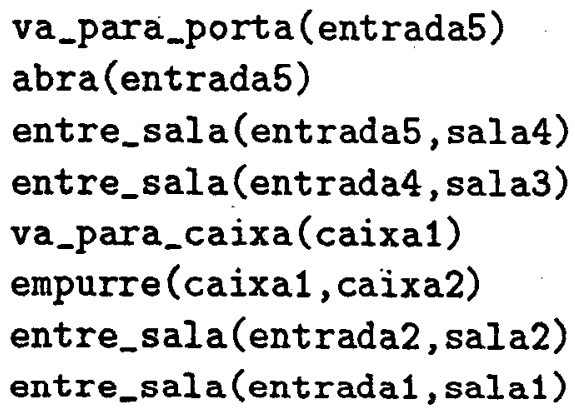

\subsection{Considerações Finais}

Neste capitulo, foram apresentadas duas implementações simplificadas representando as abordagens não hierárquica e hierárquica de planejamento.

Para a abordagem não hierárquica foi escolhido o sistema Warplan como referência. $\mathrm{O}$ aspecto que caracteriza esse tipo de sistema é a rejeição imediata de planos completos de ações devido ao surgimento de uma combinação de objetivos impossível de ser resolvida. Para tanto, sempre que um objetivo é escolhido para ser resolvido, deve ser verificado se não irá ocorrer uma combinação inadequada.

Por se tratar de um sistema não hierárquico, não é possivel distinguir quais pré-condições são mais importantes para a obtenção do plano. Para obter essa distinção, foi implementado um sistema hierárquico - usando o conceito de criticabilidades. Com isso, foi 


\section{ICMS6-USP \\ pós-graburato}

possivel planejar em vários níveis de abstração, onde para cada nível é gerado um esqueleto completo do plano. Quanto menor for o nivel de abstração maior é o grau de refinamento do plano.

Nesta implementação, foram usadas heurísticas para solucionar o problema do robô. Uma outra forma de solucionar este problema é adicionar ao planejador algumas técnicas de otimizaçâo para melhorar a rota final do robô. 


\section{Capítulo 8}

\section{Conclusões}

Planejamento tem sido um tópico de pesquisa muito ativo - nos últimos 30 anos- na área de Inteligência Artificial. Neste período, foram desenvolvidas diversas técnicas que ainda são essenciais para sistemas de planejamento apoiado em Inteligência Artificial.

Devido ser este um trabalho introdutório em planejamento apoiado em Inteligência Artjficial, foi dada uma visão geral sobre planejamento, apresentando os conceitos básicos e os termos mais comumente usados nesta área de pesquisa. Foi mostrado, também, onde planejamento pode ser aplicado em situações do mundo real, suas principais abordagens e aspectos que devem ser considerados, bem como foram apresentados alguns dos principais sistemas de planejamento desenvolvidos ao longo dos vários anos de pesquisa nesta área.

Para enriquecer essa visão geral, foram escolhidas algumas técnicas básicas usadas dentro de planejamento, tais como: análise dos meios e fins, reordenação de objetivos, ordenação por niveis de importância e regressão de objetivos. Para estas técnicas, foram desenvolvidas implementações simplificadas, na linguagem de programação lógica Prolog. $\mathrm{O}$ intuito, de apresentar as implementações, foi fornecer uma idéia de como desenvolver sistemas de planejamento utilizando uma linguagem de programação lógica.

Ao invés de procurar desenvolver um único planejador mais completo, foram desenvolvidas implementações simplificadas para as técnicas mais difundidas, fornecendo assim um base para que trabalhos futuros utilizem as idéias de implementação aqui apresentadas.

Propositalmente, foram usadas nessas implementações diversas estruturas de dados, com o objetivo de mostrar diferentes formas de representar o espaço de estados, as restrições, os planos, etc.

Em algumas implementações foi também utilizada a técnica de gravar resultados intermediários na Base de Dados de Prolog. Em geral, o uso dessa técnica permite melhorar a eficiência dos programas. Porém, o uso de predicados pré-definidos extra lógicos de gravação, pode criar problemas no caso de acontecer "backtracking", pois o que foi gravado não é automaticamente apagado por Prolog. O próprio programa do usuário deve gerenciar este aspecto que, em alguns casos, pode ser uma tarefa complexa. 
Todas as implementações foram realizadas na linguagem de programação lógica Prolog. Há várias implementações comercialmente disponíveis desta linguagem, que usam convençōes sintáticas diferentes. Neste trabalho, foi usada a chamada sintaxe de Edinburgh, que tem ampla aceitação na comunidade científica. Especificamente, foi usado o ArityProlog 5.1 para microcomputadores IBM PC-compativeis [Arity 88].

A linguagem Prolog está solidamente construída em bases científicas, e possue características apropriadas para se desenvolver planejadores. É de grande utilidade o processo de "backtracking" embutido no motor de inferência da linguagem, o que levou a uma redução do código fonte, diminuindo assim, de forma considerável, o tempo gasto com as implementações apresentadas.

Programas Prolog, quando bem definidos, podem ser facilmente estendidos ou reduzidos através da adição ou eliminação de cláusulas, respectivamente: Esta facilidade é de extrema importância para alterar um sistema de planejamento, a fim de conter outras informações que tragam um ganho em eficiência.

No entanto, para desenvolver sistemas computacionalmente eficientes, na linguagem Prolog, é necessário explorar bem os dois aspectos desta linguagem:

- o aspecto declarativo, que descreve a estrutura lógica do problema;

- o aspecto procedimental, que descreve como o computador resolve o problema.

Conciliar ambos os aspectos não é sempre uma tarefa fácil. Isto se reflete na dificuldade de documentar programas Prolog no caso em que ambos os aspectos citados devem ser evidenciados.

\subsection{Problemas Encontrados}

Uma das propostas iniciais, para o desenvolvimento deste trabalho, era adaptar um sistema de planejamento, com as características do sistema Warplan, para trabalhar com o conceito de criticabilidades. Para tanto, tentou-se incorporar o conceito de rejeição imediata de planos - por serem de solução impossível - ao sistema apresentado na seção 7.3 .

Após vários testes e tentativas foi constatado ser de pouca utilidade essa adaptação, pois a rejeição somente pode ser utilizada na montagem do primeiro esqueleto do plano, ou seja, antes de entrar nos diferentes niveis de abstração.

Para melhor entender isso, primeiro deve ser relembrado como funciona o mecanismo de rejeição de planos.

Basicamente, ao se resolver um objetivo, esse objetivo é armazenado em uma lista de objetivos protegidos e, ao tentar resolver o próximo objetivo, é verificado se sua solução 
não irá afetar os objetivos que formam a lista de protegidos. Se afetar, ocorre a rejeição do plano.

O planejador, utilizando niveis de abstração, trabalha de modo diferente, isso porque ele monta esqueletos completos de planos para cada nível de abstração. Portanto, nenhum objetivo é totalmente solucionado antes de se atingir o último nível de abstração e, consequentemente, não existe uma lista de objetivos protegidos para ser verificada.

Uma tentativa frustrada de adaptação foi criar uma lista de objetivos protegidos para cada nível de abstração. Porém, em determinados níveis, obteve-se resultados que confirmaram a inviabilidade dessa adaptação.

Para melhor visualizar esses resultados, pode ser usado o exemplo apresentado na seção 7.3. Neste exemplo, quando o sistema atingia o nivel trềs de abstração, ele resolvia a pré-condição dentro_sala(robo, sala3) - do operador empurre(caixa1, caixa2), que resolve a sub-meta proximo(caixa1, caixa2)-, e partia para resolver a pré-condição dentro_sala(robo,sala2) - do operador entre_sala(entrada1, sala1), que resolve a sub-meta dentro_sala(robo,sala1).

O motivo da inconsistência é que, dentro dessa ótica, tem-se uma combinação impossivel para esse domínio de aplicação. Para resolver dentro_sala(robo,sala2) iria afetar o objetivo já atingido anteriormente dentro_sala(robo, sala3).

$\mathrm{Na}$ verdade, não existe essa inconsistência. O que realmente ocorre é que, para usar rejeição de planos, tem-se a necessidade de que objetivos já tenham sido totalmente solucionados, antes de verificar o próximo objetivo. Como isso não acontece no planejamento usando níveis de abstração, ele não suporta a característica de rejeitar planos.

\subsection{Trabalhos Futuros}

$\mathrm{Na}$ área de planejamento há muitos problemas que ainda precisam ser resolvidos, tais como:

- Qual a melhor forma de planejar com ações não determinísticas ou situações parcialmente conhecidas?

- Como fazer para que um planejador "aprenda" e melhore a sua performance com a prática?

- Como gerar eficientemente planos para agentes múltiplos que necessitem se comunicar e negociar para atingir e preservar metas em comum?

No caso particular do autor deste trabalho, o trabalho futuro a ser realizado servirá como base para o desenvolvimento de Tese de Doutorado na área de planejamento aplicado à robótica. Por se tratar de uma área ainda pouco pesquisada no Brasil, torna-se importante um trabalho introdutório nesta área. 
O doutoramento terá início já neste ano dentro do L.S.I. (Laboratório de Sistemas Integráveis), que pertence ao Departamento de Engenharia de Eletricidade da Escola Politécnica da USP. Com isso, será possível aprofundar os estudos das técnicas mais recentes dentro de planejamento.

As pesquisas que serão iniciadas dentro do L.S.I, são referentes ao uso de planejamento na automação industrial, mais especificamente na área de sistemas flexíveis de manufatura. Dá-se o nome de sistema flexivel de manufatura à integração de células flexíveis de manufatura ${ }^{1}$ com mecanismos de transporte.

Neste contexto, planejamento é aplicado para:

- Planejar as rotas de um robô que faça parte dos mecanismos de transporte de uma indústria;

- Planejar as tarefas de um robô industrial, na montagem e na colocação das peças nos tornos;

- Planejar as operações realizadas pelas máquinas-ferramenta de controle numérico.

Para ter bons sistemas de planejamento atendendo as aplicações acima citadas, é necessário que vários aspectos sejam levados em conta. Entre esses aspectos destacam-se:

- Verificar os níveis de recursos disponíveis;

- Restrição de-tempo para escolher e executar uma ação - planejamento em tempo real;

- Planejar na presença de eventos externos.

Além dos aspectos referenciados acima, outro aspecto que deve ser explorado é o fato de que, se houver um bom conhecimento sobre o domínio de aplicação - na qual'será usado o planejador-, é possivel criar regras sobre esse conhecimento. Ao incorporar essas regras ao planejador, é possível reduzir o espaço de busca.

\footnotetext{
${ }^{1} \mathrm{~A}$ integração por computador de máquinas-ferramenta de controle numérico e robôs industriais recebe o nome de célula flexivel de manufatura.
} 


\section{Bibliografia}

[Abelson 77] Abelson, R.P.; Schank R.C. Scripts, Plans, Goals and Undertanding. Lawrence Erlbaum Associates, Publishers, 1977.

[Allen 83] Allen,J.F.; Koomen,J.A. Planning Using a Temporal World Model. Proceedings of the Eighth International Joint Conference on Artificial Inteligence, 741-742. Menlo Park, Calif.: International Joint Conferences on Artificial Intelligence, 1983. [TIMELOGIC]

[Altermann 88] Altermann,R. Adaptive Planning. Cognitive Science, 12:393-421, 1988. [PLEXUS]

[Ambros 83] Ambros-Ingerson,J.; Steel,S. Integrating Planning, Execution, and Monitoring. Proceedings of the Eighth National Conference on Artificial Inteligence, 83-88. Menlo Park, Calif.: American Association for Artificial Intelligence, 1983.

[Arariboia 89] Araribóia,G. Inteligência Artificial: Um Curso Prático. Livros Técnicos e Científicos Editora Ltda, 1989.

[Arity 88] Arity Corporation. The Arity/Prolog Programming Language. 1988.

[Barr 81] Barr,A.; Feibenbaum, Planning and Problem Solving. The Handbook of Artificial Intelligence, 515-562, Kaufman, Los Altos, Calif., 1981.

[Bell 85] Bell,C.E.; Tate,A. Using Temporal Constraints to Restrict Search in a Planner. Proceedings of the Third Workshop of the Alvey IKBS Programme Planning Special Interest Group. London: Institute if Electrical Engineers, 1985. [O-PLAN]

[Castainẽira 90] Castainẽira,M.I. Aprendizado de Máquinas por Exemplos Usando Árvores de Decisão. Tese de Mestrado, ICMSC-USP, 1990.

[Currie 85] Currie,K.; Tate,A. O-PLAN-Control in the Open Planner Architecture. BCS Expert Systems Conference. Cambridge: Cambridge University Press, 1985.[O-PLAN]

[Charniak 86] Charniak,E.; McDermott,D. Introduction to Artificial Intelligence. Addison-Wesley Publishing Company, 1986.

[Daniel 83] Daniel,L. Planning and Operations Research. Artificial Intelligence: Tools, Techniques, and Applications. New York: Harper and Row, 1983.[NONLIN] 
[Dean 88] Dean,T.; Boddy,M. Reasoning about Partially Ordered Events. Artificial Intelligence, 36:375-399, 1988.

[Dean 89] Dean,T.; Miller,D. Hierarchical Planning involving Deadlines, Travel Time, and Resources. Computational Intelligence, 3, 1989. [FORBIN]

[Drummond 88] Drummond,M.; Currie,K.W. Exploiting Temporal Coherence in NonLinear Plan Construction. Computational Intelligence, 4, 1988.

[Drummond 89] Drummond,M.; Currie,K.W. Goal Ordering in Partially Ordered Plans. Proceedings of the Eleventh International Joint Conference on Artificial Inteligence, 1010-1012. Menlo Park, Calif.: International Joint Conferences on Artificial Intelligence, 1989.

[Fikes 71] Fikes,R.E.; Nilsson,N.J.Boddy,M. Strips: A New Approach to the Application of Theorem Proving to Problem Solving. Artificial Intelligence, 2:189-208, 1971. [Strips]

[Fikes 72] Fikes,R.E.; Hart,P.E.. Learning and Executing Generalized Robot Plans. Artificial Intelligence, 3, 1972. [Strips;Planex]

[Firby 89] Firby,J. Adaptive Execution in Complex Dynamic Worlds. Ph.D. Thesis, Dept. of Computer Science, Yale Univ., 1989. [RAPS]

[Ford 87] Ford,N. How Machines Thinks. John Wiley \& Sons, 1987.

[Galanter 60] Galanter,E.; Miller,G.A.; Pribam,K.H. Plans and the Structure of Behavior. Holt, New Yok, 1960.

[Georgeff 87] Georgeff,M.; Lansky,A. Reactive Reasoning and Planning. Proceedings of the Sixth National Conference on Artificial Inteligence. Menlo Park, Calif.: American Association for Artificial Intelligence, 1987. [PRS]

[Genesereth 87] Genesereth,M.R.; Nilsson,N.J. Logical Foundations of Artificial Intelligence. Morgan Kaufmamm Publishers, Inc, 1987.

[Hammond 86] Hammond,K. Chef: A Model of Case-Based Planning. Proceedings of the Fifth National Conference on Artificial Inteligence. Menlo Park, Calif.: American Association for Artificial Intelligence, 1986. [CHEF]

[Hart 81] Hart,P.; Fikes,R.; Nilsson,N. Learning and Executing Generalized Robot Plans. Readings in Artificial Intelligence, 231-249. Tioga Publishing Company, Palo Alto, Calif., 1981.

[Hayes 75] Hayes,P.J. A Representation for Robot Plans. Advance of the 1975 International Joint Conference on Artificial Inteligence, Tbilisi, USSR, 1975.

[Hayes 81] Hayes,P.J. The Frame Problem and Related Problems in Artificial Intelligence. Readings in Artificial Intelligence, 223-230. Tioga Publishing Company, Palo Alto, Calif., 1981.

[Hayes-Roth 79] Hayes-Roth,B.; Hayes-Roth,F. A Cognitive Model of Planning. Cognitive Science, 3:275-310, 1979. [OPM] 
[Heckerman 89] Heckerman,D.; Breese,J.; Horvitz,E. The Compilation of Decision Models. Proceedings of the 1989 Workshop on Uncertainty in Artificial Intelligence, 162-173, 1989.

[Hendler 89] Hendler,J. Real-Time Planning. American Association for Artificial Intelligence Symposium on Planning and Search, Standford, Calif., 1989.

[Horvitz 88] Horvitz,E. Reasoning under Varying and Uncertain Resource Constraints. Proceedings of the Seventh National Conference on Artificial Inteligence, 111-116. Menlo Park, Calif.: American Association for Artificial Intelligence, 1988.

[Kaelbling 87] Kaelbling,L. An Architecture for Intelligence Reactive Systems. Reasoning about Actions and Plans: Proceedings of the 1986 Workshop, eds. M. Georgeff and A. Lansky. San Mateo, Calif.: Morgan Kaufmann, 1987.

[Kambhamp 89] Kambhampati,S.; Hendler,J. Flexible Reuse of Plans via Annotation and Verification. Proceedings of the Fifth Institute of Electrical and Electronic Engineers Conference on Applications of Artificial Intelligence, 1989. [PRIAR]

[Kautz 88] Kautz,H.A.; Pednault, P.D. Planning and Plan Recognition. AT\&T Journal, 67:25-40, 1988.

[Kolodner 87] Kolodner,J. Case-Based Problem Solving. Fourth International Workshop on Machine Learning, University of Calif'ornia at Irvine, 1987. [JULIA]

[Korf 87] Korf,T.; Boddy,M. Planning as Search: A Quantitative Approach. Artificial Intelligence, 33:65-88, 1987.

[Masui 83] Masui,S.; McDermott,J; Sobel,A. Decision-Making in Time Critical Situations. Proceedings of the Eighth International Joint Conference on Artificial Inteligence, 233-235. Menlo Park, Calif.: International Joint Conferences on Artificial Intelligence, 1983. [AIRPLAN]

[McDermott 78] McDermott,D.V. Planning and Acting. Cognitive Science, 2, 1978. [NASL]

[Miller 85] Miller,D.; Dean,T. Deadlines, Travel Time, and Robot Problem Solving. Proceedings of the Ninth International Joint Conference on Artificial Inteligence, 1052-1054. Menlo Park, Calif.: International Joint Conferences on Artificial Intelligence, 1985. [FORBIN]

[Newell 63] Newell,A.; Simon,H.A. GPS: A Program That Simulates Human Thought. Computers and Thought, eds. E.A. Feigenbaum and Feldman, New York: McGraw-Hill, 1963. [GPS]

[Nilsson 82] Nilsson,N.J. Principles of Artificial Intelligence. Springer-Verlog, New York, 1982.

[Prado 91] Prado,J.P.A. O Uso da Arquitetura Blackboard em Planejamento. Tese de Mestrado, ICMSC-USP, 1991. 
[Rich 83] Rich,E. Inteligência Artificial. McGraw-Hill, 1983.

[Russel 89] Russel,S.; Wefald,E. Principles of Metareasoning. Proceedings of the First International Conference on Principles of Knowledge Representation and Reasoning. San Mateo, Calif.: Morgan Kaufmann, 1989.

[Sacerdoti 73] Sacerdoti,E.D. Planning in a Hierarchy of Abstraction Spaces. Advance Papers of the Third International Joint Conference on Artificial Intelligence, 412-420, 1973. [ABSTRIPS]

[Sacerdoti 75] Sacerdoti,E.D. The Non-Linear Nature of Plans. Advance Papers of the Fourth International Joint Conference on Artificial Intelligence, 206-214, 1975. [NOAH]

[Sacerdoti 77] Sacerdoti,E.D. A Structure for Plans and Behaviour. Amsterdam: Elsevier-North Holland, 1977. [NOAH]

[Segre 88] Segre,A. Machine Learning on Robot Assembly Plans. Norwell,Mass.: Kluwer Academic, 1988.

[Shirai 86] Shirai, Y.; Tsujii, J. Artificial Inteligence, Concepts, Techniques and Aplications. A Wiley-Interscience Publication, 1986.

[Siklossy 75] Siklossy,L.; Dreussi,J. An Efficient Robot Planner That Generates Its Own Procedures. Proceedings of the Third International Joint Conference on Artificial Intelligence, 423-430. Menlo Park, Calif.: International Joint Conferences on Artificial Intelligence, 1975. [LAWALY]

[Simon 81] Simom,H.A. The Sciences of the Artificial. 2nd ed., MIT Press, Cambrigde, Mass, 1981

[Simmons 87] Simmons,R.; Davis,R. Generate, Test, and Debug: Combining Associational Rules and Causal Models. Proceedings of the Tenth International Joint Conference on Artificial Intelligence, 1071-1078. Menlo Park, Calif.: International Joint Conferences on Artificial Intelligence, 1987. [G-T-D]

[Stăllman 77] Stallman,R.M.; Sussman,G.J. Forward Reasoning and Dependency Directed Backtracking. Artificial Intelligence, 9:135-196, 1977.

[Stefik 81] Stefik,M.J. Planning with Constraints. Artificial Intelligence, 16:111-140, 1981. [MOLGEN]

[Sussman 73] Sussman,G.A. A Computational Model of Skill Acquisition. MIT AI Lab Memo, AI-TR-297, AI Lab., Massachussets Institute of Technology, 1973. [HACKER]

[Tate 75] Tate,A. Interacting Goals and Their Use. Proceedings of the Fourth International Joint Conference on Artificial Inteligence, 215-218. Menlo Park, Calif.: International Joint Conferences on Artificial Intelligence, 1975. [INTERPLAN]

[Tate 77] Táte,A. Generating Project Networks. Proceedings of the Fifth International Joint Conference on Artificial Inteligence. Menlo Park, Calif.: International Joint Conferences on Artificial Intelligence, 888-892, 1977. [NONLIN] 
[Tate 84a] Tate,A. Goal Strructure: Capturing the Intent of Plans. European Conference on Artificial Intelligence, Pisa, Italy, 1984.

[NONLIN]

[Tate 84b] … Tate,A.; Whiter,A.M. Planning with Multiple Resource Constraints and an Application to a Naval Planning Problem. First Conference on the Application of Artificial Intelligence, Denver,Colorado, USA, San Mateo, Calif.: Morgan Kaufmann, 1984. [NONLIN+]

[Vere 83] Vere,S. Planning in Time: Windows and Durations for Activies and Goals. IEEE Transactions on Pattern Analisys and Machine Intelligence, PAMI-5: 246-267, 1983. [DEVISER]

[Vere 87] Vere,S. Planning. Encyclopedia of Artificial Intelligence, 748-758. Wiley Interscience Publication, John Wiley \& Sons, 1987.

[Zadeh 65] Zadeh,L.A. Fuzzy Sets. Information and Control, 8:338-353, 1965.

[Waldinger 75] Waldinger,R. Achieving Several Goals Simultaneosly. Technical Note 107,SRI AI Center, Menlo Park, Calif., 1975.

[Warren 74] Warren,D.H.D. WARPLAN: A System fo a Gererating Plans. Memorandum, 76, Dept. of Computational Logic, Edinburgh Univ., 1974. [WARPLAN]

[Warren 76] Warren,D.H.D. Generating Conditional Plans and Programs. Proceedings of the AISB Summer Conference, 344-354, 1976.

[WARPLAN-C]

[Wilkins 83] Wilkins,D.E. Representation in a Domain-Independent Planner. Proceedings of the Eighth International Joint Conference on Artificial Inteligence, 733-740. Menlo Park, Calif.: International Joint Conferences on Artificial Intelligence, 1983. [SIPE] 